NBER WORKING PAPER SERIES

\title{
IS THE SOCIAL SAFETY NET A LONG-TERM INVESTMENT? LARGE-SCALE EVIDENCE FROM THE FOOD STAMPS PROGRAM
}

\author{
Martha J. Bailey \\ Hilary W. Hoynes \\ Maya Rossin-Slater \\ Reed Walker \\ Working Paper 26942 \\ http://www.nber.org/papers/w26942
NATIONAL BUREAU OF ECONOMIC RESEARCH
1050 Massachusetts Avenue
Cambridge, MA 02138
April 2020

The opinions and conclusions expressed herein are solely those of the authors and should not be construed as representing the opinions or policy of any agency of the U.S. Census Bureau, the National Institutes of Health (NIH), the National Science Foundation (NSF), or the Laura and John Arnold Foundation (LJAF). All results have been reviewed to ensure that no confidential information is disclosed. Data collection for the War on Poverty project was generously supported by the NIH (R03-HD066145). Data linkage and analyses for this project was supported by the LJAF (PI Bailey), the NSF (PIs Rossin-Slater and Walker, Award No. 1459940 and PI Rossin-Slater CAREER Award No. 1752203), and the Institute for Industrial Relations (PI Hoynes). We gratefully acknowledge the use of the services and facilities of the Population Studies Center at the University of Michigan (NICHD Center Grant R24 HD041028), the Michigan Research Data Center (NSF ITR-0427889), and its training program (Binder and Timpe were partially supported by the NIA T32AG000221 as University of Michigan Population Studies Center Trainees). Evan Taylor and Bryan Stuart provided exceptional assistance in translating string names in the SSA's NUMIDENT file into GNIS codes. We also thank Ariel Binder, Chris Campos, Dorian Carloni, Grant Graziani, John Iselin, Krista Ruffini, Bryan Stuart, Matt Tarduno, and Brenden Timpe for excellent research assistance and Clint Carter for the many hours spent helping us disclose these results. A pre-analysis plan for this project can be found at https://osf.io/t6vsz. The views expressed herein are those of the authors and do not necessarily reflect the views of the National Bureau of Economic Research.

NBER working papers are circulated for discussion and comment purposes. They have not been peer-reviewed or been subject to the review by the NBER Board of Directors that accompanies official NBER publications.

(C) 2020 by Martha J. Bailey, Hilary W. Hoynes, Maya Rossin-Slater, and Reed Walker. All rights reserved. Short sections of text, not to exceed two paragraphs, may be quoted without explicit permission provided that full credit, including (C) notice, is given to the source. 
Is the Social Safety Net a Long-Term Investment? Large-Scale Evidence from the Food Stamps Program

Martha J. Bailey, Hilary W. Hoynes, Maya Rossin-Slater, and Reed Walker

NBER Working Paper No. 26942

April 2020

JEL No. H53,I38

\begin{abstract}
We use novel, large-scale data on 43 million Americans from the 2000 Census and the 2001 to 2013 American Communities Survey linked to the Social Security Administration's NUMIDENT to study how a policy-driven increase in economic resources for families affects children's longterm outcomes. Using variation from the county-level roll-out of the Food Stamps program between 1961 and 1975, we find that children with access to greater economic resources before age five experience an increase of 6 percent of a standard deviation in their adult human capital, 3 percent of a standard deviation in their adult economic self-sufficiency, 8 percent of a standard deviation in the quality of their adult neighborhoods, 0.4 percentage-point increase in longevity, and a 0.5 percentage-point decrease in likelihood of being incarcerated. Based on these estimates, we conclude that Food Stamps' transfer of resources to families is a highly cost-effective investment into young children, yielding a marginal value of public funds of approximately 56 .
\end{abstract}

Martha J. Bailey

University of Michigan

Department of Economics

611 Tappan Street

207 Lorch Hall

Ann Arbor, MI 48109-1220

and NBER

baileymj@umich.edu

Hilary W. Hoynes

Richard \& Rhoda Goldman

School of Public Policy

University of California, Berkeley

2607 Hearst Avenue

Berkeley, CA 94720-7320

and NBER

hoynes@ berkeley.edu
Maya Rossin-Slater

Department of Medicine

Stanford University School of Medicine

615 Crothers Way

Encina Commons, MC 6019

Stanford, CA 94305-6006

and NBER

mrossin@stanford.edu

Reed Walker

Haas School of Business

Department of Economics

University of California Berkeley

2220 Piedmont Avenue

Berkeley, CA 94720

and NBER

rwalker@berkeley.edu

A Pre-analysis plan is available at https://osf.io/t6vsz 


\section{Introduction}

Social safety net programs are designed to help the poorest members of society meet their food, housing, and healthcare needs. The modern American safety net was greatly expanded under President Lyndon B. Johnson's War on Poverty, which aimed "not only to relieve the symptom of poverty, but to cure it and, above all, to prevent it" (Johnson 1965).

The War on Poverty substantially expanded what is today a core component of the U.S. safety net. The Food Stamps program, now called the Supplemental Nutrition Assistance Program (SNAP), provides poor individuals with vouchers to purchase food at grocery stores. As it expanded to all areas of the U.S. under the War on Poverty, the program raised food spending among participating families by 21 percent (Hoynes and Schanzenbach 2009) and improved infant health (Almond et al. 2011). Combined with other safety net programs like the Earned Income Tax Credit, Food Stamps helped lower the child poverty rate in the U.S. from 28 percent in 1967 to 16 in 2016 (National Academies of Sciences 2019). This program remains especially relevant today. SNAP is the second largest anti-poverty program for children and the most important program for reducing deep child poverty (National Academy of Sciences 2019). In 2018, Food Stamps raised 3.1 million people out of poverty at a cost of $\$ 65$ billion dollars. ${ }^{1}$

Recent evidence suggests that the effect of Food Stamps on child poverty and nutrition translated into lasting effects on human capital, health, economic self-sufficiency, and overall wellbeing - benefits that are by necessity omitted in short-term, contemporaneous evaluations of the program. Hoynes et al. (2016) break new ground in documenting some long-term benefits of Food

\footnotetext{
${ }^{1}$ By comparison, spending on the Earned Income Tax Credit was $\$ 67$ billion (https://www.irs.gov/pub/irssoi/16in25ic.xls) and spending on Temporary Assistance for Needy Families is much lower at $\$ 28.3$ billion (https://www.acf.hhs.gov/ofa/resource/tanf-financial-data-fy-2016), both for 2016. The poverty reduction figure comes from Fox (2019) and is measured for 2018.
} 
Stamps using the Panel Study of Income Dynamics (PSID). They find that greater exposure to Food Stamps in childhood, particularly before age 5, leads to a reduction in adult metabolic syndrome conditions (including obesity, high blood pressure, diabetes, heart disease) and improvements in some measures of economic self-sufficiency for women. However, the strength of these conclusions is limited by small sample sizes and high attrition rates in the PSID. More recently, Bitler and Figinski (2019) use data from the Social Security Administration's Continuous Work History Sample (CWHS), which contains information on earnings for one percent of U.S.born individuals. They find that exposure to Food Stamps before age five increases adult earnings for women but has insignificant effects for men. However, CWHS data contain only a few outcomes and do not allow for a more comprehensive analysis of the program's impact on population well-being. Data limitations in both the PSID and CWHS limit evaluations of the longterm efficacy of the program in preventing adult poverty, and the extent to which Food Stamps "pays for itself" remains an open question.

This paper provides new, more comprehensive evidence regarding the long-term impacts of childhood exposure to Food Stamps on individuals' adult economic productivity and wellbeing - evidence that is essential for calculating the returns to this large-scale poverty prevention program. Filling a crucial gap in the literature, the combined 2000 Census (a 1-in-6 sample of all U.S. households), 2001 to 2013 American Community Surveys (ACS), and Social Security Administration's (SSA) NUMIDENT allow us to calculate the likely exposure of more than 17 million American adults to the Food Stamps program in childhood. This large-scale linked survey and administrative data set also contains a wider range of outcomes than the previous literature, including educational attainment, labor-market productivity, poverty status, adult participation in safety net programs, incarceration, physical and cognitive disabilities, life expectancy, mobility 
from one's county of birth, and the quality of one's neighborhood of residence in adulthood.

Our empirical strategy, described in a pre-analysis plan to minimize concerns about multiple hypothesis testing and specification search, builds upon the validated approach of Hoynes and Schanzenbach (2009), Almond et al. (2011), and Hoynes et al. (2016), who exploit the countyby-county rollout of Food Stamps in the 1960s and 1970s. ${ }^{2}$ We estimate event-study, linear-spline, and difference-in-difference models that rely on variation in the availability of the Food Stamps program across birth counties and birth cohorts. To limit concerns about the endogeneity of the program's implementation, all specifications follow prior studies and control for birth-county fixed effects and 1960 county characteristics interacted with linear trends. Moreover, our larger samples allow us to include individual state-of-birth by birth-year fixed effects as well as survey year fixed effects, which account for the rich set of policy changes at the state level during the 1960s and dramatic changes in the U.S. economy from 2000 to 2014.

Our results show that greater access to Food Stamps in utero and in early childhood is associated with large improvements in adult measures of well-being. Using pre-specified indices (Kling et al. 2007), we document that full exposure to Food Stamps (access for the entirety of time between one's estimated month of conception and age five) leads to a 0.009 standard-deviation increase in a composite index of adult human capital and well-being. This aggregate improvement is driven by increases in the human capital ( 0.010 of a standard deviation), economic selfsufficiency (0.004 of a standard deviation), and neighborhood quality indices ( 0.012 of a standard deviation), respectively. Full exposure to the Food Stamps program is also associated with an

\footnotetext{
${ }^{2}$ See acknowledgements for web-link to the pre-analysis plan. Prior studies have documented that the initial Food Stamps rollout is largely uncorrelated with other observable county economic and demographic characteristics (Hoynes and Schanzenbach 2009, Almond et al. 2011, Hoynes et al. 2016), and we confirm this finding for the counties and years in our analysis sample.
} 
increase in life expectancy of 0.18 years and reduces the likelihood of being incarcerated by 0.08 percentage points. These are intention-to-treat (ITT) estimates and include children who never used the program. Scaling these ITT estimates by approximate Food Stamp participation rates of about 16 percent among children ages five and younger at the time the program rolled out implies that the average treatment effect on the treated (TOT) is approximately six times larger (Appendix Figure 2A). We find no significant effects of exposure to Food Stamps at ages six to 18 once we control for exposure from in utero to age five, suggesting that greater resources for mothers during pregnancy and in her child's first five years of life are especially critical in shaping adult human capital, health, and productivity. ${ }^{3}$

These findings rely crucially on our ability to observe individuals' places of birth. In our analysis of geographic mobility and neighborhood quality, we show that Food Stamps availability in early childhood increases the likelihood that individuals move away from their counties of birth, own their own home, and reside in a single-family home. This is consistent with the idea that Food Stamps in early life allows individuals to move to higher quality neighborhoods, as measured by a range of characteristics at the Census tract and county geographies. Although the impacts of Food Stamps on adult outcomes appear to operate in part through mobility, we also show longterm benefits for individuals who stay in their counties of birth until adulthood. ${ }^{4}$

Our analysis of this unprecedented set of adult outcomes has important implications for

\footnotetext{
${ }^{3}$ It is also the case that Food Stamp participation rates are somewhat lower among children ages 6-18 than children ages 5 years or younger (see Appendix Figure 2A). However, scaling the insignificant (and often opposite-signed) coefficients on exposure at ages 6-18 by the relevant participation rates yields economically small effect magnitudes. Additionally, analysis of PSID data (Appendix Figure 2B) shows that there are no discontinuous changes in the length of time individuals spend on Food Stamps between those who first use the program at age five versus age six, suggesting that the difference between exposure below and above age five is not driven by a difference in the duration of benefit receipt.

${ }^{4}$ In fact, we find that the impacts of Food Stamps are larger for individuals who are resident in their counties of birth in adulthood than for those who move away. This difference may reflect higher rates of measurement error for movers than for stayers or subgroup heterogeneity, as movers are positively selected.
} 
valuing Food Stamps as a long-term, public sector investment. For instance, when analyzing the individual components of the economic self-sufficiency index, we find that childhood exposure to Food Stamps reduces the likelihood that individuals receive income from public programs in adulthood. This implies that the social safety net for families with young children may, in part, "pay for itself" by reducing reliance on government support in the long-term.

To provide a comprehensive assessment of the benefits of early childhood access to Food Stamps relative to the costs, we follow the framework proposed by Hendren (2016) and Hendren and Sprung-Keyser (2019) to calculate the Marginal Value of Public Funds (MVPF). The MVPF is the ratio of the benefit of the policy to its recipients (i.e., childhood Food Stamps beneficiaries) to the net cost to the government. We calculate that the MVPF of childhood Food Stamps is approximately 56. The high value is consistent with Hendren and Sprung-Keyser (2019)'s finding that programs targeting children tend to generate larger MVPFs than programs for adults, and we note that the MVPF we calculate exceeds MVPFs estimated for highly regarded early childhood education interventions, such as the Perry Preschool and the Carolina Abecedarian Program. ${ }^{5}$

Our results on the long-term impacts of early life access to Food Stamps contribute to two strands of prior literature. First, past research documents that safety net programs including near cash (Food Stamps, the Earned Income Tax Credit, Aid to Families with Dependent Children) and in-kind transfers (Special Supplemental Nutrition Program for Women, Infants, and Children, Medicaid) improve infant health (see, e.g.: Currie and Cole 1993, Currie and Gruber 1996a, Currie and Gruber 1996b, Bitler and Currie 2005, Almond et al. 2011, Hoynes et al. 2011, Rossin-Slater 2013, Hoynes et al. 2016).

\footnotetext{
${ }^{5}$ Our estimated MVPF is higher than the estimate provided for the Food Stamp program in Hendren and SprungKeyser (2019). The source of the difference is how we estimate and value changes in life expectancy. Details are provided in Section VII.
} 
Second, and more broadly, a large literature documents the importance of the early life environment for individual well-being throughout the life cycle (see reviews by Almond and Currie 2011a, Almond and Currie 2011b, Almond, Currie and Duque 2018). While early work on this topic has tended to use variation from large adverse shocks to early childhood conditions, studies linking childhood access to U.S. safety net programs with long-term outcomes have only recently begun to emerge (see Hoynes and Schanzenbach 2018 for a review). Studies show that childhood access to cash welfare (Aizer et al. 2016), the Earned Income Tax Credit (Bastian and Michelmore 2018), and Medicaid (Brown et al. forthcoming, Miller and Wherry 2020, Cohodes et al. 2016, Goodman-Bacon 2016) lead to improvements in human capital and health in adulthood.

Our work is also related to the literature on the long-term effects of early childhood income (for some overviews, see, e.g.: Duncan and Brooks-Gunn 1997, Solon 1999, Duncan et al. 2010, Black et al. 2011, National Academies of Sciences, 2019). However, this work faces similar data constraints as the literature on safety net programs, along with the substantial challenge of separating the causal effects of income from other factors associated with disadvantage. Several recent studies have made important strides in overcoming this challenge by exploiting variation in aggregate economic conditions, finding positive relationships between economic activity during childhood and education, income, and health in later life (Van den Berg et al. 2006, Cutler et al. 2007, Banerjee et al. 2010, Løken et al. 2012, Cutler et al. 2016, Rao 2016, Akee et al. 2010). A related set of studies examines the relationship between parental job loss and children's long-run outcomes (Page et al. 2007, Bratberg et al. 2008, Oreopoulos et al. 2008, Coelli 2011, Hilger 2016, Stuart 2018). Complementing studies on the long-term effects of economic conditions, our results show that increasing children's income through public policy is also strongly predictive of a broad range of measures of long-term well-being. 
The paper proceeds as follows. Section II discusses the history of the Food Stamps program, its rollout, and how greater access to Food Stamps in childhood may lead to improvements in adult outcomes. Section III describes our data sources and presents summary statistics from our restricted Census-ACS-SSA sample, and Section IV discusses our empirical methods and identifying assumptions. We present our results in Section V and a discussion of magnitudes in Section VI, conduct a cost-benefit analysis in Section VII, and offer some conclusions in Section VIII.

\section{The Food Stamp Program and the Food Stamp Rollout}

\section{A. The Food Stamps Program}

Food Stamps (or SNAP) is a means-tested program designed to supplement low-income families' food budgets. It is a "voucher" program in that it can be used to purchase most foods at grocery stores. ${ }^{6}$ The benefits are structured to fill the gap between the resources a family has available to purchase food and the resources required to purchase an inexpensive food plan. Eligibility requires that families have incomes below 130 percent of the federal poverty line. The program has few other eligibility requirements and thus extends benefits to nearly all incomeeligible applicants. ${ }^{7}$ Maximum benefits vary with family size (and are adjusted for changes in food prices from year to year), and the benefit is phased out at a 30 percent rate with increases in income (after deductions). This is a federal program, administered in the U.S. Department of Agriculture, and benefits are equal across different regions of the U.S. (except Alaska and Hawaii). Benefits are paid monthly; in 2018 recipients received an average of $\$ 252$ per household per month or $\$ 4$

\footnotetext{
${ }^{6}$ Food Stamps can be used to purchase all food items available in grocery stores except hot, ready to eat foods.

${ }^{7}$ In addition to the income test, FS also has an asset test, currently set at $\$ 2,250$ (or $\$ 3,500$ for the elderly and disabled). There are also limits on access relating to immigrant status and income eligible recipients who are not aged, disabled or with children face time limits in the program.
} 
per person per day. An extensive literature documents that the Food Stamps program reduces food insecurity (see reviews by Hoynes and Schanzenbach 2016 and Bitler and Siefoddini (forthcoming).

\section{B. The Food Stamp Rollout}

The Food Stamps program began as President Kennedy's first Executive Order, issued on February 2, 1961, which led to the launch of pilot Food Stamps programs in eight counties. ${ }^{8}$ These counties were quite poor and included counties in Appalachia, Native American reservations, and Wayne county in Michigan (containing the city of Detroit). The pilot counties expanded to a total of 43 counties through 1962 and 1963.

The pilot programs were significantly expanded under President Johnson's War on Poverty with the passage of the Food Stamp Act of 1964 (FSA), which gave local areas the authority to start up the Food Stamp Programs in their county. Local officials had to apply for the program, and Congress appropriated funding to these applications. In the first year, $\$ 75$ million was appropriated; $\$ 100$ million for year 2; and $\$ 200$ million in year 3. Following the FSA, the rollout across counties increased (Appendix Figure 1). The 1973 Amendments to FSA, passed on August 10, 1973, required that the program be expanded to the entire U.S. by July 1, 1974. By mid-1973 almost 90 percent of the U.S. population lived in counties that had a Food Stamps program. Figure 1 displays a county map of the U.S. indicating the date of county Food Stamps initiation, with darker shaded counties representing later program introduction. The map shows substantial withinstate variation in the timing of implementation of the Food Stamps program which our analysis exploits.

\section{Expected Effects of Childhood Access on Long-Run Outcomes}

\footnotetext{
${ }^{8}$ For a compact history of the Food Stamp program see https://www. fns.usda.gov/snap/short-history-snap.
} 
How might having access to Food Stamps in early childhood lead to differences in adult outcomes? Food Stamps increases household resources by providing a voucher to purchase food if the family is income-eligible. ${ }^{9}$ Standard consumer theory predicts that inframarginal participants (those who receive benefits in an amount less than they would otherwise spend on food) respond to Food Stamps benefits like ordinary income (Hoynes and Schanzenbach 2009). This suggests that the launch of Food Stamps would lead to increases in spending on food and other goods. The available evidence, from the contemporary Food Stamps program, shows that the vast majority of Food Stamps recipients spend more on food than their Food Stamps benefit amount, implying most would be inframarginal (Hoynes, McGranahan and Schanzenbach 2015). The evidence is mixed with some studies finding that households respond to Food Stamps like ordinary cash income (Schanzenbach 2007, Hoynes and Schanzenbach 2009, Beatty and Tuttle 2020, Bruich 2014), while other studies find that Food Stamps yields more spending on food than ordinary income (Hastings and Shapiro 2018). Either way, one potential channel for long run impacts is an increase in the quantity or quality of food available in the household during early childhood.

An extensive body of evidence, beginning with Barker (1990), establishes that better early life nutrition leads to improvements in adult health. This implies that the availability of Food Stamps, in utero and in early childhood in particular, could lead to increases in adult health. Moreover, greater health and nutrition in early life may make subsequent investments in child development more productive (Cunha and Heckman, 2007; Heckman and Masterov, 2007; Heckman and Mosso, 2014) compounding more for children who are younger when they are first exposed. More generally, many aspects of the early life environment have been found to be

\footnotetext{
${ }^{9}$ This is net of any efficiency loss due to any induced reduction in labor supply due to the benefit and phase-out rate (Hoynes and Schanzenbach 2012, East 2018).
} 
important for individual well-being throughout the life cycle (Almond and Currie 2011a, Almond and Currie 2011b, Almond, Currie and Duque 2018).

To what extent does the research on the long run effects of the social safety net line up with these predictions? First, there is consistent evidence that social safety net investments during childhood lead to improved adult human capital and economic outcomes as well as health. Aizer et al. (2016) examine an early 20th century cash welfare program and find that additional income in childhood leads to greater educational attainment, income, body weight, and life expectancy. Increased family resources during childhood through the Earned Income Tax Credit have been shown to increase children's cognitive outcomes (Dahl and Lochner 2012, 2017, Chetty et al. 2011) as well as educational attainment and employment in young adulthood (Bastian and Michelmore 2018). While perhaps less mechanistically connected to the increase in resources from these near cash programs, related work shows that public investments through Head Start preschools $^{10}$ and Medicaid ${ }^{11}$ also lead to improvements in adult human capital and health. The evidence on the relative importance of early childhood exposure is a more mixed. Hoynes et al. (2016) show that the beneficial effects of Food Stamps on adult metabolic health derive from exposure prior to age five. Aizer et al. (2016) provide suggestive evidence that the positive effects of cash welfare may be larger for children exposed at younger ages. Bastian and Michelmore

\footnotetext{
${ }^{10}$ Using a county-birth-cohort research design and the same restricted dataset as this paper, Bailey et al. (2019) show that Head Start programs that began in the 1960s had long-term effects on children's educational attainment as well as economic self-sufficiency, poverty status, and public assistance receipt as adults. Barr and Gibbs (2018) show that these effects persisted across generations. Work using the PSID and NLSY based on sibling comparisons also shows that test-scores and outcomes in early adulthood appear to have improved (Garces et al. 2002, Deming 2009).

${ }^{11}$ Additionally, studies show that access to Medicaid in utero and in childhood leads to improvements in educational attainment (Brown et al. forthcoming, Miller and Wherry forthcoming, Cohodes et al. 2016), earnings (Brown et al. forthcoming), mortality (Goodman-Bacon 2016, Wherry and Meyer 2015, Brown et al. forthcoming), and the health of the next generation (East et al. 2017). While the mechanisms for the long run effects of health insurance may be different from Food Stamps (or other cash and near cash assistance), the research consistently points to positive impacts of these investments in early childhood.
} 
(2018), however, find that larger EITC payments during the teen years, rather than early childhood, drive the increases in educational attainment and earnings in young adulthood.

Another mechanism for long-run effects of Food Stamps is a reduction in stress. Recent work shows that lower socioeconomic status may be causally related to stress hormones (e.g. cortisol) and that additional resources may attenuate this relationship (Aizer et al. 2016b, Evans and Garthwaite 2014, Fernald and Gunnar 2009). In turn, Black et al. (2016) and Persson and Rossin-Slater (2018) document that in utero exposure to maternal stress has adverse impacts on children's short- and long-term outcomes.

In light of this evidence, we expect childhood exposure to Food Stamps to improve adult human capital and economic outcomes with possibly larger impacts for exposure in early childhood. To illustrate these effects, Figure 2 plots the relationship between adult well-being and the age when Food Stamps was introduced. Movement along the x-axis from right to left represents earlier (and longer) exposure to Food Stamps. The dashed line illustrates the case of a "dose response" of Food Stamps whereby each year of exposure (moving left on the x-axis) leads to a fixed increase in the adult outcome. The line is downward sloping representing improved outcomes with an additional year of exposure. Given the evidence summarized above, we may expect the effects of Food Stamps to manifest non-linearly based on the age at which a cohort was first exposed. The solid line in Figure 2 illustrates this relationship whereby an additional year of exposure in early childhood (here before age five) leads to larger improvements in adult well-being than an additional year of exposure in later childhood. The dotted line illustrates the case where additional years of exposure in later childhood leads to no improvement in adult outcomes.

Another feature illustrated in Figure 2 is that we do not expect individuals who were conceived after the Food Stamps program began (cohorts age -1 or younger on the x-axis) to 
experience larger effects than those conceived in the year it began. The rationale for this conjecture is that children born one, two, or five years before the Food Stamps program should have access to the program their entire childhood. Our empirical analysis tests for both the declining effects of the Food Stamps program by age at its introduction as well as the flattening of this relationship for children born in the years after the program began. ${ }^{12}$

\section{Data}

Our primary source of data combines information on individual outcomes in adulthood with information on their exact counties and dates of birth. We also use several sources of data on county-level economic conditions, social safety net programs, and other controls.

Individual-level outcome data: Our primary data sources are the 2000 Census Long Form (1-in-6 sample) and 2001-2013 ACS files, each linked to the SSA NUMIDENT file. In addition to the large number of individual outcomes, which we describe below, the NUMIDENT contains information on individuals' dates and places of birth, as well as the date of death for those who are deceased. The data sets are linked using a unique internal individual identifier at the Census Bureau called the Personal Identification Key (PIK). These data cover a large share of the U.S. population. In particular, the Census covers 16.7 percent of the U.S. population. After accounting for overlap in the samples, the ACS brings the total coverage to roughly 25 percent of the U.S. population; and the NUMIDENT file represents the full set of U.S. individuals applying for a Social Security card.

\footnotetext{
${ }^{12}$ Almond et al. (2011) show that Food Stamp programs ramp up quickly with adoption of a new program. Bitler and Figinski (2019) show that in the 10 percent of counties that did not have a Commodity Distribution Program (CDP) at some point prior to implementation of the Food Stamp Program, ramp up was slower, taking perhaps five years to reach the eligible population. The 90 percent with a CDP experienced quick ramp up which Bitler and Figinski attribute to a mature administrative process for eligibility determination and program implementation. We discuss the role of the Commodity Distribution Program in the history of FS in Section IV.
} 
The NUMIDENT place-of-birth variable is a string variable detailing in most cases the city and state of birth. We have developed a matching algorithm to translate this string variable to the Census Bureau's database of places, counties, and minor civil divisions as well as the United States Geological Survey's Geographic Names Information System (GNIS) file, building on prior work by Isen et al. (2017) and Black et al. (2015). Summarized in Taylor et al. (2016), this algorithm delivers a crosswalk between the NUMIDENT place-of-birth string variable and county Federal Information Processing Standards (FIPS) codes, with over 90 percent of individuals matched to their counties of birth. ${ }^{13}$

Our primary sample includes individuals who were born in the U.S. between 1950 and 1980 in order to span cohorts born before, during, and after the Food Stamps program rolled out. We limit the sample to individuals ages 25 to 54 to capture completed education and labor-market outcomes in prime-age working years. ${ }^{14}$ To minimize disclosure risk, we limit our sample to observations with non-allocated, non-missing values for all outcomes in our analysis. ${ }^{15} \mathrm{We}$ also limit the sample to individuals with valid PIKs (to enable linkage to the NUMIDENT file) and with a place of birth that can be matched to a county FIPS code (see the Online Appendix for more details).

Our resulting sample size consists of 17.5 million individuals. In some specifications, we test the robustness of our results to the inclusion of various county-level controls described below, and therefore limit our baseline sample to cohorts for which these control variables are available.

\footnotetext{
${ }^{13}$ Details on the matching algorithm are stored with Research Data Center files for the 1284 project and can be accessed by individuals who obtain access from the Census. Additionally, see the Online Appendix to Black et al. (2015) and Isen et al. (2017).

${ }^{14}$ For two outcome variables - physical disability and survival to 2012 - we widen the age range to 25-64.

${ }^{15}$ We allow for missing information physical disability and incarceration for the survey years when these variables are not available.
} 
To mitigate concerns about multiple hypothesis testing, we follow our pre-analysis plan in analyzing four standardized outcome indices (Kling et al. 2007). We orient the outcomes that are observed in all of the Census/ACS survey years such that a positive value represents a "better" outcome and calculate z-scores by subtracting the control group mean and dividing by the control group standard deviation, where we use the 1950-54 cohorts as the control group.

We create a composite index of well-being by taking an unweighted average of the four indices and also analyze each of the following sub-indices individually:

1. Productivity and Human Capital Index (years of schooling; high school or GED completed; any college received; college or more completed; professional degree obtained; professional occupation);

2. Economic Self-Sufficiency Index (in labor force; worked last year; weeks worked last year; usual hours worked per week; labor income; other income not from public sources; income-to-poverty ratio; not in poverty; reverse coded income from welfare, supplemental security, and other government sources);

3. Neighborhood Quality Index (value of home; gross rent; home or apartment ownership; residence with single and not multiple families; income-to-poverty ratio in census tract of residence; reverse-coded teen pregnancy in tract; reverse-coded share of single-headship in census tract, reverse-coded share of poor children in tract; share of home ownership in census tract of residence; median house price in census tract of residence; median gross rent in census tract of residence; and county absolute mobility score using estimates from Chetty et al. 2014);

4. Physical Ability and Health Index (no work disability; no ambulatory difficulty; no cognitive difficulty; no independent living difficulty; no vision or hearing 
difficulty; no self-care difficulty). ${ }^{16}$

Additionally, we separately consider two more outcomes:

5. Not Incarcerated (indicator for not being incarcerated, which we can infer based on information on residence in group quarters in the 2006-2013 ACS data).

6. Survival to Year 2012 (i.e., individual does not have a date of death in the 2011 NUMIDENT). This outcome is based on the full NUMIDENT with valid place of birth strings and is not limited to our Census/ACS samples. ${ }^{17,18}$

Appendix Table 1 presents means of incarceration, survival, and the elements of each of the indices for the full sample and for the race by gender subgroups. ${ }^{19}$

Data on Food Stamps Rollout: Dates of Food Stamps introduction are available at the county-by-year-by-month level from data originally collected by Hoynes and Schanzenbach (2009) and subsequently used in Almond et al. (2011) and Hoynes et al. (2016). These data were derived from USDA annual reports on Food Stamps monthly caseloads by county and are available for years 1961-1979.

\footnotetext{
${ }^{16}$ Physical ability and health measures are only available in years 2000-2007.

17 The NUMIDENT sample is limited to those who applied for a Social Security Number, are born in the U.S. and whose county of birth string was successfully matched to the county FIPS codes. The variable "Survived to 2012" is the count of the individuals in a birth-year/birth-county cell that have no date of death on record through 2011, expressed as a share of the number of births in that cell.

${ }^{18}$ In Section VII, we also calculate a measure of life expectancy as an alternative outcome, which we use in our costbenefit calculation.

${ }^{19}$ The share incarcerated in our sample is higher than other estimates. We weight our regressions using the number of observations in the cell (rather than the sum of the survey weights) to reflect the different sample sizes across our two data sources. Because we are combining the 2000 Decennial Census 1-in-6 sample and the annual ACS, using the sum of the weights would equate the importance across these two samples (since each ACS is representative of the entire U.S. population). Instead by using the sum of observations in the cell, we upweight the Decennial Census relative to the ACS reflecting its significantly larger samples. Practically, however, this has no impact on sample means or model estimates for the outcomes other than incarceration. However, because of ACS sampling, incarcerated (and all those in group quarters) have systematically lower survey weights compared to non-incarcerated in that sample; therefore our share incarcerated is higher than other sources (and higher than we get using survey weights). Our model results for incarceration are not changed qualitatively if we use survey weights. See the Online Data Appendix for more information.
} 
Data on Potential County-level Confounders: In our main model, we use data on countylevel characteristics from the 1960 Census of Population and Census of Agriculture including: the percent of the 1960 county population that lives in an urban area, is black, is younger than 5 , is older than 65 , has income less than $\$ 3000$ (in 1959 dollars), the percent of land in the county used for farming, and log county population. In some models, we also use data on time varying county controls. We use data from the BEA Regional Economic Information System (REIS) to measure county-level control variables on per capita transfers (originally collected by Almond et al. 2011) and population. The REIS data are available for 1959 and 1962, and then annually from 1965. Data from the National Center for Health Statistics (NCHS) are used to measure infant and adult mortality from 1959-1980. We also control for the roll-out of other War on Poverty programs including WIC, Head Start and Community Health Centers (Bailey 2012, Bailey and Duquette 2014, Bailey and Goodman-Bacon 2015, Bailey et al. 2019, Hoynes et al. 2011).

The Online Appendix contains more details about the data sources and construction of variables.

\section{Empirical Methods for Identifying the Effects of the Food Stamps Program}

We exploit the county-of-birth-by-year-of-birth (or birth year and month) variation in Food Stamps availability in event-study, linear spline, and difference-in-difference models. For computational ease, we collapse our data into birth-year x birth-county x survey-year cells, separately by gender and race (white versus non-white). ${ }^{20}$ In some models we collapse the data by birth month, birth year, and birth county to capture more detailed information on exposure to the Food Stamps program in months since conception.

\footnotetext{
${ }^{20}$ Nonwhite includes all individuals with a non-missing race variable who do not report being white.
} 
In order to characterize the effect dynamics by age, we use an event-study specification of the following form:

$$
Y_{c b t}=\theta_{c}+\delta_{s(c) b}+\psi_{t}+X_{c b} \beta+Z_{c 60} b \eta+\sum_{a=-5[a \neq 10]}^{a=17} \pi_{a} 1\left[b-F S_{c}=a\right]+\epsilon_{c b t}
$$

where an outcome, $Y$, is defined for a cohort born in county $c$ in state $s(c)$, in birth year $b$, and observed in survey year $t . F S_{c}$ is the year in which Food Stamps was first available in county $c$ and event time is $a$, denoting the age of the individual when Food Stamps was first introduced ( $a=$ $b-F S_{c}$ ), and event-time coefficients range from five years before birth to age 17 , with age 10 as the omitted category. ${ }^{21}$ We control for fixed effects for the birth county, $\theta_{c}$, and a full set of fixed effects for birth state by birth year, $\delta_{s(c) b}$, and survey year, $\psi_{t} \cdot{ }^{22}$ Per a pre-analysis plan and following the earlier studies using the Food Stamps roll-out (Hoynes and Schanzenbach 2009, Almond et al. 2011, Hoynes et al. 2016), we control for county-level controls from the 1960 Census, each interacted with a linear birth-cohort trend, $Z_{c 60} b$. In robustness checks, we also control for birth-county x birth-year and birth-cohort-varying controls, $X_{c b}$. The event-study coefficients, $\pi_{a}$, capture the effect of access to Food Stamps beginning at age $a$ (relative to the omitted age, 10) on outcome, $Y_{c b t}$. We cluster standard errors by county of birth and weight using the number of observations in the collapsed cell (Solon et al. 2015).

Importantly, the years prior to conception (event-time $<-1$ ) provide a pre-birth pre-trend test per Figure 2. The event-study model allows for non-parametric estimation of the time path of effects of exposure to Food Stamps at different ages during childhood. Following Lafortune et al. (2018), we also estimate a more parsimonious spline model, that allows for different linear slopes

\footnotetext{
${ }^{21}$ Given birth cohorts 1950-1980 and Food Stamps rollout spans 1961 to 1975, the event-time model is balanced between ages -5 and +11 . Therefore, we add binned end points for event time $\leq-6$ and $\geq 18$ but suppress them from the plots because they are compositionally imbalanced.

${ }^{22}$ We have also estimated a model that adds a quadratic polynomial in age at survey year. The results are very similar and available upon request.
} 
for exposure to Food Stamps during different age ranges: pre-conception (prior to exposure age 1), in utero through age five $(-1$ to +5$)$, middle childhood (ages six to 11$)$, and older childhood (ages 12 to17). The linear spline model takes the form:

$$
\begin{gathered}
Y_{c b t}=\theta_{c}+\delta_{s(c) b}+\psi_{t}+X_{c b} \beta+Z_{c 60} b \eta+\omega_{1} 1\left[b-F S_{c}<-1\right] *\left(b-F S_{c}\right)+ \\
\omega_{2} 1\left[-1 \leq b-F S_{c}<6\right] *\left(b-F S_{c}\right)+\omega_{3} 1\left[6 \leq b-F S_{c}<11\right] *\left(b-F S_{c}\right)+ \\
\omega_{4} 1\left[11 \leq b-F S_{c}\right] *\left(b-F S_{c}\right)+\epsilon_{c b t}
\end{gathered}
$$

for each cohort born in county $c$ in state $s(c)$, and year $b$, and observed in survey year $t$. The segment, $b-F S_{c}$, is the age at Food Stamps introduction, which we interact linearly with four separate indicators for the exposure groups described above. We use the spline model to test for pre-trends for exposure before birth, or that $\omega_{1}=0$. Additionally, we expect that the spline coefficients on exposure after birth, $\omega_{2}, \omega_{3}$, and $\omega_{4}$, are negative in sign because as age at Food Stamps introduction increases (i.e., $b-F S_{c}$ is higher), cohorts have less exposure to the program. Thus, when discussing the spline estimates below, we often refer to the absolute values of these coefficients. With these estimates, we examine whether the marginal effect of one more year of exposure is larger in the in utero and early years than at older ages (i.e., $\left|\omega_{2}\right|>\left|\omega_{i}\right|, i=3,4$ ).

Lastly, we estimate a difference-in-difference (DD) model, using cumulative exposure in early childhood as the "dose" of the program (Hoynes et al. 2016). We calculate the share of months each cohort is exposed to Food Stamps using the month and year the program began in each county and the (approximate) month of conception and age five, Share $F S_{c b}^{I U-5} \cdot{ }^{23}$ We use this measure as the primary explanatory variable in the following equation:

\footnotetext{
${ }^{23}$ In this model we use the data collapsed at the birth year $\mathrm{x}$ birth month $\mathrm{x}$ birth county $\mathrm{x}$ survey year. Conception is approximated as 9 months prior to the exact date of birth. Whenever we have data at the birth-year $\mathrm{x}$ birth-month level, we control for fixed effects for month and year of birth.
} 


$$
Y_{c b t}=\theta_{c}+\delta_{s(c) b}+\psi_{t}+X_{c b} \beta+Z_{c 60} b \eta+\kappa S h a r e F S_{c b}^{I U-5}+v_{c b t}
$$

for each cohort born in county $c$ in state $s(c)$, and year $b$, and observed in survey year $t$.

Regardless of the model, Food Stamps introduction is permanent-once a county implements Food Stamps, it never eliminates it. This feature restricts the set of comparisons that we can make. For example, our data do not allow us to observe a birth cohort first exposed at age two but without exposure in later childhood - if children move after birth, we do not see this in the data. ${ }^{24}$ Therefore, our estimates reflect the effect of additional Food Stamps exposure earlier in childhood, conditional on also having access to it later in childhood. Furthermore, in our setting, exposure earlier in life also means exposure for more years.

Identifying Assumptions and Balance Test. Our research design relies on the assumption that the timing of the Food Stamps roll-out across counties is uncorrelated with other county timevarying determinants of our long-term outcomes of interest. A central threat to identification relates to the potential endogeneity of the policy change, whereby the early adopting counties experience different cohort trends than later adopting counties.

What might be the source of endogenous county adoption of Food Stamps? First, prior to Food Stamps, some counties provided food aid through the CDP. The CDP was foremost an agricultural price support program, in which the surplus food was distributed to the poor. Counties were not permitted to operate both Food Stamps and a CDP, so they had to drop the CDP to implement Food Stamps. Thus, adopting Food Stamps led to a political economy conflict between agricultural interests who favored the commodity program and advocates for the poor who favored Food Stamps (MacDonald 1977; Berry 1984). Hoynes and Schanzenbach (2009) show that,

\footnotetext{
${ }^{24}$ Migration in early childhood could be endogenous. As discussed below, we use the PSID to explore this issue and find little evidence of Food Stamps directed migration.
} 
consistent with the historical accounts, more populous counties and those with a greater fraction of the population that was urban, black, or low income implemented Food Stamps earlier, while more agricultural counties adopted later. ${ }^{25}$ Yet they also find that the county characteristics explain very little of the variation in adoption dates, a fact that is consistent with the characterization of Congressional appropriate limits controlling the movement of counties off the waiting list (Berry 1984).

Bitler and Figinski (2019) find that counties with a CDP prior the Food Stamps adoption had a more rapid expansion in the Food Stamps program following county adoption, which they attribute to the presence of a developed administrative system. Because we do not have data on this unobserved source of heterogeneity, we are not able to test for this relationship directly. However, the fact that some counties already had some form of food aid program would lead our analysis to understate the effects of providing Food Stamps relative to no prior program.

Second, the Food Stamps introduction took place during a massive expansion of federal programs as part of Johnson's War on Poverty, and many of these programs were rolled out across counties. If Food Stamps programs expanded at the same time as other programs were being launched in a county, it would limit our ability to separate the effects of Food Stamps from these other programs. Bailey and Duquette (2014) and Bailey and Goodman-Bacon (2015) compiled information from the National Archives and Records Administration on changes in other countylevel funding under the War on Poverty between 1965 and 1980. Using these data, Bailey and Goodman-Bacon (2015) and Bailey, Sun and Timpe (2019) show little cause for concern. They show that the timing of the Food Stamp rollout is not correlated with the launch of CHCs or Head Start.

${ }^{25}$ See Table 1 and Appendix Figure 2 in Hoynes and Schanzenbach (2009). 
In addition, we assess the validity of the research design in four ways. First, we directly test whether our treatment variable is correlated with observable county time-varying characteristics, using the linear exposure model. Second, we test the sensitivity of our estimates to adding county-by-year controls including the rollout of other War on Poverty programs. Third, our preferred model includes a full set of birth-state-by-birth-year fixed effects, which likely absorbs some of the potential non-randomness of Food Stamps introduction and means that we only rely on within-state variation in program rollout. Finally, the pre-birth, pre-trend test in the event-study and linear-spline models provides an evaluation of differential trends in outcomes, which-if they exist-suggest threats to the internal validity of our estimates.

Table 1 presents estimates from the linear exposure model (3), using data collapsed to the birth-year x birth-month x birth-county level. Each row presents three sets of estimates of the coefficient on Share $F S_{c b}^{I U-5}$ from the model using the listed county characteristic as the dependent variable. All models include birth-county fixed effects and birth-state x birth-year fixed effects, as well as 1960 county characteristics interacted with a birth cohort trend. Column (1) uses 1960 county characteristics interacted with a linear birth-cohort trend, column (2) uses county characteristics interacted with a quadratic in birth cohort, while column (3) uses county characteristics interacted with a cubic in birth cohort. Out of 14 coefficients, 4 are statistically significant at the 5-percent level. Consistent with earlier work, we find greater Food Stamps exposure is associated with larger populations (Hoynes and Schanzenbach 2009) and has no association with other War on Poverty programs including WIC, Head Start and Community Health Centers (Bailey and Goodman-Bacon 2015, Bailey et al. 2019). We also find no relationship between Food Stamps exposure and county income, county employment, or county adult or infant mortality. We do find a statistically significant association between Food Stamps 
exposure and per capita spending on other transfer programs (Social Security, health, cash welfare). These estimates, however, are relatively small and are negative, implying that as Food Stamps exposure increases, there is less spending on other transfers in the county. This relationship suggests that, if anything, we should expect a downward bias in our estimates. We do not find that these conclusions change as we change the polynomial order of the trend interacted with 1960 county characteristics (columns 2 and 3). As we indicate in the table, none of these variables is available for all birth cohorts in our sample (1950-1980). Accordingly, we do not include these controls in our main estimates, but in a robustness analysis we find that including them does not change our qualitative conclusions.

\section{Results: How Food Stamps Exposure in Childhood Affects Outcomes in Adulthood}

\section{A. Full Sample}

We begin by presenting estimates for the composite index for the full sample. Panel A of Figure 3 presents the event-study estimates (equation 1), where the series with solid circles is from a model that includes fixed effects for county, birth year, survey year, as well as 1960 county characteristics interacted with linear cohort trends. The series with squares is from a model that includes all of those variables and adds fixed effects for birth state $\mathrm{x}$ birth year. The latter is our preferred specification because it captures potentially confounding, time-varying state policies, such as the roll-out of Medicaid (Goodman-Bacon 2015), the Elementary and Secondary Education Act (Cascio et al. 2013), the Civil Rights Act (Donohue and Heckman 1991, Almond et al. 2007), and the Economic Opportunity Act (Bailey and Duquette 2014). The estimates (and the y-axis) are scaled in standard-deviation units. Consistent with these confounders obscuring the effects of the Food Stamps program, including these state-year effects tends to make the estimates larger. Because we do not observe program participation, these are intent-to-treat (ITT) estimates 
using all individuals in our sample and not just those participating in the program (more on magnitudes below).

Recall from Figure 2 that movement along the $\mathrm{x}$-axis from right to left represents earlier (and longer) exposure to Food Stamps. Our estimates suggest that additional years of access to Food Stamps in the early childhood (prior to age 5) lead to larger increases in the composite index while there is little evidence of effects for children who were aged 6 to 18 years when the program began, where the line segment has little slope. Notably, there is no evidence of a differential trend after full implementation: individuals exposed prior to their conception (age at Food Stamps rollout $<-1$ ) exhibit very similar effects to children in utero (age at Food Stamps rollout=0) at the time the program started. This evidence supports the validity of our identification strategy.

However, even with our large samples, the event-study coefficients are not precisely estimated. Panel B of Figure 3 repeats the most saturated event study model (with birth-state $\mathrm{x}$ birth-year fixed effects) and adds the fitted spline function (see equation 2) including the same sets of fixed effects. To match the event study graph, we plot the spline relative to a value of zero for age 10. We also report the spline coefficient estimates and standard errors in the text box. This figure shows that the spline provides a good representation of the estimates in the event study and highlights that the parsimonious, parametric, model yields more precise estimates.

The estimates from the spline model show that one additional year of exposure in early life (in utero to age five) leads to a statistically significant 0.002 standard-deviation (ITT) increase in the composite index and an insignificant, and order-of-magnitude smaller, effect of additional years of exposure at older ages (insignificant 0.0003 for ages six to 11 and insignificant 0.0005 for ages $12-17) .{ }^{26}$ Additionally, supporting the research design, the cohorts exposed to the program

\footnotetext{
${ }^{26}$ As discussed in the description of model (2) above, we refer to the absolute values of the spline coefficients in order
} 
before conception (the spline between ages of exposure -5 to in utero, labeled "-5 to IU") is small and statistically insignificant.

Table 2 presents the results from the early life cumulative exposure model (equation 3), both with (column 3) and without (column 2) birth-state $x$ birth-year fixed effects. For completeness we also show results for models without the 1960 county characteristics interacted with linear cohort trends (column 1). The coefficients on Food Stamps exposure in early life are statistically significant and qualitatively similar in models with and without the state-by-year fixed effects. Thus, the rest of the paper presents results from the most saturated model that includes birth-state x birth-year fixed effects, which more effectively captures state-level confounders.

The preferred model (column 3, Table 2) implies that moving from no access to Food Stamps to full access from conception through age five leads to a 0.009 standard-deviation increase in the adult composite index. To translate this ITT estimate into an average treatment-on-thetreated (TOT) effect, we require information on Food Stamp participation rates. In Appendix Figure 2A, we use PSID data to plot the share of children living in households who report receiving Food Stamps, by the age of the child, averaging over survey years 1975-1978 to increase our precision. We choose these years as they are the first three calendar years where Food Stamps is available nationwide. The figure shows that Food Stamps participation among all children averaged 14 percent in these years, breaking down to 16 percent for children ages zero to five and 13 percent for children ages six to seventeen. ${ }^{27}$ Thus, we divide our exposure model estimates by 0.16 to obtain the implied TOT effects of full exposure from conception to age five. Doing so

to interpret the effect of an additional year of exposure.

27 The PSID provides the earliest available survey estimates for calculating food stamp participation rates and we use the first years when food stamps is available in all counties. The Current Population Survey begins measuring the food stamp participation in 1980 (measuring food stamps in 1979); there food stamp participation for children zero to 5 is 18 percent. 
yields a TOT effect of 0.06 standard-deviation units for the adult composite index outcome. The implied TOT from the spline model generates a similar effect, as do the implied TOT magnitudes from the event-study. ${ }^{28}$

Having established the composite results and congruence across the specifications, we next examine each of our four indices separately (human capital, economic self-sufficiency, neighborhood quality and physical disability) as well as survival to 2012 and non-incarceration. Figure 4 presents the absolute value of the spline estimates and their confidence intervals, and Figure 5 presents the event-study graphs along with the fitted spline models for these six outcomes. To facilitate comparisons across outcomes (and for the splines, across different ages of exposure), we use the same y-axis scaling across the four outcomes. The graphs for the survival and nonincarceration outcomes are on different scales just below, since those impacts are estimated as percentage-point effects rather than standard-deviation effects.

Looking across these results, several findings emerge. First, Figure 4 shows that none of the slopes for children born before the program began are statistically different from zero (plotted as dashed lines with circles), and their magnitudes are the smallest among all of the splines for most outcomes. This evidence supports our research design. Second, across most outcomes, we see large and statistically significant impacts of additional exposure to Food Stamps in early childhood (IU to age five) while the impact of additional years of exposure beginning in middle and older childhood does not translate into statistically significant improvements in long-run outcomes. This is evident in Figure 4 where the coefficients on the spline for additional exposure

\footnotetext{
${ }^{28}$ The absolute value of the estimate of the linear spline covering early life $\left(\omega_{2}\right)$ is 0.0017 (see textbox in Figure 3B), which multiplied by the 5.75 years of exposure (conception to age five) implies a 0.01 standard-deviation increase in the composite index ITT or 0.06 TOT. One can see a similar magnitude by reading off the coefficients in the eventstudy.
} 
in early childhood (solid lines with triangles) are consistently larger and statistically significant. This greater effect of early-life exposure is also evident in the event-study models in Figures 2 and 5.

Returning to the estimates, Table 3 provides the estimates for the early-life cumulative exposure model for these six outcomes. The magnitudes show that an increase from no access to full exposure from conception through age five leads to a 0.010 standard-deviation increase in human capital, an 0.004 standard-deviation increase in economic self-sufficiency, and a 0.012 standard-deviation increase in neighborhood quality. We find no statistically significant effects on physical disability, possibly reflecting the relatively young ages of our sample as well as restricted data availability (this outcome is only available before 2008). Interestingly, full exposure to Food Stamps leads to a 0.07 percentage-point increase in the likelihood of surviving until 2012. We also find a 0.08 percentage-point increase in the likelihood of not being incarcerated. Dividing these ITT estimates by the Food Stamps participation rate of 16 percent (for children ages five years and younger), we obtain approximate TOT impacts. The resulting magnitudes suggest quantitatively important impacts on long run outcomes. For example, given that 96 percent of the sample survives to year 2012, the effect on the likelihood of survival expressed as a share of the mean non-survival rate yields a 11 percent TOT impact: $(0.0007 /(0.04 \mathrm{x} 0.16))=0.109$. As a share of the mean survival rate, this is a 0.5 percent TOT impact. ${ }^{29}$

Appendix Figure 3 provides estimates of effects for each of the elements of the four indices based on the exposure model, which we summarize here. In order to facilitate comparisons across outcomes, each outcome is standardized (z-score) so the estimates reflect standard-deviation

\footnotetext{
${ }^{29}$ As detailed in the data section and the Online Data Appendix, the share incarcerated in our sample is higher than other estimates due to a lack of using survey weights in our main analysis. Our results are not qualitatively changed we weight with the sum of survey weights.
} 
impacts. The human-capital estimates show increases in education up through college graduation (and not beyond). Economic self-sufficiency estimates show small and statistically insignificant effects on extensive (in the labor force, worked last year) and intensive margins of labor supply (weeks worked, usual hours worked per week), with positive and statistically significant impacts on log earnings, the log family income to poverty ratio, and the likelihood of not being in poverty according to the official measure. We also find that more exposure to Food Stamps in early life leads to a large reduction in the likelihood of having no income from public assistance in adulthood. These findings imply that by reducing the likelihood of reliance on government support in adulthood, the social safety net serves as a long-term investment that may at least in part "pay for itself".

Interestingly, the components of the neighborhood quality index show the most consistent positive and statistically significant impacts. We document that greater childhood exposure to Food Stamps leads to a large increase in the likelihood of home ownership, residence in a singlefamily home, and overall improvement in the quality of the neighborhoods in which individuals live as adults. Specifically, using Census tract statistics, we find that Food Stamps leads to improvements in neighborhood of residence: increases in mean income as well as reductions in child poverty, teen pregnancy rates, and single-headship of one's neighbors. We also find that early childhood exposure to Food Stamps is associated with an increase in absolute upward mobility in one's county of residence in adulthood (Chetty et al., 2014), suggesting potential intergenerational effects of Food Stamps.

The magnitudes suggest important effects of resources on long-run outcomes. The unstandardized estimates for each of the sub-index components are provided in the first column of Appendix Table 2. Full exposure to Food Stamps between conception and age five leads to a 0.2 
percentage-point increase (or 1.3 percentage-point TOT) in having a high school degree (or GED) compared to the mean of 93 percent (Appendix Table 1). Full exposure between conception and age five leads to a 0.4 percentage-point decrease (or 2.5 percentage-point TOT) in living below the poverty line compared to the mean of 10 percent. Full exposure to Food Stamps leads to a 1.1 percent increase in earnings (or 7.1 percent increase TOT).

\section{B. Heterogeneity in Estimates}

Table 4 presents the estimates from the exposure model for the four indices plus survival and non-incarceration, separately for white men, white women, nonwhite men, and nonwhite women. The results in the first row show that the ITT effects on human capital are largest for white males ( 0.010 of a standard deviation) with slightly smaller effects for white females ( 0.008 of a standard deviation) and statistically insignificant effects for nonwhite men and women. These findings may be surprising given that, all else equal, we expect larger ITT effects for nonwhites due to their lower average incomes and higher rates of eligibility for Food Stamps.

There are several important considerations when interpreting these effects. First, the lack of statistically significant findings for nonwhites may reflect differences in sample sizes and sampling variation. Limiting the sample to nonwhites reduces the sample sizes to less than 15 percent of the overall sample and, unlike the PSID, the Census/ACS data have few family background characteristics to explain the considerable variation in outcomes. In addition, the lack of access to high quality schools for blacks during this time period may have prevented them from reaping the full benefits of the Food Stamps program. Consistent with this idea, Johnson and Jackson (2019) document the importance of "dynamic complementarities" between investments in early childhood (Head Start in their case) and school quality at older ages.

Appendix Figures 4 through 6 further explore the differences by race and gender by 
presenting event-study graphs for a few outcomes separately by subgroup. Appendix Figure 4 shows that the gains in survival are concentrated among nonwhite men and women, with small and insignificant (and for white men opposite-signed) effects for whites. Additionally, the effect of Food Stamps exposure on survival for nonwhites is spread throughout childhood, rather than concentrated in early life as we see in other outcomes. Appendix Figure 5 demonstrates that access to Food Stamps leads to a decrease in the probability of being incarcerated but only for nonwhite men (with noisy and wrong signed results for white men and nonwhite women). As with survival, the long-run benefits of Food Stamps for nonwhite males are consistent through childhood rather than being concentrated in early life. The estimates are sizable - for every year of exposure during early life (in utero through age 5) incarceration declines by 0.1 percentage points or about 1 percent (ITT). Appendix Figure 6 shows that the impacts of Food Stamps on neighborhood quality is consistent across the four race-gender subgroups.

Appendix Figure 7 plots the absolute value of the relationship (and confidence intervals) for the composite indices and outcomes for the cohorts born after the program began (our prebirth, pre-trend spline) across the four subgroups. The figure shows that of the 28 estimates only two are statistically different from zero (neighborhood quality index for nonwhite men and disability index for white women), no more than expected by chance. This provides additional evidence supporting our research design. The figure also makes clear that we have less precision when estimating effects for nonwhites, who represent less than 15 percent of the overall sample.

Finally, we explore mobility as a potential mechanism in Table 5. In the first column, we use our entire sample and estimate the exposure model (equation 3) using as the dependent variable the share moving from one's county of birth to a different county in adulthood in our outcome 
data. ${ }^{30}$ We find that full exposure to Food Stamps from conception to age five significantly increases the likelihood of moving away from one's county of birth by 0.85 percentage points ( 5.3 percentage-point TOT, or 7.5 percent TOT relative to the sample mean of 71 percent). ${ }^{31}$ This result suggests that the effect of Food Stamps on neighborhood quality (and, potentially, the other outcomes) at least in part operates through individuals being able to move to better places. The rest of Table 5 examines the differences in impacts on our main outcomes between the subsample who remain in their county of birth (labeled "Stayers") and those whom we observe no longer living in their county of birth at the time of the survey (labeled "Movers"). Overall, comparing across the human capital, economic self-sufficiency and neighborhood quality indices (we drop the physical disability index from the main paper for space reasons, as the results are consistently statistically insignificant), the estimates of exposure to Food Stamps are larger for stayers compared to movers. The smaller estimates for movers are consistent with misclassification in childhood Food Stamps exposure, subgroup heterogeneity, or that geographic mobility is a mechanism for the treatment effect of Food Stamps (the means of the dependent variables are larger and Food Stamps increases the likelihood of being a mover). ${ }^{32}$

\footnotetext{
${ }^{30} \mathrm{We}$ observe location of birth in the NUMIDENT file (capturing county of birth) and in the Census/ACS (capturing residence at the time of the Census or survey). We assign stayer/mover status using those two points in time.

${ }^{32}$ Recall that we assign Food Stamps exposure using county of birth and we observe location only at birth and in adulthood in our outcome sample. Consequently, we do not have data on when the individual moved (if they did). If children move in early childhood, this could generate misclassification error in Food Stamp exposure. Alternatively, endogenous or "directed" migration could introduce bias into our exposure measure if motivated (and potentially more economically successful) individuals who are not exposed to Food Stamps are systematically more likely to move to counties with Food Stamps before age five (i.e., a negative correlation between Food Stamps exposure at birth and subsequent Food Stamps availability in one's destination county). We have explored this possibility using restricted longitudinal PSID data, which contains information on individuals' counties of birth and counties of residence during childhood for cohorts born in 1968 or later. Appendix Table 4 presents those estimates where we relate the incidence of moving by age five (columns 1,3) and moving by age five to a county with Food Stamps (columns 2,4) to our Food Stamp exposure measure (share of time between conception and age five that Food Stamps was in place in your county of birth). We do not find evidence consistent with endogenous migration - if anything, Food Stamps exposure in one's county of birth is slightly positively correlated with the likelihood of moving to a county with Food Stamps during childhood.
} 


\section{Robustness}

Table 6 examines the sensitivity of our results to adding time-varying county controls, using the full sample composite index, and using the exposure model. We include all of the variables in our balance table (Table 1) that are available for 1959-1980 (covering most of our full birth cohort sample of 1950-1980), including presence of War on Poverty programs, REIS transfer spending, county mortality, and the natural log of county population. We limit the sample to the observations with non-missing variables for all of these controls. In column (1) we estimate our baseline specification for this restricted sample and the coefficient on the Food Stamp exposure (0.0087) is unchanged from the full sample (Table 2, column 3). Adding the control for log population (column 2) reduces the magnitude of the impact of Food Stamps exposure slightly, and adding further controls leaves the estimate virtually unchanged.

Once Food Stamps is in place it is never eliminated. Therefore, exposure at younger ages implies exposure at older ages. Our main exposure model captures the share of time between conception and age five that Food Stamps is in place and does not account for exposure throughout the rest of childhood. In Table 7, we present estimates for the six main outcomes for the full sample adding a second exposure variable - the share of time between ages 6 and 18 that Food Stamps is in place. None of the estimates of the later child exposure is statistically significant, and the estimates on the early-life exposure variable remain of similar magnitude and statistical significance as in the main results. ${ }^{33}$

\footnotetext{
${ }^{33}$ As seen in Appendix Figure 2A, Food Stamps participation rates among children ages 6-18 are slightly lower than those among children ages 5 years or less (13\% vs. 16\%). Yet even if we scale the (insignificant) coefficients on exposure at ages $6-18$ by the age specific participation rates, we get economically small magnitudes. Additionally, in Appendix Figure 2B, we use PSID data to demonstrate that there are no discontinuous changes in the length of time individuals spend on Food Stamps between those who first use the program at ages younger than 5 versus ages older than 5. This suggests that the difference in effect sizes between exposure below and above age five is not driven by a difference in the duration of benefit receipt. Further, Appendix Figure 8 uses 1970 and 1980 Census data to show that there are no discontinuous jumps in migration rates between children under age five and over age five among children
} 


\section{Magnitudes and Relation to the Existing Literature}

The literature on the long-run impacts of early-life exposure to the near-cash social safety net is small. However, a few estimates provide good comparisons to our outcomes. Hoynes et al. (2016) find that full exposure from conception to age five leads to a 0.7 standard deviation improvement in an index of metabolic syndrome and a statistically insignificant effect on economic self-sufficiency (TOT). Bitler and Figinski (2019) find that full exposure to Food Stamps from conception to age five leads to a 15 percent (TOT) increase in earnings at age 32 for women and insignificant effects for men. We find a 7 percent (TOT) increase in labor income for the full sample of men and women (Appendix Table 2, 0.0114/0.16). Like Bitler and Figinski (2019) we find no significant effects on employment (Appendix Table 2).

Other comparisons come from studies on the long-run impacts of Head Start participation and Medicaid. Deming (2009) uses the PSID and NLSY and a sibling fixed effects model and finds that participating in Head Start leads to a 0.23 standard deviation increase (TOT) in a summary index of young adult outcomes that includes high school graduation, college attendance, idleness, crime, teen parenthood and health status. This is probably best compared to our Food Stamps TOT impact on human capital of 0.06 standard deviation. Bailey et al. (2019) use the Census/ACS/NUMIDENT data used here along with a county Head Start rollout design and find that a TOT effect of Head Start on human capital index of 0.10 standard deviation (slightly larger than our estimate).

Brown et al. (forthcoming) use the variation in expansions of child eligibility for Medicaid across states and years and find that greater childhood Medicaid coverage leads to a reduction in

in disadvantaged families (as proxied by mothers having less than a high school degree). Thus, the difference in effects between exposure below and above age five is also not driven by differences in measurement error when assigning exposure based on a child's county of birth. 
mortality in young adulthood. Using their estimates for the linear effect of years of Medicaid eligibility multiplied by 5.75 years of access (equivalent to length of access for our in utero through age five exposure model) and adjusting for take-up, their estimates generate an 8 percent TOT reduction in mortality for women and a 13 percent TOT reduction for men. This compares to our 11 percent TOT estimate for the full sample.

\section{Comparing Costs and Benefits of Early Childhood Food Stamps Exposure}

This final section uses the framework proposed by Hendren (2016) and used in Hendren and Sprung-Keyser (2019) to calculate the Food Stamps Program's marginal value of public funds (MVPF), or the ratio of benefits to the net government costs (i.e., fiscal externalities). Equivalently, the MVPF is the ratio of the beneficiaries' willingness to pay for the increase in expenditure out of their own income to the cost to the government of the policy per beneficiary.

In terms of benefits, how much would Food Stamps recipients be willing to pay for a dollar of program expenditures? Because the benefits must be used to purchase food, they may not be valued dollar for dollar by beneficiaries. In addition, we need to value how much children of eligible parents would be willing to pay out of their own income for an extra dollar of Food Stamps benefits transferred to their parents. We use our estimates of (i) the increases in labor income, (ii) the increases in survival rates, (iii) the reductions in incarceration rates, and (iv) the reductions in public-program income of affected children in adulthood to quantify the benefits to children. We then translate these benefits into willingness to pay (WTP) measures, while also calculating the implied fiscal externalities associated with these changes. In order to value the improvement in survival rates, we create an additional outcome variable, life expectancy, which we use to estimate the ITT/TOT benefits in terms of years of life gained. The Online Appendix provides more detail 
for this life expectancy measure and the associated results (Appendix Table 5).

We make the following assumptions when evaluating WTP for the Food Stamps program for a household with children between conception and five. While some evidence suggests that Food Stamps receipt does not significantly alter purchase decisions in ways that would imply dollar for dollar valuation (Smeeding 1982), Whitmore (2002) suggests that individuals only value a dollar of SNAP payments at 80 cents. For children, we include their willingness to pay for their increase in after tax earnings and estimated increases in life expectancy. To estimate after tax earnings gains for children, we follow Hendren and Sprung-Keyser (2019) to estimate, first, the lifetime earnings of children exposed to Food Stamps during early childhood. They use the parental earnings estimates from Hoynes, Schanzenbach and Almond (2016), which they convert to present discounted lifetime parental income using the profile of lifetime earnings in the 2015 ACS, a 0.5 percent wage growth assumption, and estimates of the distribution of parental earnings from Chetty et al. (2018). They then apply an intergenerational elasticity to this number to recover a predicted present discounted value of child lifetime income as adults. Lastly, they take the TOT estimates on the labor-market returns from this study and apply an average tax rate of $12.9 \%$ to suggest that children would be willing to pay $\$ 0.45$ for every $\$ 1$ of Food Stamps spending due only to the gains in the labor income. Our preferred estimate of the increase in life expectancy implies a TOT increase of 1.1 life years for full exposure to Food Stamps between conception and age five $(0.176 / 0.16$, Appendix Table 5, column 3$)$. We follow the standard approach of using the value of a statistical life (VSL) to convert changes in mortality rates into dollars. Our primary approach relies on the U.S. Environmental Protection Agency's (EPA) VSL estimate of \$10.95 million (2018 USD).$^{34}$ Following Carleton et al. (2019), we calculate the value of lost life-years

\footnotetext{
${ }^{34}$ This VSL is from the 2012 U.S. EPA Regulatory Impact Analysis (RIA) for the Clean Power Plan Final Rule, which
} 
by dividing the U.S. EPA VSL by the remaining life expectancy of the median-aged American (47.2). This recovers an implied value per life-year of $\$ 232,000$. In 2018 , recipients received an average of $\$ 3,024$ per household annually. Using an average family size of 3.29 and computing the total benefit from conception to five years, an average child from a treated household would receive $\$ 4,595$ in benefits. Thus, the implied WTP for the increase in life expectancy for children is estimated to be around $\$ 255,200$ (a 1.1 year increase in life expectance times $\$ 232,000$ in value per life year) or $\$ 55$ per dollar of SNAP spending for a child from conception to age five.

Fiscal externalities associated with the program include the potentially distortionary impact of Food Stamp provision on earnings and government revenue (Hoynes and Schanzenbach 2012), the program-generated long-run reductions in public assistance income and incarceration rates, and the increased tax revenues stemming from improvements in labor income of affected children. The distortionary impact of the program on adult earnings is a cost to the government in terms of foregone tax revenue, whereas the reductions in government payments on public assistance, incarceration, and increased tax revenue from children's labor-market gains offset some of these costs.

Following Hoynes and Schanzenbach (2012) and Hendren and Sprung-Keyser (2019), Food Stamp's introduction leads to a statistically insignificant decline in labor earnings of \$219 among households headed by a nonelderly individual with a high school education or less, which, scaling by the participation rate of six percent, implies that Food Stamps enrollment leads to a $\$ 3,650$ decline in annual labor earnings. Using a tax rate of 12.9 percent, this calculation implies a fiscal externality or cost of $\$ 471$, or $\$ 0.16$ for every $\$ 1$ of Food Stamps benefits expenditures. In terms of public assistance spending, the average participant in our sample receives less than $\$ 0.01$

provides a 2020 income-adjusted VSL in 2011 USD, which we convert to 2018 USD. 
in per capita payments. Thus, any benefits to the government in terms of TOT reductions in public assistance spending are small enough to be negligible, and we ignore these fiscal externalities (i.e. benefits). In terms of our estimated reductions in incarceration rates, the current estimated costs of incarceration are $\$ 31,978$ annually (in 2016 dollars). ${ }^{35}$ According to the Bureau of Justice Statistics, the average length of time spent incarcerated is 2.6 years. ${ }^{36}$ Our TOT estimates suggest that Food Stamps increased the fraction not incarcerated by 0.5 percentage points, and thus the total fiscal externality amounts to $\$ 416(\$ 31,978 * 2.6 * 0.005)$ or $\$ 0.09$ per dollar of expenditure using the $\$ 4,595$ in benefit expenditure from above. Lastly, additional fiscal externalities are associated with the increases in government tax revenue, because of the long-run labor-market impacts of the children. As mentioned above, the after-tax earnings benefits for children are $\$ 0.45$ per dollar of expenditure using an average tax rate of 12.9 percent. This implies a revenue externality for the government of $\$ 0.07$ per dollar of expenditure. ${ }^{37}$ The net impact of these offsetting costs/benefits turns out to be a fiscal cost of $\$ 0$ per dollar of Food Stamps expenditures (i.e., $-0.16+0.09+0.07)$.

Based on these calculations, we arrive at an MVPF of $56.25 .{ }^{38}$ Note that one could also amend these calculations to incorporate relative social welfare weights between parents and children, whereas here we treated them equally. Our Food Stamp MVPF is similar to or larger than the MVPFs estimated for child Medicaid expansions and highly regarded early childhood education interventions, such as the Perry Preschool and the Carolina Abecedarian Program

\footnotetext{
${ }^{35}$ See https://www.federalregister.gov/documents/2016/07/19/2016-17040/annual-determination-of-average-cost-ofincarceration (accessed on 3/11/2020).

${ }^{36} \mathrm{See}$ https://www.bjs.gov/index.cfm?ty=pbdetail\&iid=6446 (accessed on 3/11/2020).

${ }^{37}$ This calculation comes from the difference in the pre-tax earnings gains per dollar of expenditure $(\$ 0.516)$, relative to the post-tax earnings gains per dollar of expenditure (0.45).

${ }^{38}$ This is calculated by summing the willingness to pay and dividing by the net cost to the government (i.e., $(0.8+0.45+55) /(1+0)=56.25)$.
} 
(Hendren and Sprung-Keyser 2019). It is also higher than Hendren and Sprung-Keyser (2019)'s calculation of the MVPF associated with the Food Stamps program. There are two main differences between our estimates and Hendren and Sprung-Keyser (2019). The first is that we directly estimated improvements in life expectancy as opposed to backing them out from estimates of survival until the year 2012. Second, we use a VSL amount that is more consistent with recent federal regulatory impact analyses and is larger than the value used in Hendren and Sprung-Keyser (2019).

\section{Conclusion}

Children constitute nearly one third of all poor individuals in the United States, making them important beneficiaries of the social safety net system. ${ }^{39}$ A recent report from the National Academies of Sciences documents that since the inception of Johnson's War on Poverty in the 1960s, there has been substantial progress in reducing the child poverty rate from 28.4 percent in 1967 to 15.6 in 2016 (National Academies of Sciences 2019).

However, changes to the poverty rate provide an insufficient metric for evaluating the success (or failure) of safety net programs. . At their inception, these programs aspired to prevent poverty, increase opportunities and give beneficiaries a "hand up, not a handout." Today, policy makers often use this rationale to motivate spending on early childhood programs - such as preschool and nurse home visiting interventions - which generate upfront costs but can be viewed as an investments into adult human capital, health, and economic well-being. That is, the value of these investments may not materialize for many years.

A similar logic suggests that understanding the potential long-term benefits of access to

39 See the U.S. Census Bureau for statistics about the age distribution of the poor: https://www.census.gov/data/tables/time-series/demo/income-poverty/historical-poverty-people.html 
anti-poverty programs in early life is critical from a public finance perspective-if these programs improve adult economic well-being, thus generating both private returns and public benefits, the social safety net system may partially pay for itself.

In this paper, we use data on 43 million Americans to provide the most comprehensive analysis to-date of the long-term impacts of early childhood access to the Food Stamps program, a central pillar of the U.S. social safety net. We combine data from the 2000 Census and the 20012013 ACS with data from the SSA NUMIDENT, and exploit the county-by-year variation in the initial rollout of Food Stamps over 1961 to 1974 to measure the impacts of exposure to the program at various ages during childhood on a wide range of adult outcomes, including human capital, economic self-sufficiency, neighborhood quality, disability, incarceration, and longevity.

Our results show that access to Food Stamps in one's county of birth in every month between the time of conception and age five has large consequences for adult well-being. Specifically, we find a 0.009 standard-deviation increase in a composite index of adult human capital and well-being, driven by a 0.010 standard-deviation increase in human capital, a 0.004 standard-deviation increase in economic self-sufficiency, and a 0.012 standard deviation increase in neighborhood quality. We also document a 0.07 percentage-point increase in the likelihood of survival to 2012 and a 0.08 percentage-point reduction in the likelihood of being incarcerated. Scaling these ITT impacts by the approximate 16 percent Food Stamps participation rates in early childhood implies large long-term benefits of Food Stamps for participating children. These estimates imply a MVPF of 56.25 , suggesting the program is highly cost effective.

Our findings have important implications for current debates about the social safety net. The Food Stamps program (currently renamed as the Supplemental Nutrition Assistance Program, or SNAP) is one of the largest U.S. cash or near-cash means-tested transfer programs and is the 
only safety net program available to nearly all income eligible families (other programs limit eligibility to particular subgroups determined by age, disability status, or household structure). ${ }^{40}$ Food Stamps also plays an important countercyclical role by automatically increasing benefits as need increases (Bitler and Hoynes 2016); in the peak of the Great Recession nearly one in every seven individuals received Food Stamps benefits. Credible and comprehensive estimates of the program's long-term impacts are essential for informing cost-benefit calculations that may influence budgetary decisions.

There are still many questions left open by this study. Importantly, we are unable to observe the precise mechanisms driving the impacts of early childhood exposure to Food Stamps on adult outcomes. Additionally, the fact that we find improvements in adult economic self-sufficiency and neighborhood quality suggests that there may be intergenerational impacts of the program on the children of the children who benefitted during the program's initial roll out. As more time passes and additional data linkages become available, investigating these even-longer-term benefits may be fruitful areas for future research.

\footnotetext{
${ }^{40}$ Able-bodied adults 18 to 49 without dependents can only receive SNAP for three months in three years if they do not meet work requirements.
} 


\section{References}

Aizer, Anna, Shari Eli, Joseph Ferrie, and Adriana Lleras-Muney. 2016. "The Long Run Impact of Cash Transfers to Poor Families.” American Economic Review 106 (4): 935-71.

Aizer, Anna, Laura Stroud, and Stephen Buka. 2016b. "Maternal Stress and Child Outcomes: Evidence From Siblings." Journal of Human Resources 51(3): 523-555.

Akee, Randall K. Q., William E. Copeland, Gordon Keeler, Adrian Angold, and E. Jane Costello. 2010. "Parents' Incomes and Children's Outcomes: A Quasi-Experiment Using Transfer Payments from Casino Profits." American Economics Journal: Applied Economics 2 (1): 86-115.

Almond, Douglas, Kenneth Y. Chay, and Michael Greenstone. 2007. "Civil Rights, the War on Poverty, and Black-White Convergence in Infant Mortality in the Rural South and Mississippi. SSRN Working Paper, https://papers.ssrn.com/sol3/papers.cfm?abstract id=961021.

Almond, Douglas and Janet Currie, 2011a. "Human Capital Development Before Age Five," in O. Ashenfelter and D. Card, Eds., Handbook of Labor Economics, Vol. 4, Elsevier, pp. $1315-1486$.

Almond, Douglas, and Janet Currie. 2011b. "Killing Me Softly: The Fetal Origins Hypothesis." Journal of Economic Perspectives 25 (3): 153-72.

Almond, Douglas, Janet Currie, and Valentina Duque,. 2018. "Childhood Circumstances and Adult Outcomes: Act II," Journal of Economic Literature.

Almond, Douglas, Hoynes, Hilary and Diane Schanzenbach. 2011. "Inside the War on Poverty: the Impact of Food Stamps on Birth Outcomes," Review of Economics and Statistics, 93 (2), 387-403.

Bailey, Martha J and Andrew Goodman-Bacon. 2015. "The War on Poverty's Experiment in Public Medicine: Community Health Centers and the Mortality of Older Americans," American Economic Review 105 (3): 1067-1104.

Bailey, Martha J., 2012. "Reexamining the Impact of U.S. Family Planning Programs on Fertility: Evidence from the War on Poverty and the Early Years of Title X," American Economic Journal: Applied Economics 4(2): 62-97.

Bailey, Martha J. and Nicolas J. Duquette. 2014. "How Johnson Fought the War on Poverty: The Economics and Politics of Funding at the Office of Economic Opportunity." Journal of Economic History 74(2): 351-388.

Bailey, Martha J., Shuqiao Sun, and Brenden Timpe. 2019. "Prep School for Poor Kids: The Long-Run Impact of Head Start on Human Capital and Productivity," University of Michigan Working Paper, http://www-personal.umich.edu/ baileymj/Bailey_Sun_Timpe.html.

Banerjee, Abhijit, Esther Duflo, Gilles Postel-Vinay, and Tim Watts. 2010. "Long-Run Health Impacts of Income Shocks: Wine and Phylloxera in Nineteenth-Century France," Review 
of Economics and Statistics 92 (4): 714-728.

Barker, David J. 1990. "The Fetal and Infant Origins of Adult Disease," BMJ: British Medical Journal 301 (6761): 1111.

Barr, Andrew and Chloe R. Gibbs. 2018. "Breaking the Cycle? Intergenerational Effects of an Anti-Poverty Program in Early Childhood.” Notre Dame Working Paper.

Bastian, Jacob, and Katherine Michelmore. 2018. "The Long-Term Impact of the Earned Income Tax Credit on Children's Education and Employment Outcomes." Journal of Labor Economics 36 (4).

Beatty, Timothy and Charlotte Tuttle. forthcoming. "Expenditure Response to Increases in In-Kind Transfers: Evidence from the Supplemental Nutrition Assistance Program," American Journal of Agricultural Economics.

Bitler, Marianne P. and Arian Siefoddini. forthcoming. "Health Impacts of Food Assistance: Evidence from the United States," Annual Review of Resource Economics.

Bitler, Marianne P and Janet Currie. 2005. "Does WIC Work? The Effects of WIC on Pregnancy and Birth Outcomes," Journal of Policy Analysis and Management 24(1): 73-91.

Bitler, Marianne P and Theodore Figinski (2019). "Long-Run Effects of Food Assistance: Evidence from the Food Stamp Program,” ESSPRI Working Paper Series Paper \#20195.

Bitler, Marianne and Hilary Hoynes. 2016. "The More Things Change, the More They Stay the Same? The Safety Net and Poverty in the Great Recession." Journal of Labor Economics 34, supplement 1: S403-S444.

Black, Dan A, Seth G Sanders, Evan J Taylor, and Lowell J Taylor. 2015. "The Impact of the Great Migration on Mortality of African Americans: Evidence from the Deep South." American Economic Review 105 (2): 477-503.

Black, Sandra E, Paul J Devereux. 2011. "Recent Developments in Intergenerational Mobility," Handbook of Labor Economics Vol. 4, pp. 1487-1541.

Black, Sandra E., Paul J. Devereux, and Kjell G. Salvanes. 2016. "Does Grief Transfer Across Generations? Bereavements During Pregnancy and Child Outcomes." American Economic Journal:Applied Economics 8 (1): 193-223.

Boudreaux, Michel H, Ezra Golberstein, and Donna D Mcalpine. 2016. "The Long-Term Impacts of Medicaid Exposure in Early Childhood: Evidence from the Program's Origin," Journal of Health Economics 45: 161-175.

Bureau of the Census. County Business Patterns, 1969-1980 [United States]: State and County Data. Ann Arbor, MI: Inter-university Consortium for Political and Social Research [distributor], 2006-01-18. https://doi.org/10.3886/ICPSR03549.v1 
Bratberg, Espen, Øivind Anti Nilsen, and Kjell Vaage. 2008. "Job Losses and Child Outcomes," Labour Economics 15 (4): 591-603.

Brown, David, Amanda E Kowalski, and Ithai Z Lurie. forthcoming. "Long-Term Impacts of Childhood Medicaid Expansions on Outcomes in Adulthood," Review of Economic Studies.

Bruich, Gregory. 2014. The effect of SNAP benefits on expenditures: New evidence from scanner data and the November 2013 benefit cuts," Harvard University Working Paper.

Carleton, Tamma and Delgado, Michael and Greenstone, Michael and Houser, Trevor and Hsiang, Solomon and Hultgren, Andrew and Jina, Amir and Kopp, Robert E. and McCusker, Kelly and Nath, Ishan and Rising, James and Rode, Ashwin and Seo, Hee Kwon and Simcock, Justin and Viaene, Arvid and Yuan, Jiacan and Zhang, Alice Tianbo. "Valuing the Global Mortality Consequences of Climate Change Accounting for Adaptation Costs and Benefits" (July 31, 2019). University of Chicago, Becker Friedman Institute for Economics Working Paper No. 2018-51.

Cascio, Elizabeth U., Nora Gordon, and Sarah Reber. 2013. Local Responses to Federal Grants: Evidence from the Introduction of Title I in the South. American Economic Review 5 (3): 126-59.

Chetty, Raj, John N. Friedman, and Jonah Rockoff. 2011. "New Evidence on the LongTerm Impacts of Tax Credits." Washington: Internal Revenue Service. https://www.irs.gov/pub/irs-soi/11 rpchettyfriedmanrockoff.pdf

Chetty, Raj and Nathaniel Hendren. 2016. "The Impacts of Neighborhoods on Intergenerational Mobility I: Childhood Exposure Effects,"National Bureau of Economic Research Working Paper 23001.

Chetty, Raj and Nathaniel Hendren. 2016. "The Impacts of Neighborhoods on Intergenerational Mobility II: County-Level Estimates," National Bureau of Economic Research Working Paper 23002.

Chetty, Raj, Nathaniel Hendren, Patrick Kline, and Emmanuel Saez. 2014. "Where Is the Land of Opportunity? The Geography of Intergenerational Mobility in the United States," Quarterly Journal of Economics 129 (4): 1553-1623.

Chetty, Raj, Michael Stepner, Sarah Abraham, Shelby Lin, Benjamin Scuderi, Nicholas Turner, Augustin Bergeron, and David Cutler. 2016. The Association between Income and Life Expectancy in the United States, 2001 - 2014. Journal of the American Medical Association, April 11, 2016, 315, No. 14.

Coelli, Michael B. 2011. "Parental Job Loss and the Education Enrollment of Youth," Labour Economics 18 (1): 25-35.

Cohodes, Sarah R., Daniel S. Grossman, Samuel A. Kleiner, and Michael F. Lovenheim. 2016. "The Effect of Child Health Insurance Access on Schooling: Evidence from Public Insurance Expansions.” Journal of Human Resources 51 (3): 727-59. 
Cuhna, Flavio and James Heckman. 2007. “The Technology of Skill Formation,” American Economic Review 97(2):31-47.

Currie, Janet, and Nancy Cole. 1993. "Welfare and Child Health: The Link between AFDC Participation and Birth Weight." American Economic Review 83 (4): 971-85.

Currie, Janet and Jonathan Gruber. 1996. "Health Insurance Eligibility, Utilization of Medical Care, and Child Health," Quarterly Journal of Economics 111 (2): 431-466.

Currie, Janet and Jonathan Gruber. 1996. "Saving Babies: the Efficacy and Cost of Recent Changes in the Medicaid Eligibility of Pregnant Women," Journal of Political Economy104 (6): $1263-1296$.

Cutler, David, Wei Huang, and Adriana Lleras-Muney. 2016. "Economic Conditions and Mortality: Evidence from 200 Years of Data," National Bureau of Economic Research Working Paper 22690.

Cutler, David M, Grant Miller, and Douglas M Norton. 2007. "Evidence on Early-Life Income and Late-Life Health from America's Dust Bowl Era." Proceedings of the National Academy of Sciences 104 (33): 13244-13249.

Dahl, Gordon B., and Lance Lochner. 2012. "The Impact of Family Income on Child Achievement: Evidence from the Earned Income Tax Credit." American Economic Review 102 (5): 1927-56.

Dahl, Gordon B., and Lance Lochner. 2017. "The Impact of Family Income on Child Achievement: Evidence from the Earned Income Tax Credit: Reply.” American Economic Review 107 (2): 629-31.

Deming, David. 2009. "Early Childhood Intervention and Life-Cycle Skill Development: Evidence from Head Start." American Economic Journal: Applied Economics 1 (3): 111-34.

Donohue, John J. and James Heckman. 1991. "Continuous Versus Episodic Change: the Impact of Civil Rights Policy on the Economic Status of Blacks." Journal of Economic Literature 29 (4): 1603-1643.

Duncan, Greg J and Jeanne Brooks-Gunn, Eds. 1997. Consequences of Growing Up Poor, Russell Sage Foundation.

Duncan, Greg J, Jeanne Brooks-Gunn, Kathleen M Ziol-Guest, and Ariel Kalil. 2010. "Early-Childhood Poverty and Adult Attainment, Behavior, and Health," Child Development 81(1): 306-325.

East, Chloe N. 2018. The Labor Supply Response to Food Stamp Access, Labour Economics 51: 202-226.

East, Chloe N., Sarah Miller, Marianne Page, and Laura R. Wherry. 2017. "MultiGenerational Impacts of Childhood Access to the Safety Net: Early Life Exposure to Medicaid 
and the Next Generation's Health.”National Bureau of Economic Research Working Paper 23810.

Evans, William N., and Craig L. Garthwaite. 2014. "Giving Mom a Break: The Effect of Higher EITC Payments on Maternal Health." American Economic Journal: Economic Policy 6 (2): $258-90$.

Fernald, Lia and Megan Gunnar. 2009. "Poverty-alleviation program participation and salivary cortisol in very low-income children." Social Science Medicine Jun 68(12): 2180-9.

Fox, Liana (2019). "The Supplemental Poverty Measure: 2018”, Current Population Reports, P60-268.

Garces, Eliana, Duncan Thomas and Janet Currie. 2002. Longer-Term Effects of Head Start, American Economic Review 92 (4): 999-1012.

Goodman-Bacon, Andrew. 2016. "The Long-Run Effects of Childhood Insurance Coverage: Medicaid Implementation, Adult Health, and Labor Market Outcomes." Cambridge, Mass.: National Bureau of Economic Research Working Paper 22899.

Hastings, Justine S., and Jesse M. Shapiro. 2018. "How Are SNAP Benefits Spent? Evidence from a Retail Panel.” American Economic Review 108 (12): 3493-3540.

Heckman, J. and D. Masterov. 2007. "The Productivity Argument for Investing in Young Children," Applied Economics Perspectives and Policy29.

Heckman, J. and S. Mosso. 2014. "The Economics of Human Development and Social Mobility," Annual Review of Economics 6(1): 689-733.

Hendren, Nathan. 2016. The Policy Elasticity. Tax Policy and the Economy 30 (1): 51-89.

Hendren, Nathan and Ben Sprung-Keyser. 2019. A Unified Welfare Analysis of Government Policies. Cambridge, Mass.: National Bureau of Economic Research Working Paper 26144.

Hilger, Nathaniel G. 2016. "Parental Job Loss and Children's Long-Term Outcomes: Evidence from 7 Million Fathers' Layoffs," American Economic Journal: Applied Economics8 (3): 247-83.

Hoynes, Hilary, Leslie McGranahan and Diane Schanzenbach. 2015. "SNAP and Food Consumption". In SNAP Matters: How Food Stamps Affect Health and Well-Being, Edited by Judith Bartfeld, Craig Gundersen, Timothy Smeeding, and James P. Ziliak, Stanford University Press.

Hoynes, Hilary, Marianne Page, and Ann Huff Stevens. 2011. "Can Targeted Transfers Improve Birth Outcomes? Evidence from the Introduction of the WIC Program," Journal of Public Economics 95 (7): 813-827.

Hoynes, Hilary W and Diane Whitmore Schanzenbach. 2009., "Consumption Responses 
to In-Kind Transfers: Evidence from the Introduction of the Food Stamp Program," American Economic Journal: Applied Economics 1 (4): 109-139.

Hoynes, Hilary and Diane Whitmore Schanzenbach. 2012. "Work Incentives and the Food Stamp Program,” Journal of Public Economics 96 (1-2): 151-162.

Hoynes, Hilary, and Diane Whitmore Schanzenbach. 2015. "US Food and Nutrition Programs." In Means-Tested Transfer Programs, Vol. II, edited by Robert Moffitt. Chicago: University of Chicago Press.

Hoynes, Hilary and Diane Whitmore Schanzenbach. 2016. "U.S. Food and Nutrition Programs", in Economics of Means-Tested Transfer Programs in the U.S. Volume I, edited by Robert Moffitt, University of Chicago Press.

Hoynes, Hilary, Diane Whitmore Schanzenbach, and Douglas Almond. 2016. "Long-Run Impacts of Childhood Access to the Safety Net," American Economic Review 106 (4): 903-934.

Isen, Adam, Maya Rossin-Slater, and Reed Walker. 2017. "Every Breath You Take Every Dollar You'll Make: the Long-Term Consequences of the Clean Air Act of 1970," Journal of Political Economy 125 (3): 848-902.

Johnson, Lyndon B. 1965. “Annual Message to Congress on the State of the Union, January 8, 1964." In Public Papers of the Presidents of the United States: Lyndon B. Johnson, 1963-1964. Vol. I, 112-17. Washington, DC: GPO.

Johnson, Rucker C. and C. Kirabo Jackson. 2019. "Reducing Inequality Through Dynamic Complementarity: Evidence from Head Start and Public School Spending". American Economic Journal: Economic Policy Vol. 11, No. 4.

Kling, Jeffrey R, Jeffrey B Liebman, and Lawrence F Katz. 2007. "Experimental Analysis of Neighborhood Effects." Econometrica 75 (1): 83-119.

Lafortune, Julien, Jesse Rothstein, and Diane Whitmore Schanzenbach. 2018. "School Finance Reform and the Distribution of Student Achievement," American Economic Journal: Applied Economics 10 (2): 1-26.

Løken, Katrine V, Magne Mogstad, and Matthew Wiswall. 2012. "What Linear Estimators Miss: the Effects of Family Income on Child Outcomes," American Economic Journal: Applied Economics 4 (2): 1-35.

Ludwig, Jens, and Douglas L. Miller. 2007. "Does Head Start Improve Children's Life Chances? Evidence from a Regression Discontinuity Design." Quarterly Journal of Economics 122 (1):159-208.

MacDonald, Maurice. 1977. Food, Stamps, and Income Maintenance. Madison, WI: Institute for Poverty Research.

Miller, Sarah, and Laura R. Wherry. Forthcoming. "The Long-Term Effects of Early Life 
Medicaid Coverage.” Journal of Human Resources.

National Academy of Sciences, Engineering and Medicine. 2019. A Roadmap to Reducing Child Poverty, Consensus Report.

National Research Council. 2012. Small Populations, Large Effects: Improving the Measurement of the Group Quarters Population in the American Community Survey. Washington, DC: The National Academies Press. https://doi.org/10.17226/13387.

Ody, Christopher John, and Hubbard, Thomas N. County Business Patterns, 1962, 19641970: U.S. Summary, State, and County Data. Ann Arbor, MI: Inter-university Consortium for Political and Social Research [distributor], 2011-08-03. https://doi.org/10.3886/ICPSR25984.v2

Oreopoulos, Philip, Marianne Page, and Ann Huff Stevens. 2008. "The Intergenerational Effects of Worker Displacement," Journal of Labor Economics 26 (3): 455-483.

Page, Marianne, Ann Huff Stevens, and Jason Lindo. 2007. "Parental Income Shocks and Outcomes of Disadvantaged Youth in the United States," in Jonathan Gruber, Ed., The Problems of Disadvantaged Youth: An Economic Perspective, University of Chicago Press: 213-235.

Persson, Petra and Maya Rossin-Slater. 2018. "Family Ruptures, Stress, and the Mental Health of the Next Generation," American Economic Review 108, No. 4-5, April 2018 (Pp. 1214$52)$.

Rao, Neel. 2016. "The Impact of Macroeconomic Conditions in Childhood on Adult Labor Market Outcomes,” Economic Inquiry 54 (3): 1425-1444.

Rossin-Slater, Maya. 2013. "WIC in Your Neighborhood: New Evidence on the Impacts of Geographic Access to Clinics," Journal of Public Economics 102:51-69.

Solon, Gary. 1999. "Intergenerational Mobility in the Labor Market," in Handbook of Labor Economics, Vol. 3, Elsevier: 1761-1800.

Schanzenbach, Diane Whitmore 2007. What Are Food Stamps Worth?” Working paper.

Solon, Gary, Steven J. Haider, and Jeffrey M. Woodridge. 2014. "What Are We Weighting For?" Journal of Human Resources 50 (2), 301-316.

Stuart, Bryan. 2018. "The Long-Run Effects of Recessions on Education and Income," George Washington University Working Paper.

Taylor, Evan J., Martha J. Bailey, and Bryan A. Stuart. 2016. "Summary of Procedure to Match NUMIDENT Place of Birth County to GNIS Places." Center for Economic Studies, U.S. Census Bureau. CES Technical Note Series.

Van Den Berg, G. J., M. Lindeboom, and F. Portrait. 2006. "Economic Conditions Early in Life and Individual Mortality," American Economic Review 96: 290-302. 


\section{Online Appendix}

\section{DATA DETAILS CENSUS/ACS}

Allocated Values: We treat as missing any variable that is allocated. An important exception to this rule arises for allocations of age, sex, relationship to household head, and marital status. Because the family interrelationship assignment relies on the location of individuals within a household, we follow IPUMS and use these variables to construct the family interrelationship variable. After these relationship variables are constructed, we treat these four variables as missing if they are allocated.

Top-coded Values: For each income measure, we follow IPUMS and designate as the top code the 99.5th percentile of the (weighted) income measure distribution. Following the IPUMS, this top-coding is done at the state-year, identifying those at the 99.5th percentile and above separately for each state and year. Any observation greater than or equal to the top code is replaced with the state-year mean among all observations above the top code. This top-coding is done on the sample after eliminating allocated income variables. Aggregate income measures (e.g., earned income: the sum of wage and business/farm income) are constructed after the top code adjustment. We follow the same procedure for gross rent, which is the sum of rents and the cost of electricity, water, gas, and fuel. In particular, we separately top code each component and then construct gross rent as the sum of the top-coded components. We also follow the same procedure for housing values in years 2000 and 2008-2013; in years 2001-2007, housing values are only reported in intervals, which eliminates the need for top-code adjustments.

Imputation of Categorical Variables: Only categorical values of certain variables appear in some years. For example, from 2008-onwards, weeks worked last year is reported in intervals: 113, 14-26, 27-39, 40-47, 48-49, and 50-52. Using data from 2000-2007, we calculate the average number of weeks worked for each interval, and use this imputed mean in our analysis. We use the same method to impute means for housing value (2001-2007), and education (for 2000-2007, education is binned for grades 1-4, 5-6, and 7-8).

Real Values: All monetary variables are expressed in in 2015 dollars, adjusting for inflation using the Consumer Price Index.

Unit of observation: For computational reasons, all models are estimated on data collapsed to cells using Census or ACS weights. For the event study (equation 1) and spline (equation 2) models, cells are defined as birth-year $\mathrm{x}$ birth-county $\mathrm{x}$ survey year. For the exposure model (equation 3) the cells are birth-year x birth-month x birth-county x survey year. We collapse separately for all sex and race categories combined as well as by four gender $\mathrm{x}$ race subgroups (male-female-white-nonwhite). Sometimes, we do not have a cell for each combination, because the distribution of race is not even across all counties or there are no births in a given county for a specific month-year-race combination. In addition, a handful of counties are dropped from the analysis if we do not have information on when Food Stamps start (these are indicated in yellow in Figure 1).ed.

Weighting the Data: In our main estimates we weight by the number of observations in each cell. We have also explored alternative weighting using the sum of the person weights (the 
recommended census/ACS weights) in the cell, which yield similar estimates. In accordance with the Census policy of minimizing disclosures, we have only disclosed our preferred set of estimates.

Creating Indices: We ignore observations with missing values on any outcome of interest when aggregating to indices so indices will have the same number of observations in our sample for all outcomes. This is in accordance with Census policy to minimize implicit samples in disclosure.

Incarceration and Group Quarters: Incarceration is assigned using the group quarters variable. Group quarters are separated between the institutionalized and noninstitutionalized. We proxy for incarceration using the institutionalized indicator (National Research Council 2012, Ch. 2 ). This data is available for the 2006-2013 in the ACS. The group quarters question is included in the 2000 Census but this variable is unfortunately not available in the RDC.

Appendix Table 1 shows that the mean incarceration rate for our nonwhite male sample is 14 percent, whereas tabulations of the public use 5-year 2010 ACS yield estimates more along the lines of 6 percent. Our higher incarceration rate is due to two factors. First, and most importantly, while we use Census and ACS survey weights to construct cell means, we use the number of observations represented in each cell to weight the regression and to construct global means. That works well for most of our outcomes, but the nature of group quarter survey design yields person weights for incarcerated individuals that are lower than non-incarcerated individuals. For example, in the public use 2016 ACS, institutionalized men 25-54 have a person weight of 61 on average compared to 112 for non-institutionalized men of this age. As a result, when the number of observations is used as a weight for each cell, institutionalized individuals are upweighted relative to their incidence in the population. Second, we construct our sample to include only "full information" observations: in particular, we drop all observations that are missing or allocated for any of our outcome variables. As discussed in Section III we do this to minimize disclosure risk (e.g. to maintain one sample across the outcomes). However, we cannot impose this restriction on the institutionalized (group quarters) sample because they are enumerated in the Census but not subject to the full survey. Thus this also upweights the incarcerated sample. These two factors explain the higher than expected incarceration rate. These factors have no impact on other variables in our analysis. And the estimated models for incarceration are qualitatively similar if we incorporate survey weights (using the sum of the weights instead of the number of observations) and yields a mean that is more consistent with other sources.

\section{COUNTY CONTROL VARIABLES}

In robustness checks (Table 6), we examine the sensitivity to adding county-time varying variables to our models. In Table 1, we use a longer list of county variables for a balance test on our design. These variables are assigned at the county-by-year-of-birth level.

\section{A. Other War on Poverty Programs}

We use data from Bailey and Duquette (2014) and Bailey and Goodman-Bacon (2015) to account for the launch of other War on Poverty programs. They collected data on the OEO's community programs from the National Archives Community Action Program (NACAP) files as well as from some administrative sources. 
For Head Start, they compared data with Ludwig and Miller (2007) and Barr and Gibbs (2018) on county-level Head Start program expenditures over 1965-1980 and also compared their figures against state-level administrative reports. The resulting database contains information on (1) the county where a program delivered services, which allows each federal grant to be linked to birth counties and (2) the date that each county received its first program services grant, which typically provides the year that programs began operating.

For Community Health Centers, they entered information from annual Public Health Service (PHS) Reports. This database contains information on (1) the county where CHCs delivered services, which allows each federal grant to be linked to county-level mortality rates; (2) the date that each county received its first $\mathrm{CHC}$ services grant (this excludes planning grants), which provides a consistent proxy for the year that each $\mathrm{CHC}$ began operating; and (3) information on CHC grants between 1978 and 1980 from the National Archives Federal Outlays (NAFO) files.

For WIC we use data from Hoynes, Page, and Stevens (2011) who collected data on the countyby-county rollout of the WIC program from several directories and congressional filings that provide lists of local agencies that provided WIC services. The rollout occurred between 1974 and 1980. This information is available for years 1974, 1975, 1978, 1979, and 1989.

For each of these programs, we construct an indicator variable capturing whether the county had a given War on Poverty program in place that year.

\section{B. REIS County Transfer Spending}

We use data from Hoynes and Schanzenbach (2009) and Almond et al. (2011) to control for other social safety net spending at the county level. Hoynes and Schanzenbach (2009) use data from the Bureau of Economic Analysis Regional Economic Information System (REIS) to construct four per capita county transfer variables: cash public assistance benefits (AFDC, Supplemental Security Income, and General Assistance), medical spending (Medicare, Medicaid, and military health care), cash retirement and disability payments (Old-Age Survivors Insurance, Disability Insurance, and other), and all transfers. The data are available digitally beginning in 1969. Almond et al. (2011) extended the REIS data to 1959 by handentering data from microfiche for 1959, 1962, and 1965 to 1968 . We linear interpolate within counties to fill in the gaps $(1960,1961,1963$, and 1964).

\section{County Employment, Income, and Population}

County income is real per capita county income and is available from the Bureau of Economic Analysis and County Business Patterns (Ody and Hubbard 2011, Bureau of the Census 2006) and available for 1969-1980. County employment comes from Bureau of Economic Analysis Local Area Employment Indicators for 1969-1980. County population is available from SEER from 1969-1980 and is interpolated between decennial censuses for years prior to 1969 .

\section{County Mortality Data}

We use data from Almond et al. (2011) who create county-by-year measures of infant mortality 
for 1959-1980 using the Vital Statistics Detailed Cause of Death data. The data encompass the universe of death certificates (except in 1972, when they are a 50-percent sample); we use information on age of the decedent and the year and county of death. We then construct infant mortality (deaths in the first year), neonatal mortality rate (deaths in the first 28 days) and postneonatal mortality (deaths in months 2-12) each expressed per 1,000 live births. Vital statistics data on births (per year and county) are used to construct the denominator for live births.

Adult mortality rates (deaths per 1,000) comes from Bailey and Bacon-Goodman (2015).

\section{E. 1960 County Control Variables}

We capture trends across counties over time, we control for 1960 County Characteristics interacted with linear trend in birth cohort. Following Hoynes and Schanzenbach (2009) we use the 1960 City and County Data Book, which compiles data from the 1960 Census of Population and Census of Agriculture, is used to measure economic, demographic, and agricultural variables for the counties' pretreatment (before Food Stamps is rolled out) period. In particular, we use the percentage of the 1960 population that lives in an urban area, is black, is less than 5 years old, is 65 years or over, has income less than $\$ 3,000$ (in 1959 dollars), the percentage of land in the county that is farmland, and log of the county population.

\section{ADDITIONAL ROBUSTNESS}

In addition to the robustness analyses discussed in the text, we have explored the sensitivity of our findings to other specifications. We examined whether the findings were robust to excluding observations with missing values on any outcome variable. We also estimated models where the dependent variable was the share of the cell missing as an outcome variables. There was no relationship between Food Stamp rollout and the incidence of missing values. We estimated models with different weighting procedures, including counties that could not be easily linked to GNIS FIPS codes, and using different birth-years in our sample. In accordance with Census guidelines to minimize implicit samples and disclosure burden, we have not disclosed these results from the RDC.

\section{LIFE EXPECTANCY ESTIMATES}

In our main estimates, we use the social security NUMINDENT file to estimate the probability of surviving to 2012. For our cost-benefit analysis, it is valuable to extend this survival analysis to calculate measures of life expectancy. Here we describe that process, following methods in Chetty et al. (2016).

We estimate life expectancy conditional on reaching age 40 by first using Gompertz functions to estimate mortality rates by age for different subgroups of the population. We then sum over these mortality rates to arrive at group-specific life expectancy estimates. The steps below cover this process in more detail. 
1. We first create a "group" variable (gender $\times$ birth-year $\times$ county-of-birth) and calculate raw mortality rates for each age by dividing the number of individuals in each group $\times$ age cell by the number of deaths at that age during our sample window (Decennial Census and ACS yields a 2000-2013 sample window).

2. We then estimate a Gompertz function, which imposes that the mortality rate $m$ is an exponential function of age $a$ in the following expression $m(a)=e^{\alpha+\beta a}$. We use maximum likelihood to estimate these models, allowing for different mortality gradients $(\alpha$ and $\beta$ ) by sex, county, and birth year.

We restrict this analysis to ages 30-63, as the oldest individuals in our sample to receive Food Stamps would have been 63 in 2013 (birth cohort 1950). We then predict mortality rates for ages 40-90 within each group.

3. For mortality rates at ages over 90 , we use estimates from the NCHS and the SSA. The NCHS provides estimates of mortality rates by sex $\times$ race for those ages $90-100$. For ages 101-111, we use estimates (by sex) from the SSA. We use year 2000 SSA mortality estimates, and averages of the NCHS mortality rates from 2001 to 2011. We append these mortality rates onto the age 40-90 mortality rates estimated in step 2 .

4. The Gompertz function together with the NCHS and SSA data give us mortality rates by age $\left(m_{a}\right)$ for each group. We then calculate life expectancy as follows:

a. Calculate $l_{a}=\prod_{a=40}^{a-1}\left(1-m_{a}\right)$. This is the "survivorship" to age a.

b. Calculate $L_{a}=\frac{l_{a}+l_{a+1}}{2}$. This is "midpoint survivorship;" the proportion of the population that makes it to the midpoint of age a.

c. Calculate life expectancy $L E=\sum_{a=40}^{a=119}\left(L_{a} * m_{a} * a g e\right)$.

We then merge these life-expectancy measures back onto the Census microdata by the group identifiers (sex $\times$ birthyear $\times$ county)

Appendix Table 5 presents results from using this measure of life expectancy as the dependent variable in our standard exposure specification from the text (model 3). Our preferred ITT estimates from Column (3) suggest that exposure to food stamps from conception to age 5 increases life expectancy by 0.176 years on average. The TOT analogue corresponds to an increase in life expectancy of 1.1 years $(0.176 / 0.16)$. 
Figure 1: The Geography of the Roll-Out of the Food Stamps Program, 1961-1975

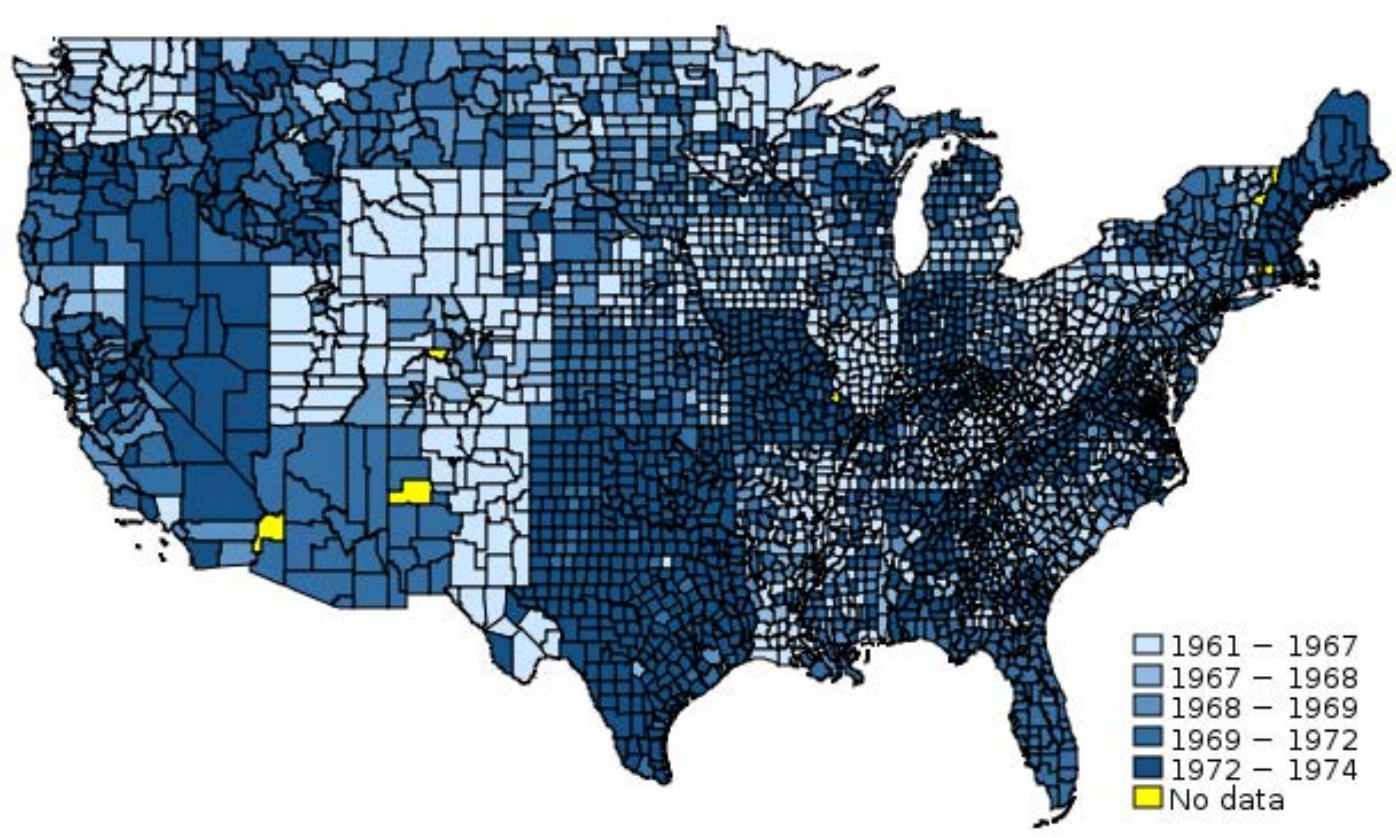

Notes: Hoynes and Schanzenbach (2009) tabulations based on administrative data from the U.S. Department of Agriculture in various years. 
Figure 2: Expected ITT Effects of Food Stamps on Adult Well-Being by Age of the Cohort when the Program Began

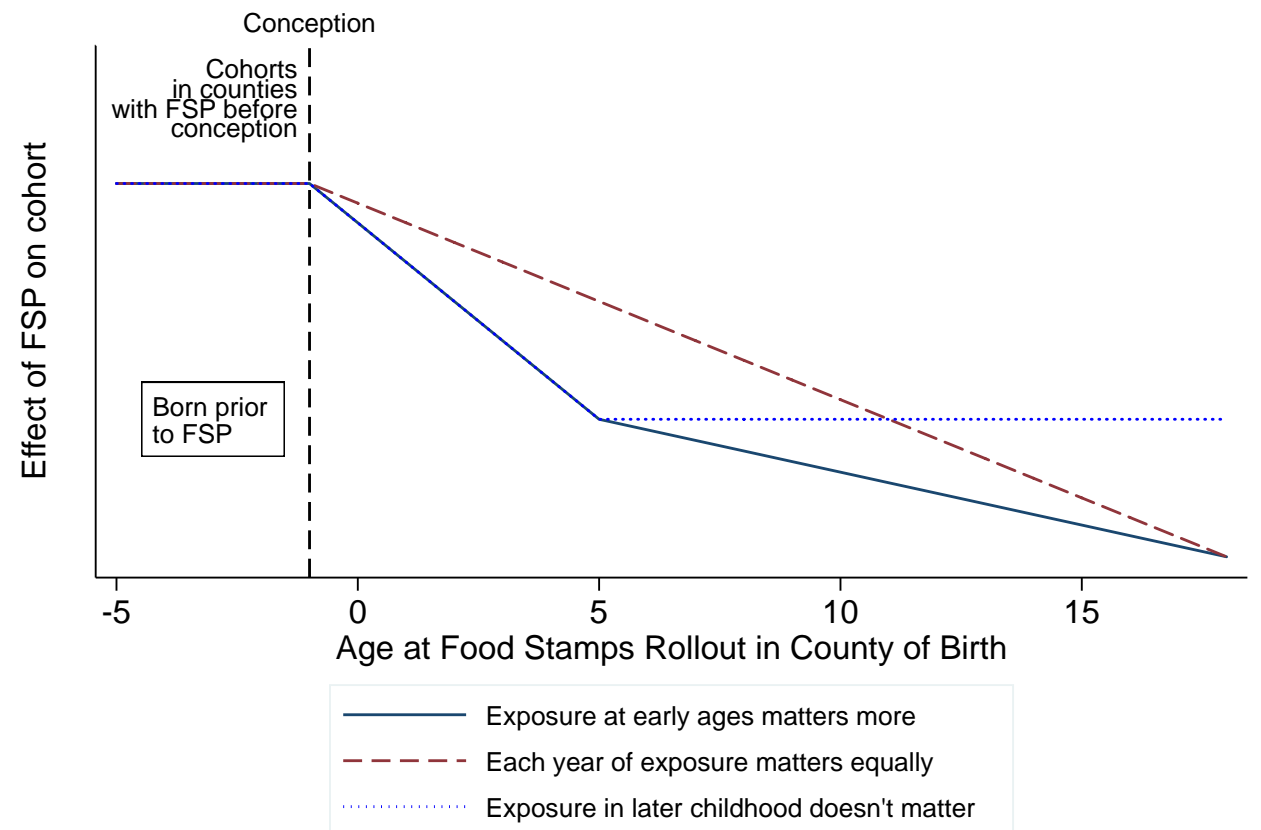

Notes: Figure illustrates the potential effects of Food Stamps by a cohort's age at the time the program started. Unlike other War on Poverty programs, the take up of Food Stamps was very rapid, so we do not model delayed take-up. The two series show different hypothetical effects: one series demonstrates how the estimates would appear if the effects on adult outcomes are the same for each year of additional exposure to the Food Stamps in childhood, which results in a linear pattern between ages 0 (in utero) and age 18. Alternatively, a second series show how the effect may be non-linear, with the effects of Food Stamps having a larger effect on adult outcomes for children with access in early childhood (before the age of 5). 
Figure 3: Event-Study and Spline Estimates of the Estimated ITT Effects of Food Stamps Exposure by a Cohort's Age when the Program Launched

Panel A. Composite Index, Event-Study Estimates

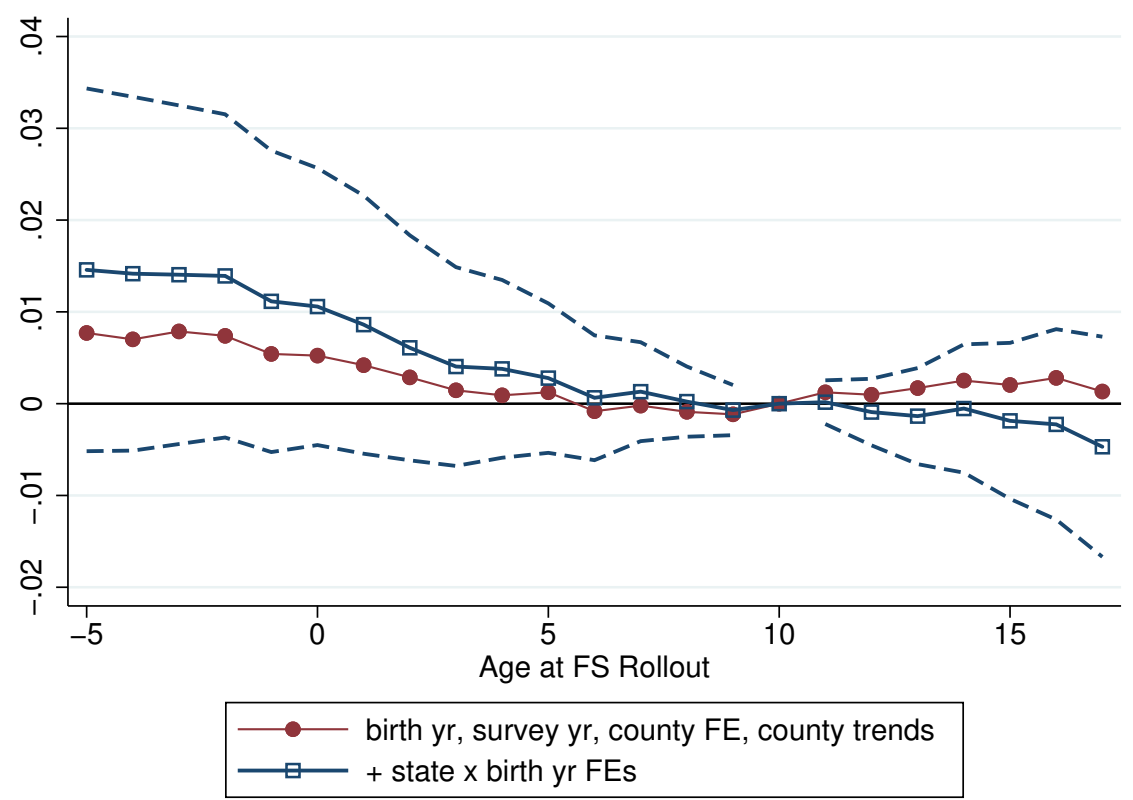

Panel B. Composite Index, Four-Part Spline

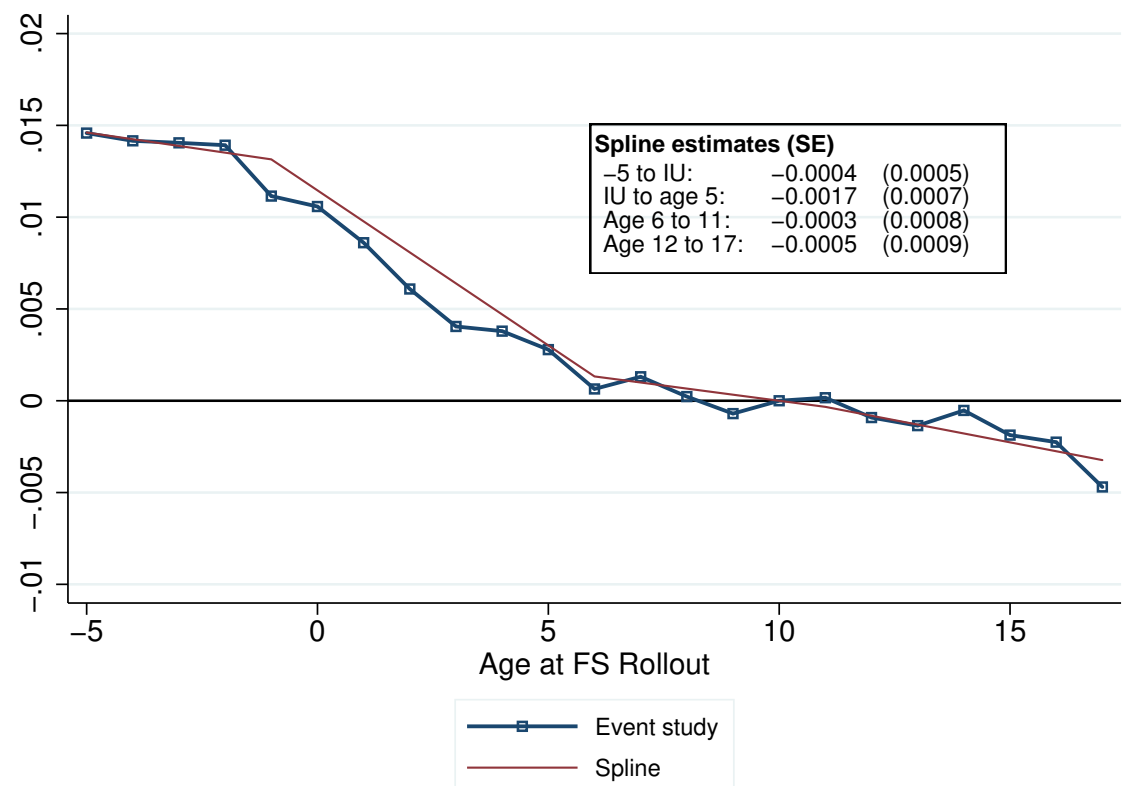

Notes: The panels plot event-study estimates for the composite standardized index of adult outcomes using the specifications in equations (1) and (2). Standard errors clustered at the birth-county level. Dashed lines show 95percent, point-wise confidence intervals for each estimate in Panel A. Models in Panel B include fixed effects for birth-county, birth-year, survey year, and birth-state x birth-year as well as 1960 county characteristics interacted with a linear trend in year of birth. Data includes more than 17 million U.S. individuals born in the U.S. between 1950 and 1980 who are observed in the 2000 Census 1-in-6 sample and 2001 to 2013 ACS merged to the SSA's NUMIDENT file using PIKs. Regressions estimated on data collapsed to cells defined by birth-county $\mathrm{x}$ birth-year $\mathrm{x}$ survey years and regressions are weighted using the number of observations per cell. 
Figure 4: Spline Estimates of the ITT Effects of Food Stamps for Cohorts of Different Ages when the Program Launched for Different Indices of Well-Being, Longevity, and Incarceration

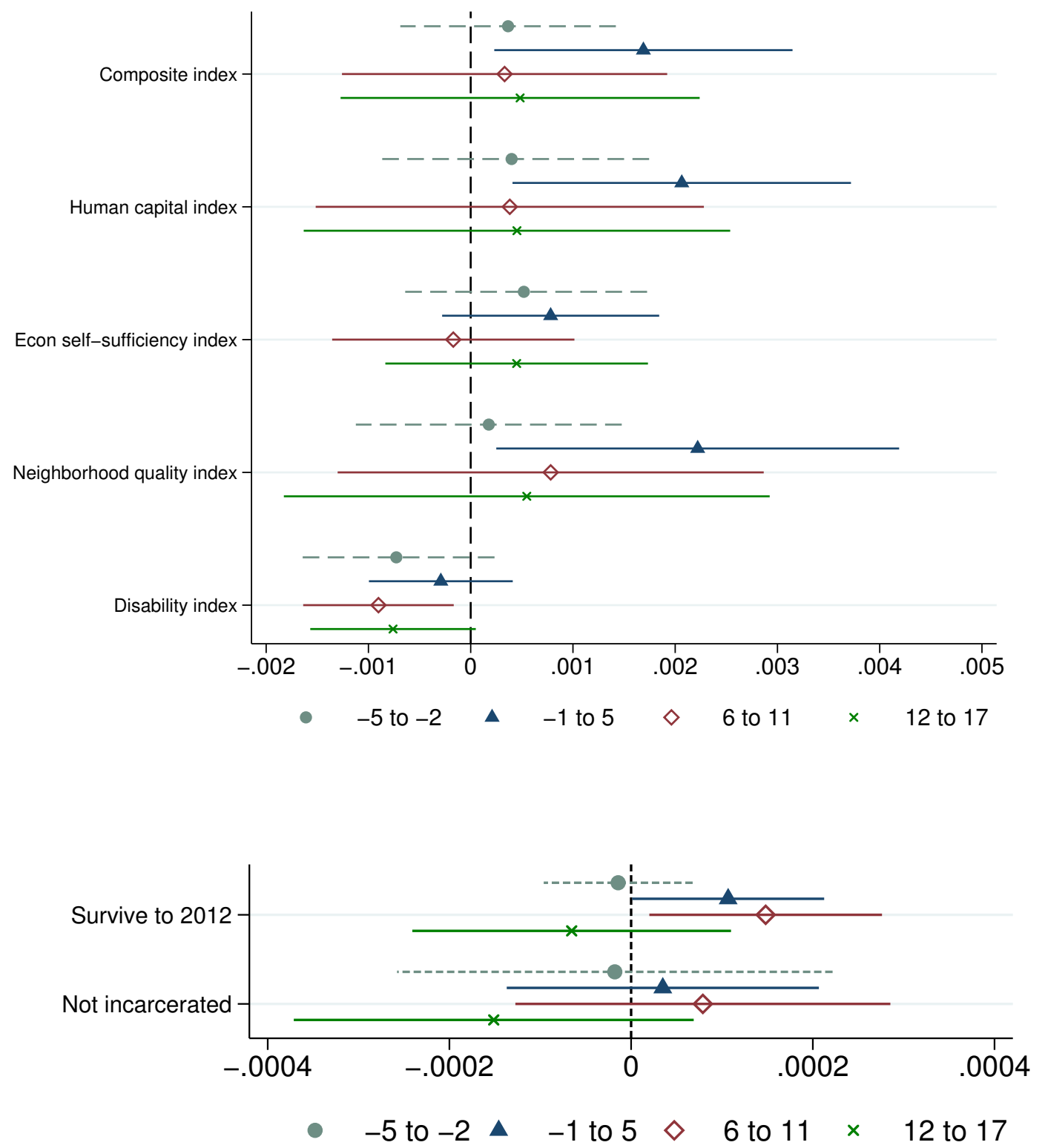

Notes: The panels plot-for different indices - the absolute value of the estimates on the four linear splines in equation (2). In particular, we plot $\left|\omega_{1}\right|$ (ages -5 to -2 ), $\left|\omega_{2}\right|$ (ages -1 to 5 ), $\left|\omega_{3}\right|$ (ages 6 to 11 ), and $\left|\omega_{4}\right|$ (ages 12 to 17 ), where age is when Food Stamps launched in their county of birth. See text for more information on indices and outcomes. The indices are standardized in terms of standard deviations, but "Survive to 2012" and "Not incarcerated" are not, which is why these outcomes appear on different scales. All models include fixed effects for birth-county, birth-year, survey year, and birth-state x birth-year as well as 1960 county characteristics interacted with a linear trend in year of birth. Data includes than 17 million U.S. individuals born in the U.S. between 1950 and 1980 who are observed in the 2000 Census 1-in-6 sample and 2001 to 2013 ACS merged to the SSA's NUMIDENT file using PIKs. Regressions estimated on data collapsed to cells defined by birth-county x birth-year x survey years and regressions are weighted using the number of observations per cell. 
Figure 5: Event-Study and Spline Estimates of the ITT Effects of Food Stamps for Cohorts of Different Ages when the Program Launched for Different Indices of Well-Being, Longevity, and Incarceration
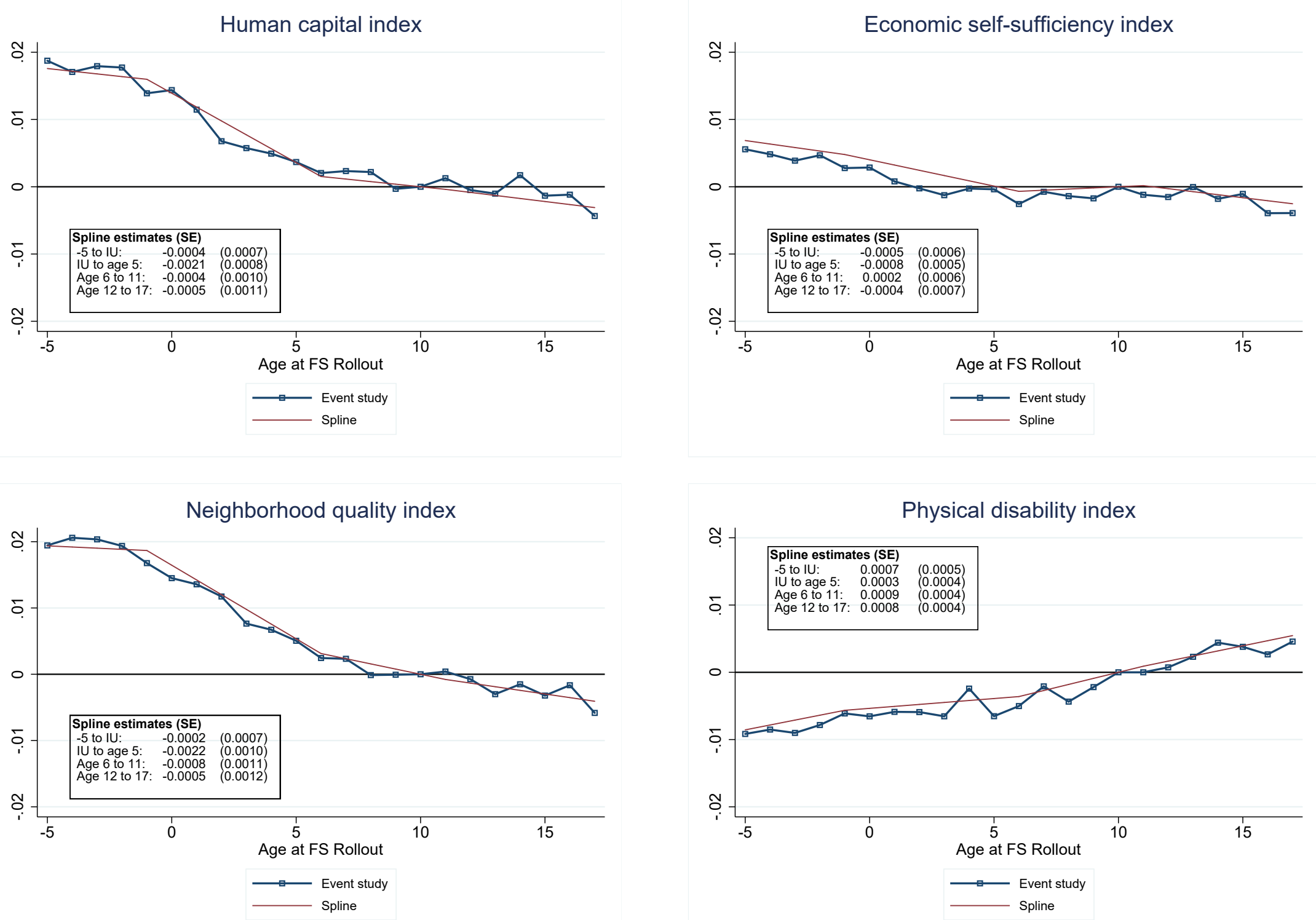
Figure 5: (continued)
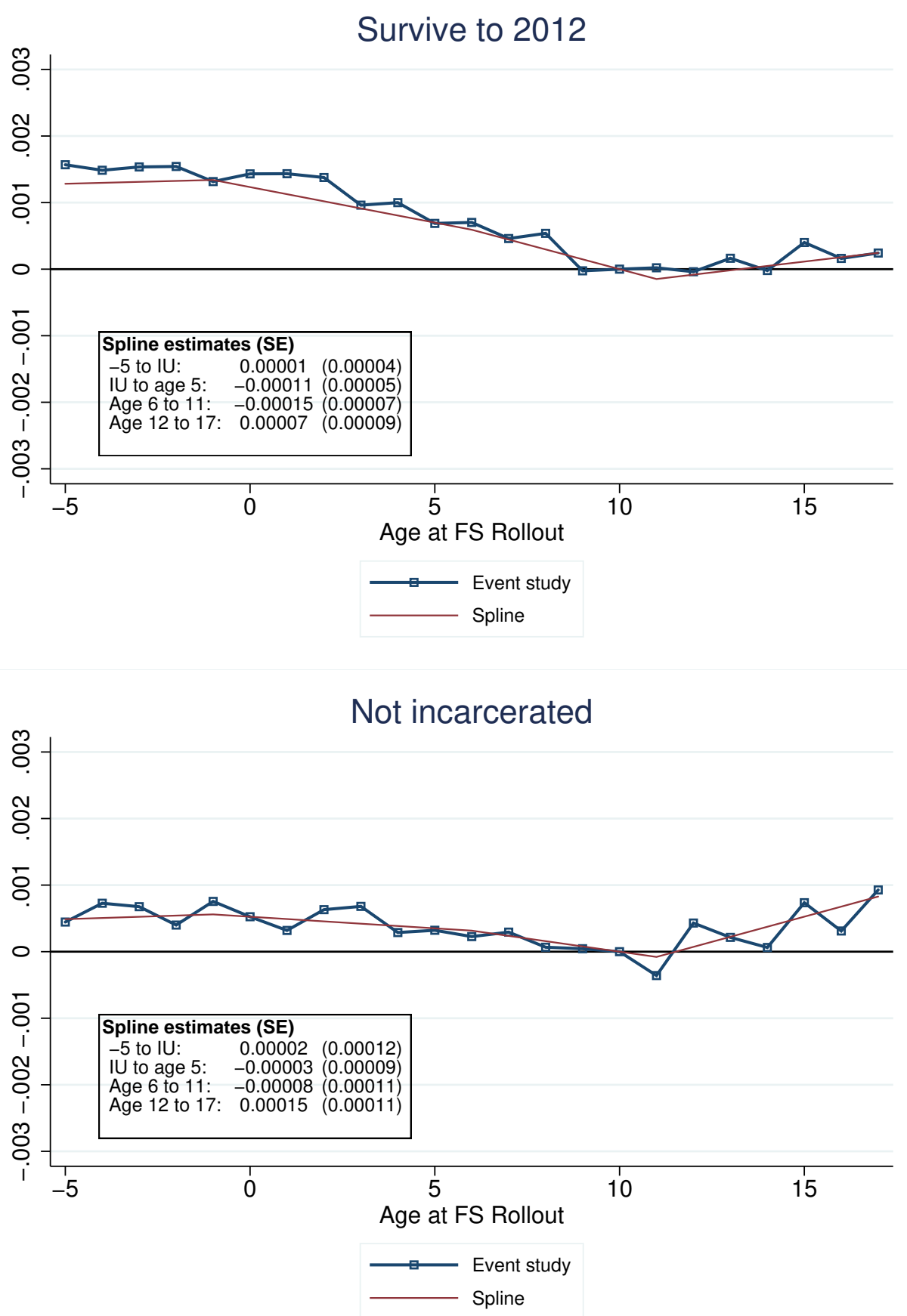

Notes: The panels plot event-study and splines estimates-for various outcomes- using the specifications in equations (1) and (2). All models include fixed effects for birth-county, birth-year, survey year, and birth-state x birth-year as well as 1960 county characteristics interacted with a linear trend in year of birth. See text for more information on indices and outcomes. The indices are standardized in terms of standard deviations, but "Survive to 2012" and "Not incarcerated" are not, which is why these outcomes appear on different scales. Data includes more than 17 million U.S. individuals born in the U.S. between 1950 and 1980 who are observed in the 2000 Census 1-in-6 sample and 2001 to 2013 ACS merged to the SSA's NUMIDENT file using PIKs. Regressions estimated on data collapsed to cells defined by birth-county $\mathrm{x}$ birth-year $\mathrm{x}$ survey years and regressions are weighted using the number of observations per cell. 
Table 1: Balance Tests: Estimated Effects of Food Stamps Exposure on County Characteristics and Other Programs

\begin{tabular}{|c|c|c|c|c|c|c|}
\hline Dependent Variable & (1) & $(2)$ & $(3)$ & $\begin{array}{l}\text { Number } \\
\text { of cells } \\
(1000 s)\end{array}$ & MDV & $\begin{array}{l}\text { Range of years } \\
\text { covered in } \\
\text { the data }\end{array}$ \\
\hline \multicolumn{7}{|l|}{ Other War on Poverty } \\
\hline WIC & $\begin{array}{c}-0.0758 \\
(0.0526)\end{array}$ & $\begin{array}{c}0.0227 \\
(0.0482)\end{array}$ & $\begin{array}{c}0.0227 \\
(0.0482)\end{array}$ & 348 & 0.389 & $1970-1980$ \\
\hline Head Start & $\begin{array}{c}0.0196 \\
(0.0208)\end{array}$ & $\begin{array}{c}-0.0188 \\
(0.0188)\end{array}$ & $\begin{array}{c}-0.0188 \\
(0.0188)\end{array}$ & 722 & 0.500 & 1959-1980 \\
\hline Community Health Center & $\begin{array}{c}-0.0254 \\
(0.0293)\end{array}$ & $\begin{array}{c}-0.0864 \\
(0.0242)\end{array}$ & $\begin{array}{c}-0.0863 \\
(0.0242)\end{array}$ & 722 & 0.063 & 1959-1980 \\
\hline \multicolumn{7}{|l|}{ REIS Income Transfers Per Capita (\$1000s) } \\
\hline Retirement and DI benefits & $\begin{array}{c}-0.2089 \\
(0.0598)\end{array}$ & $\begin{array}{c}-0.2122 \\
(0.0608)\end{array}$ & $\begin{array}{l}-0.2121 \\
(0.0608)\end{array}$ & 725 & 1.003 & $1959-1980$ \\
\hline Military and military Medicaid & $\begin{array}{c}-0.0280 \\
(0.0052)\end{array}$ & $\begin{array}{c}-0.0238 \\
(0.0052)\end{array}$ & $\begin{array}{c}-0.0239 \\
(0.0052)\end{array}$ & 725 & 0.177 & 1959-1980 \\
\hline Income maintenance (exc Food Stamps) & $\begin{array}{c}-0.0525 \\
(0.0190)\end{array}$ & $\begin{array}{c}-0.0591 \\
(0.0188)\end{array}$ & $\begin{array}{c}-0.0591 \\
(0.0188)\end{array}$ & 725 & 0.242 & $1959-1980$ \\
\hline Real total transfers & $\begin{array}{c}0.0282 \\
(0.0286)\end{array}$ & $\begin{array}{c}0.0523 \\
(0.0285)\end{array}$ & $\begin{array}{c}0.0523 \\
(0.0285)\end{array}$ & 382 & 2.266 & 1969-1980 \\
\hline \multicolumn{7}{|l|}{ Other County } \\
\hline Real personal income & $\begin{array}{l}-0.0710 \\
(0.1967)\end{array}$ & $\begin{array}{c}-0.1565 \\
(0.1955)\end{array}$ & $\begin{array}{c}-0.1565 \\
(0.1955)\end{array}$ & 382 & 19.960 & $1969-1980$ \\
\hline Log population & $\begin{array}{c}0.0499 \\
(0.0084)\end{array}$ & $\begin{array}{c}0.0379 \\
(0.0084)\end{array}$ & $\begin{array}{c}0.0379 \\
(0.0084)\end{array}$ & 722 & 12.340 & 1959-1980 \\
\hline Log employment & $\begin{array}{l}-0.0006 \\
(0.0156)\end{array}$ & $\begin{array}{l}-0.0049 \\
(0.0160)\end{array}$ & $\begin{array}{l}-0.0049 \\
(0.0160)\end{array}$ & 382 & 11.710 & 1969-1980 \\
\hline \multicolumn{7}{|l|}{ Mortality } \\
\hline Adult mortality rate & $\begin{array}{l}-1.2420 \\
(3.1300)\end{array}$ & $\begin{array}{c}0.9264 \\
(3.2310)\end{array}$ & $\begin{array}{c}0.9275 \\
(3.2310)\end{array}$ & 722 & 866.700 & 1959-1980 \\
\hline Infant mortality rate & $\begin{array}{c}0.0154 \\
(0.1805)\end{array}$ & $\begin{array}{c}0.1454 \\
(0.1909)\end{array}$ & $\begin{array}{c}0.1453 \\
(0.1909)\end{array}$ & 711 & 20.110 & 1959-1980 \\
\hline Neonatal mortality rate & $\begin{array}{c}0.0902 \\
(0.1450)\end{array}$ & $\begin{array}{c}0.2427 \\
(0.1550)\end{array}$ & $\begin{array}{c}0.2425 \\
(0.1549)\end{array}$ & 711 & 14.620 & $1959-1980$ \\
\hline Post-neonatal mortality rate & $\begin{array}{l}-0.0748 \\
(0.0991)\end{array}$ & $\begin{array}{l}-0.0973 \\
(0.1023)\end{array}$ & $\begin{array}{l}-0.0973 \\
(0.1023)\end{array}$ & 711 & 5.495 & 1959-1980 \\
\hline FE county, state $\mathrm{x}$ birth year & $\mathrm{X}$ & $\mathrm{X}$ & $\mathrm{X}$ & & & \\
\hline Cty $_{60} \mathrm{x}$ linear cohort & $\mathrm{X}$ & & & & & \\
\hline $\mathrm{Cty}_{60} \mathrm{x}$ quadratic cohort & & $\mathrm{X}$ & & & & \\
\hline Cty $_{60} \times$ cubic cohort & & & $\mathrm{X}$ & & & \\
\hline
\end{tabular}

Notes: Each row and column provide estimates for the exposure model in equation (3). The unit of analysis is at the county $\mathrm{x}$ year $\mathrm{x}$ month and the coefficient is on the exposure variable: the share of time between conception and age 5 that Food Stamps is in place (for someone born in this county-year-month cell). We test for whether exposure predicts a given county characteristic, including Other War on Poverty Programs, REIS Transfers and Income per capita, Mortality and other county characteristics. Each row and column presents a regression estimate. Regressions are weighted using the population in each cell. Column 1 includes county of birth and state by birth year fixed effects. Column 2 adds 1960 county characteristics interacted with a linear and quadratic in year of birth. Column 3 adds 1960 county characteristics interacted with a cubic in year of birth. Standard errors are clustered by county of birth and indicated in parentheses. The number of observations appears in column 4 , and the mean of the dependent variable is presented in column 5 . Some outcome variables are not available in all years, which is indicated in column 6. See Online Appendix for more information on data, samples, and sources. 
Table 2: Estimated ITT Effects of Food Stamps Exposure between Conception and Age 5 on a Composite Index of Well-Being

\begin{tabular}{lccc}
\hline \hline & $(1)$ & $(2)$ & $(3)$ \\
\hline \%IU - Age 5 & 0.0042 & 0.0075 & 0.0087 \\
& $(0.0025)$ & $(0.0027)$ & $(0.0025)$ \\
& & & \\
FE county, birth year, survey year & $\mathrm{X}$ & $\mathrm{X}$ & $\mathrm{X}$ \\
Cty60 x linear cohort & & $\mathrm{X}$ & $\mathrm{X}$ \\
State X birth year FE & & & $\mathrm{X}$ \\
Number of observations & $17,400,000$ & $17,400,000$ & $17,400,000$ \\
Number of cells & $4,272,000$ & $4,272,000$ & $4,272,000$ \\
Number of counties & 3000 & 3000 & 3000 \\
$R^{2}$ & 0.229 & 0.231 & 0.232 \\
\hline \hline
\end{tabular}

Notes: Each column provides estimates for the exposure model in equation (3). The unit of analysis is at the birthcounty $\mathrm{x}$ birth-year $\mathrm{x}$ birth-month $\mathrm{x}$ survey-year level and the coefficient is on the exposure variable: the share of months between conception and age 5 that a cohort would have been exposed to Food Stamps based on when the program began in the cohort's county of birth. All columns include fixed effects for birth-county, birth-year, birthmonth, and survey year. Column 2 adds 1960 county characteristics interacted with a linear trend in year of birth. Column 3 adds birth-state x birth-year fixed effects Standard errors are clustered by county of birth and indicated in parentheses. The number of observations, number of cells and number of counties are rounded to the nearest 1,000 for disclosure purposes. See also Figure 3 notes for more information on the sample and outcome. 
Table 3: Estimated ITT Effects of Food Stamps Exposure between Conception and Age 5 on Different Indices of Well-Being, Longevity, and Incarceration

\begin{tabular}{lcccccc}
\hline \hline & \multicolumn{9}{c}{ Indices } & & \\
\cline { 2 - 5 } & Human & Economic self- & Neighborhood \\
capital & sufficiency & Puality & Physical & Survive to & Not \\
disability & 2012 & incarcerated \\
\cline { 2 - 5 } \%IU - Age 5 & 0.0103 & 0.0043 & 0.0115 & 0.0013 & 0.0007 & 0.0008 \\
& $(0.0035)$ & $(0.0016)$ & $(0.0036)$ & $(0.0013)$ & $(0.0003)$ & $(0.0004)$ \\
FE county, survey year & $\mathrm{X}$ & $\mathrm{X}$ & $\mathrm{X}$ & $\mathrm{X}$ & $\mathrm{X}$ & $\mathrm{X}$ \\
Cty60 x linear cohort & $\mathrm{X}$ & $\mathrm{X}$ & $\mathrm{X}$ & $\mathrm{X}$ & $\mathrm{X}$ & $\mathrm{X}$ \\
State x birth year FE & $\mathrm{X}$ & $\mathrm{X}$ & $\mathrm{X}$ & $\mathrm{X}$ & $\mathrm{X}$ & $\mathrm{X}$ \\
Number of observations & $17,400,000$ & $17,400,000$ & $17,400,000$ & $16,800,000$ & $114,000,000$ & $7,705,000$ \\
Number of cells & $4,272,000$ & $4,272,000$ & $4,272,000$ & $2,796,000$ & 943,000 & $2,591,000$ \\
Number of counties & 3000 & 3000 & 3000 & 3100 & 3000 & 3000 \\
$R^{2}$ & 0.127 & 0.058 & 0.379 & 0.053 & 0.696 & 0.027 \\
\hline \hline
\end{tabular}

Notes: Each column provides estimates for the exposure model in equation (3). The unit of analysis is at the birth-county x birth-year x birth-month $\mathrm{x}$ survey-year level and the coefficient is on the exposure variable: the share of months between conception and age 5 that a cohort would have been exposed to Food Stamps based on when the program began in the cohort's county of birth. All columns include fixed effects for birth-county, birth-year, birth-month, survey year, and birth-state x birth-year as well as 1960 county characteristics interacted with a linear trend in year of birth. Standard errors are clustered by county of birth and indicated in parentheses. See text for more information on indices and outcomes. The indices are standardized in terms of standard deviations, but "Survive to 2012" and "Not incarcerated" are not. The number of observations, number of cells and number of counties are rounded to the nearest 1,000 for disclosure purposes. See also Figure 3 notes for more information on the sample and outcome. 
Table 4: Estimated ITT Effects of Food Stamps Exposure between Conception and Age 5 on Different Outcomes, by Race and Sex

\begin{tabular}{|c|c|c|c|c|c|c|}
\hline & \multicolumn{4}{|c|}{ Indices } & \multirow[b]{2}{*}{$\begin{array}{l}\text { Survive to } \\
\quad 2012\end{array}$} & \multirow[b]{2}{*}{$\begin{array}{c}\text { Not } \\
\text { incarcerated }\end{array}$} \\
\hline & $\begin{array}{l}\text { Human } \\
\text { capital }\end{array}$ & $\begin{array}{l}\text { Economic self- } \\
\text { sufficiency }\end{array}$ & $\begin{array}{l}\text { Neighborhood } \\
\text { quality }\end{array}$ & $\begin{array}{l}\text { Physical } \\
\text { disability }\end{array}$ & & \\
\hline$\frac{\text { White males }}{\% \text { IU - Age } 5}$ & $\begin{array}{c}0.0102 \\
(0.0036)\end{array}$ & $\begin{array}{c}0.0037 \\
(0.0020)\end{array}$ & $\begin{array}{c}0.0048 \\
(0.0024)\end{array}$ & $\begin{array}{l}-0.0001 \\
(0.0018)\end{array}$ & $\begin{array}{c}0.0006 \\
(0.0004)\end{array}$ & $\begin{array}{c}0.0004 \\
(0.0006)\end{array}$ \\
\hline $\begin{array}{l}\text { Number of observations } \\
\text { Number of cells } \\
\text { Number of counties }\end{array}$ & $\begin{array}{c}7,423,000 \\
2,684,000 \\
3,000\end{array}$ & $\begin{array}{c}7,423,000 \\
2,684,000 \\
3,000\end{array}$ & $\begin{array}{c}7,423,000 \\
2,684,000 \\
3,000\end{array}$ & $\begin{array}{c}7,077,000 \\
1,831,000 \\
3,000\end{array}$ & $\begin{array}{c}44,900,000 \\
916,000 \\
3,000\end{array}$ & $\begin{array}{c}3,264,000 \\
1,586,000 \\
3,000\end{array}$ \\
\hline$\frac{\text { White females }}{\% \text { IU - Age } 5}$ & $\begin{array}{c}0.0078 \\
(0.0030)\end{array}$ & $\begin{array}{l}-0.0002 \\
(0.0027)\end{array}$ & $\begin{array}{c}0.0095 \\
(0.0028)\end{array}$ & $\begin{array}{c}0.0001 \\
(0.0016)\end{array}$ & $\begin{array}{c}0.0003 \\
(0.0002)\end{array}$ & $\begin{array}{c}0.0001 \\
(0.0002)\end{array}$ \\
\hline $\begin{array}{l}\text { Number of observations } \\
\text { Number of cells } \\
\text { Number of counties }\end{array}$ & $\begin{array}{l}7,817,000 \\
2,781,000 \\
3,000\end{array}$ & $\begin{array}{c}7,817,000 \\
2,781,000 \\
3,000\end{array}$ & $\begin{array}{c}7,817,000 \\
2,781,000 \\
3,000\end{array}$ & $\begin{array}{c}7,340,000 \\
1,878,000 \\
3,000\end{array}$ & $\begin{array}{c}43,000,000 \\
913,000 \\
3,000\end{array}$ & $\begin{array}{c}3,411,000 \\
1,629,000 \\
3,000\end{array}$ \\
\hline$\frac{\text { Nonwhite males }}{\% \mathrm{IU}-\text { Age } 5}$ & $\begin{array}{c}0.0044 \\
(0.0067)\end{array}$ & $\begin{array}{c}0.0063 \\
(0.0044)\end{array}$ & $\begin{array}{c}0.0019 \\
(0.0050)\end{array}$ & $\begin{array}{c}0.0083 \\
(0.0036)\end{array}$ & $\begin{array}{c}0.0007 \\
(0.0009)\end{array}$ & $\begin{array}{l}-0.0001 \\
(0.0039)\end{array}$ \\
\hline $\begin{array}{l}\text { Number of observations } \\
\text { Number of cells } \\
\text { Number of counties }\end{array}$ & $\begin{array}{c}951,000 \\
561,000 \\
2,900\end{array}$ & $\begin{array}{c}951,000 \\
561,000 \\
2,900\end{array}$ & $\begin{array}{c}951,000 \\
561,000 \\
2,900\end{array}$ & $\begin{array}{c}1,028,000 \\
466,000 \\
2,900\end{array}$ & $\begin{array}{c}12,900,000 \\
622,000 \\
3,000\end{array}$ & $\begin{array}{c}494,000 \\
338,000 \\
2,700\end{array}$ \\
\hline$\frac{\text { Nonwhite females }}{\% \text { IU }- \text { Age } 5}$ & $\begin{array}{l}-0.0007 \\
(0.0068)\end{array}$ & $\begin{array}{c}0.0038 \\
(0.0049)\end{array}$ & $\begin{array}{l}-0.0042 \\
(0.0046)\end{array}$ & $\begin{array}{l}-0.0035 \\
(0.0032)\end{array}$ & $\begin{array}{c}0.0001 \\
(0.0006)\end{array}$ & $\begin{array}{c}0.0002 \\
(0.0011)\end{array}$ \\
\hline $\begin{array}{l}\text { Number of observations } \\
\text { Number of cells } \\
\text { Number of counties }\end{array}$ & $\begin{array}{c}1,204,000 \\
668,000 \\
2,900\end{array}$ & $\begin{array}{c}1,204,000 \\
668,000 \\
2,900\end{array}$ & $\begin{array}{c}1,204,000 \\
668,000 \\
2,900\end{array}$ & $\begin{array}{c}1,310,000 \\
546,000 \\
2,900\end{array}$ & $\begin{array}{c}13,000,000 \\
627,000 \\
3,000\end{array}$ & $\begin{array}{c}536,000 \\
360,000 \\
2,700\end{array}$ \\
\hline $\begin{array}{l}\text { FE county, survey year } \\
\text { Cty } 60 \text { x linear cohort } \\
\text { State x birth year FE }\end{array}$ & $\begin{array}{l}X \\
X \\
X\end{array}$ & $\begin{array}{l}X \\
X \\
X\end{array}$ & $\begin{array}{l}\mathrm{X} \\
\mathrm{X} \\
\mathrm{X}\end{array}$ & $\begin{array}{l}X \\
X \\
X\end{array}$ & $\begin{array}{l}X \\
X \\
X\end{array}$ & $\begin{array}{l}X \\
X \\
X\end{array}$ \\
\hline
\end{tabular}

Notes: See Table 3 notes. 
Table 5: Estimated ITT Effects of Food Stamps Exposure between Conception and Age 5 on Indices of Adult Well-Being, by Mobility

\begin{tabular}{|c|c|c|c|c|c|c|c|}
\hline & $(1)$ & $(2)$ & $(3)$ & (4) & $(5)$ & $(6)$ & $(7)$ \\
\hline & Incidence of & \multicolumn{2}{|c|}{ Human capital } & \multicolumn{2}{|c|}{ Economic self-sufficiency } & \multicolumn{2}{|c|}{ Neighborhood quality } \\
\hline & Mobility & Stayers & Movers & Stayers & Movers & Stayers & Movers \\
\hline$\%$ IU - Age 5 & $\begin{array}{c}0.0085 \\
(0.0031)\end{array}$ & $\begin{array}{c}0.0113 \\
(0.0031)\end{array}$ & $\begin{array}{c}0.0064 \\
(0.0021)\end{array}$ & $\begin{array}{c}0.0062 \\
(0.0029)\end{array}$ & $\begin{array}{c}0.0031 \\
(0.0019)\end{array}$ & $\begin{array}{c}0.0156 \\
(0.0035)\end{array}$ & $\begin{array}{c}0.0085 \\
(0.0031)\end{array}$ \\
\hline FE county, survey year & $\mathrm{X}$ & $\mathrm{X}$ & $\mathrm{X}$ & $\mathrm{X}$ & $\mathrm{X}$ & $\mathrm{X}$ & $\mathrm{X}$ \\
\hline Cty $_{60} \mathrm{x}$ linear cohort & $\mathrm{X}$ & $\mathrm{X}$ & $\mathrm{X}$ & $\mathrm{X}$ & $\mathrm{X}$ & $\mathrm{X}$ & $\mathrm{X}$ \\
\hline State $\mathrm{x}$ birth year FE & $\mathrm{X}$ & $\mathrm{X}$ & $\mathrm{X}$ & $\mathrm{X}$ & $\mathrm{X}$ & $\mathrm{X}$ & $\mathrm{X}$ \\
\hline Number of observations & $17,400,000$ & $5,182,000$ & $12,200,000$ & $5,182,000$ & $12,200,000$ & $5,182,000$ & $12,200,000$ \\
\hline Number of cells & $4,272,000$ & $2,101,000$ & $3,567,000$ & $2,101,000$ & $3,567,000$ & $2,101,000$ & $3,567,000$ \\
\hline Number of counties & 3000 & 2700 & 3000 & 2700 & 3000 & 2700 & 3000 \\
\hline Mean DV & 0.712 & -0.115 & 0.068 & -0.0228 & 0.0533 & -0.152 & 0.0679 \\
\hline$R^{2}$ & 0.18 & 0.283 & 0.181 & 0.0662 & 0.0425 & 0.538 & 0.301 \\
\hline
\end{tabular}

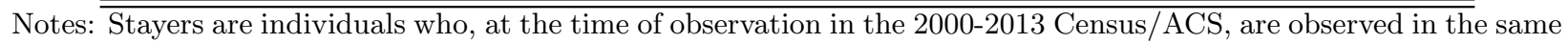
county as they were born. Movers are individuals who are not living in their birth county at the time of observation. See also Table 3 notes. 
Table 6: Robustness of the Estimated ITT Effects of Food Stamps Exposure between Ages 0 and 5 on a Composite Index of Well-Being

\begin{tabular}{lccc}
\hline \hline & $(1)$ & $(2)$ & $(3)$ \\
\hline \%IU - Age 5 & 0.0087 & 0.0070 & 0.0074 \\
& $(0.0034)$ & $(0.0033)$ & $(0.0029)$ \\
FE county, year & $\mathrm{X}$ & $\mathrm{X}$ & $\mathrm{X}$ \\
Cty60 x linear cohort & $\mathrm{X}$ & $\mathrm{X}$ & $\mathrm{X}$ \\
State x year FE & $\mathrm{X}$ & $\mathrm{X}$ & $\mathrm{X}$ \\
County population & & $\mathrm{X}$ & $\mathrm{X}$ \\
Other county controls & & & $\mathrm{X}$ \\
Number of observations & $11,200,000$ & $11,200,000$ & $11,200,000$ \\
Number of cells & $3,115,000$ & $3,115,000$ & $3,115,000$ \\
Number of counties & 3000 & 3000 & 3000 \\
$R^{2}$ & 0.213 & 0.213 & 0.213 \\
\hline \hline
\end{tabular}

Notes: Each column provides estimates for the exposure model in equation (3). The unit of analysis is at the birthcounty $\mathrm{x}$ birth-year x birth-month x survey-year level and the coefficient is on the exposure variable: the share of months between conception and age 5 that a cohort would have been exposed to Food Stamps based on when the program began in the cohort's county of birth. All columns include fixed effects for birth-county, birth-year, birthmonth, survey year, and birth-state x birth-year as well as 1960 county characteristics interacted with a linear trend in year of birth. Column 2 adds a control for the $\log$ (population) and Column 3 adds all other controls in Table 1 that are available for 1959-1980 (War on Poverty programs, REIS transfer spending, and mortality). Data limited to those born between 1959 and 1980. Standard errors are clustered by county of birth and indicated in parentheses. See also Table 3 notes. 
Table 7: Estimated ITT Effects of Food Stamps Exposure in Early (Conception to Age 5) and Later Childhood (Ages 6 to 18) on Different Indices of Well-Being, Longevity, and Incarceration

\begin{tabular}{|c|c|c|c|c|c|c|}
\hline & \multicolumn{4}{|c|}{ Indices } & \multirow[b]{2}{*}{$\begin{array}{c}\text { Survive to } \\
2012\end{array}$} & \multirow[b]{2}{*}{$\begin{array}{c}\text { Not } \\
\text { incarcerated }\end{array}$} \\
\hline & $\begin{array}{c}\text { Human } \\
\text { capital }\end{array}$ & $\begin{array}{l}\text { Economic self- } \\
\text { sufficiency }\end{array}$ & $\begin{array}{c}\text { Neighborhood } \\
\text { quality }\end{array}$ & $\begin{array}{l}\text { Physical } \\
\text { disability }\end{array}$ & & \\
\hline$\%$ IU - Age 5 & $\begin{array}{c}0.0092 \\
(0.0047)\end{array}$ & $\begin{array}{c}0.0027 \\
(0.0023)\end{array}$ & $\begin{array}{c}0.0123 \\
(0.0052)\end{array}$ & $\begin{array}{l}-0.0015 \\
(0.0016)\end{array}$ & $\begin{array}{c}0.0010 \\
(0.0003)\end{array}$ & $\begin{array}{c}0.0008 \\
(0.0006)\end{array}$ \\
\hline$\% 6-18$ & $\begin{array}{l}-0.0033 \\
(0.0112)\end{array}$ & $\begin{array}{l}-0.0049 \\
(0.0053)\end{array}$ & $\begin{array}{c}0.0025 \\
(0.0122)\end{array}$ & $\begin{array}{l}-0.0081 \\
(0.0031)\end{array}$ & $\begin{array}{c}0.0012 \\
(0.0008)\end{array}$ & $\begin{array}{c}0.0002 \\
(0.0014)\end{array}$ \\
\hline FE county, survey year & $\mathrm{X}$ & $\mathrm{X}$ & $\mathrm{X}$ & $\mathrm{X}$ & $\mathrm{X}$ & $\mathrm{X}$ \\
\hline Cty $_{60} \mathrm{x}$ linear cohort & $\mathrm{X}$ & $\mathrm{X}$ & $\mathrm{X}$ & $\mathrm{X}$ & $\mathrm{X}$ & $\mathrm{X}$ \\
\hline State $\mathrm{x}$ birth year FE & $\mathrm{X}$ & $\mathrm{X}$ & $\mathrm{X}$ & $\mathrm{X}$ & $\mathrm{X}$ & $\mathrm{X}$ \\
\hline Number of observations & $17,400,000$ & $17,400,000$ & $17,400,000$ & $16,800,000$ & $114,000,000$ & $7,705,000$ \\
\hline Number of cells & $4,272,000$ & $4,272,000$ & $4,272,000$ & $2,796,000$ & 943,000 & $2,591,000$ \\
\hline Number of counties & 3000 & 3000 & 3000 & 3100 & 3000 & 3000 \\
\hline$R^{2}$ & 0.127 & 0.058 & 0.379 & 0.053 & 0.696 & 0.027 \\
\hline
\end{tabular}

Notes: Each column provides estimates for the exposure model (equation 3) that includes two exposure variables share of months between conception and age 5 and share of months between ages 6 and 18. See notes to Table 3 for more on model, sample, and data. 
Appendix Figure 1: Population Weighed Share of Counties With a Food Stamp Program, by Year

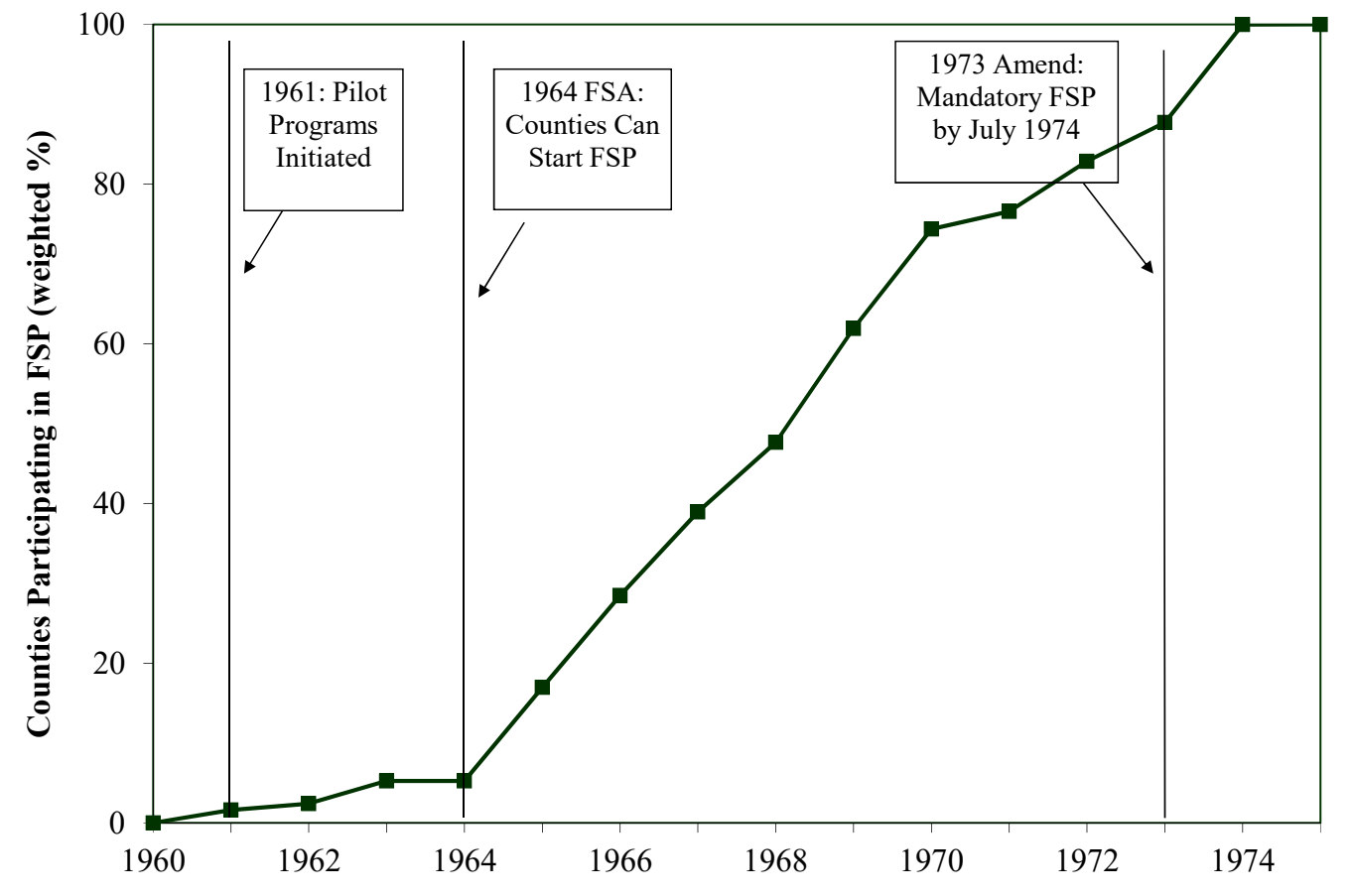

Notes: Hoynes and Schanzenbach (2009) tabulations based on administrative data from the U.S. Department of Agriculture in various years. 
Appendix Figure 2: Childhood use of the FSP in the PSID

(A) Child Participation Rates in Food Stamps, by Age

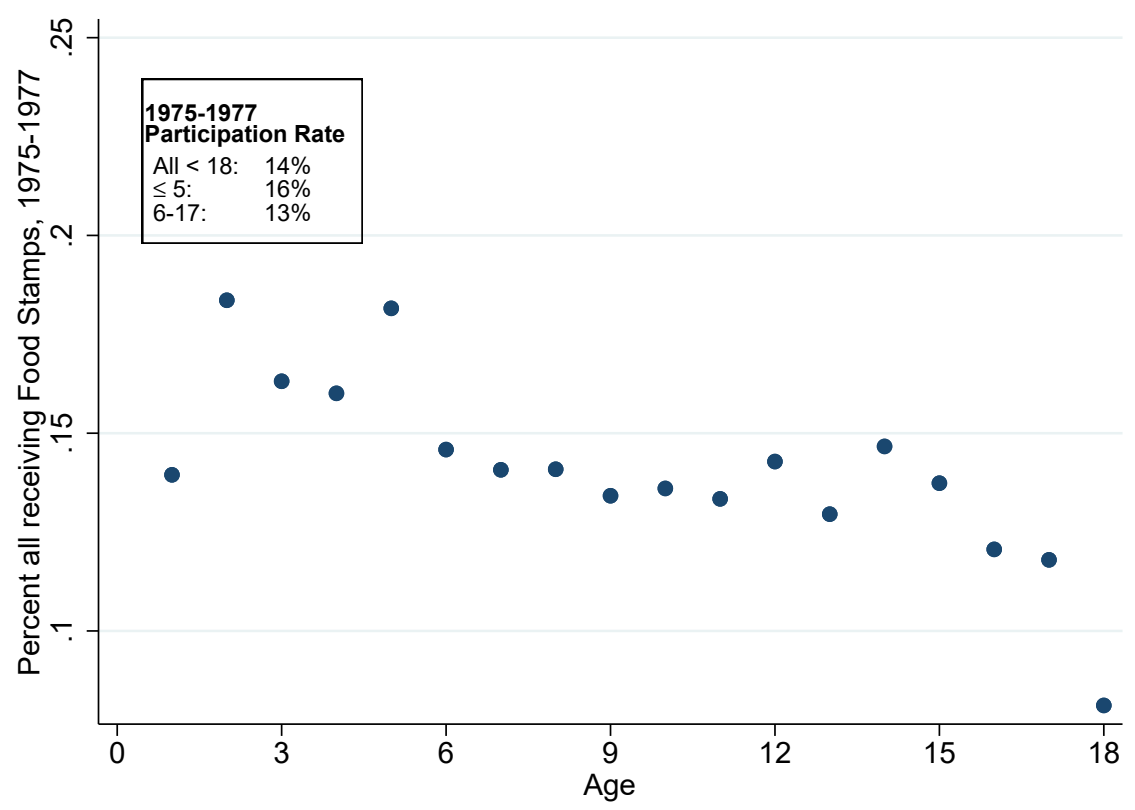

Source: Panel Study of Income Dynamics, pooling calendar years 1975-1977.

Note: We use this period because 1975, 1976, and 1977 are the first three years where Food Stamps were universally available.

(B) Years of Childhood on Food Stamps, by Age at First Use

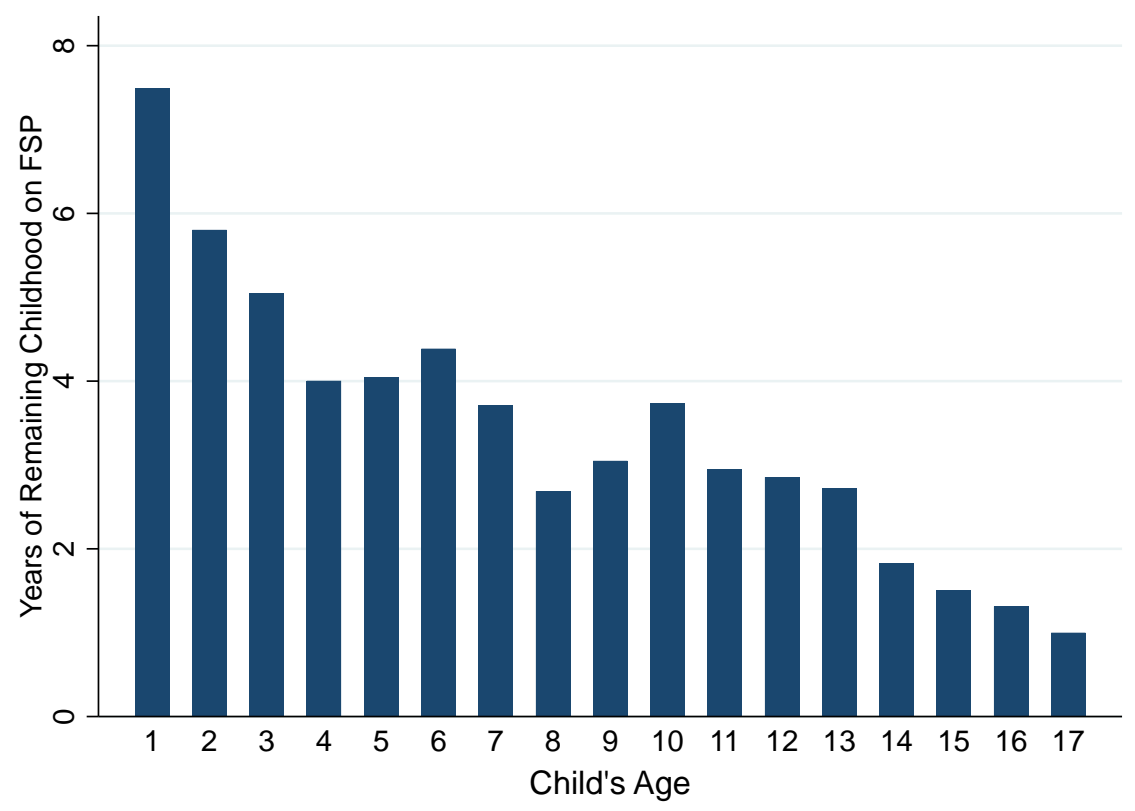

Source: Panel Study of Income Dynamics, 1972-1999

Note: We limit our sample to children who were first observed on the Food Stamp Program between 1972 and 1975. We start this period in 1972 because the PSID begins in 1968, and we wanted to assure that there was no participation in the prior four years. We end this period in 1975 to target the rollout period. The results are similar when we change the sample to include children who were first observed on the Food Stamp Program between 1972 and 1981, although the results are slightly less noisy due to the larger sample size. 
Appendix Figure 3: Exposure Model Estimates of the ITT Effects of Food Stamps for Standardized SubIndex Components

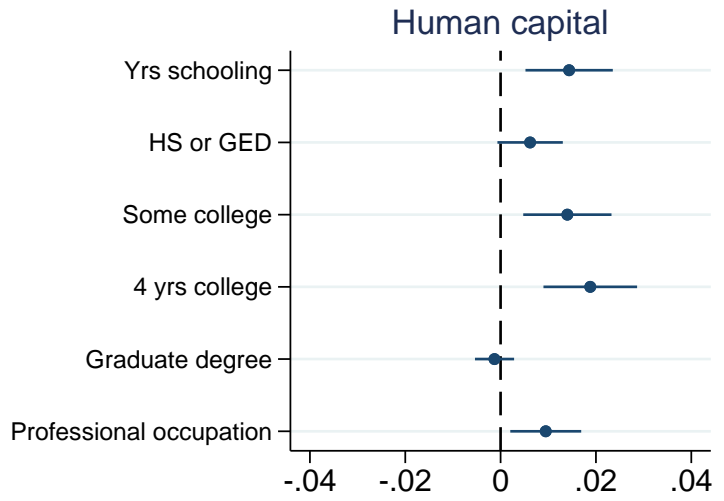

Neighborhood quality

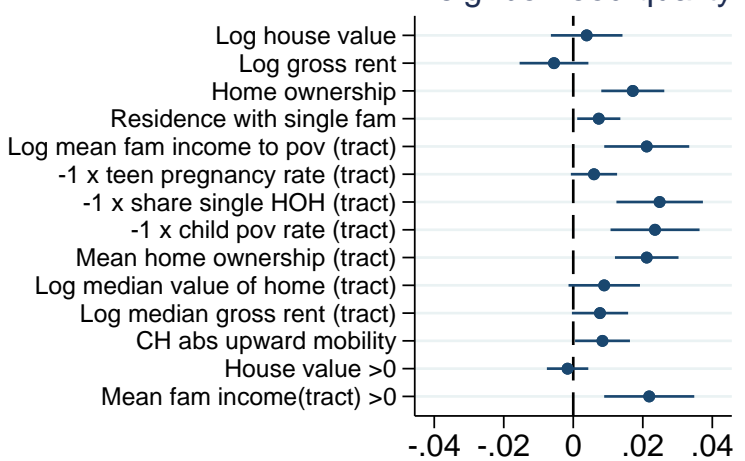

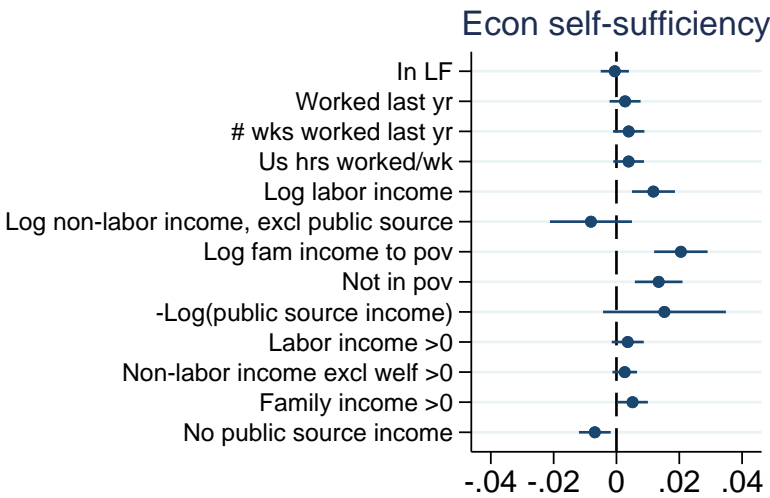

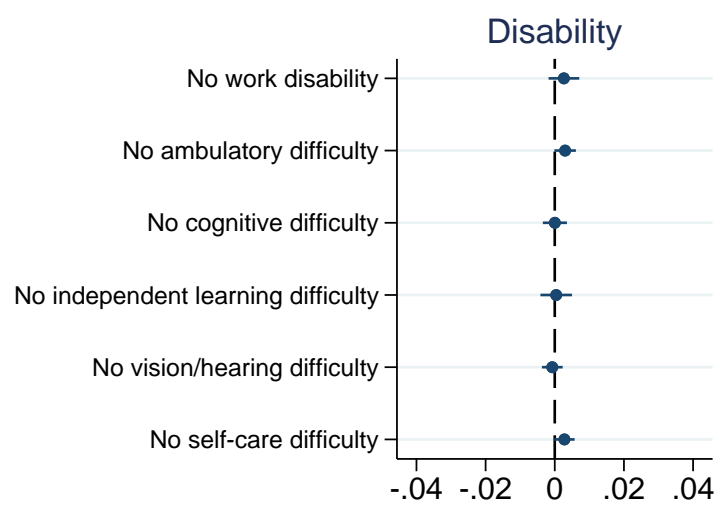

Notes: Each row in each figure provides estimates for the exposure model in equation (3). The unit of analysis is at the birth-county $\mathrm{x}$ birth-year $\mathrm{x}$ birth-month $\mathrm{x}$ survey-year level and the coefficient is on the exposure variable: the share of months between conception and age 5 that a cohort would have been exposed to Food Stamps based on when the program began in the cohort's county of birth. Standard errors are clustered by county of birth and 95 percent confidence intervals are included. Each outcome is a sub-index where each is standardized in terms of standard deviations. Estimated models and samples are identical to Table 3. 
Appendix Figure 4: Event-Study and Spline Estimates of the ITT Effects of Food Stamps Exposure on Longevity by a Cohort's Age when the Program Launched, by Sex and Race
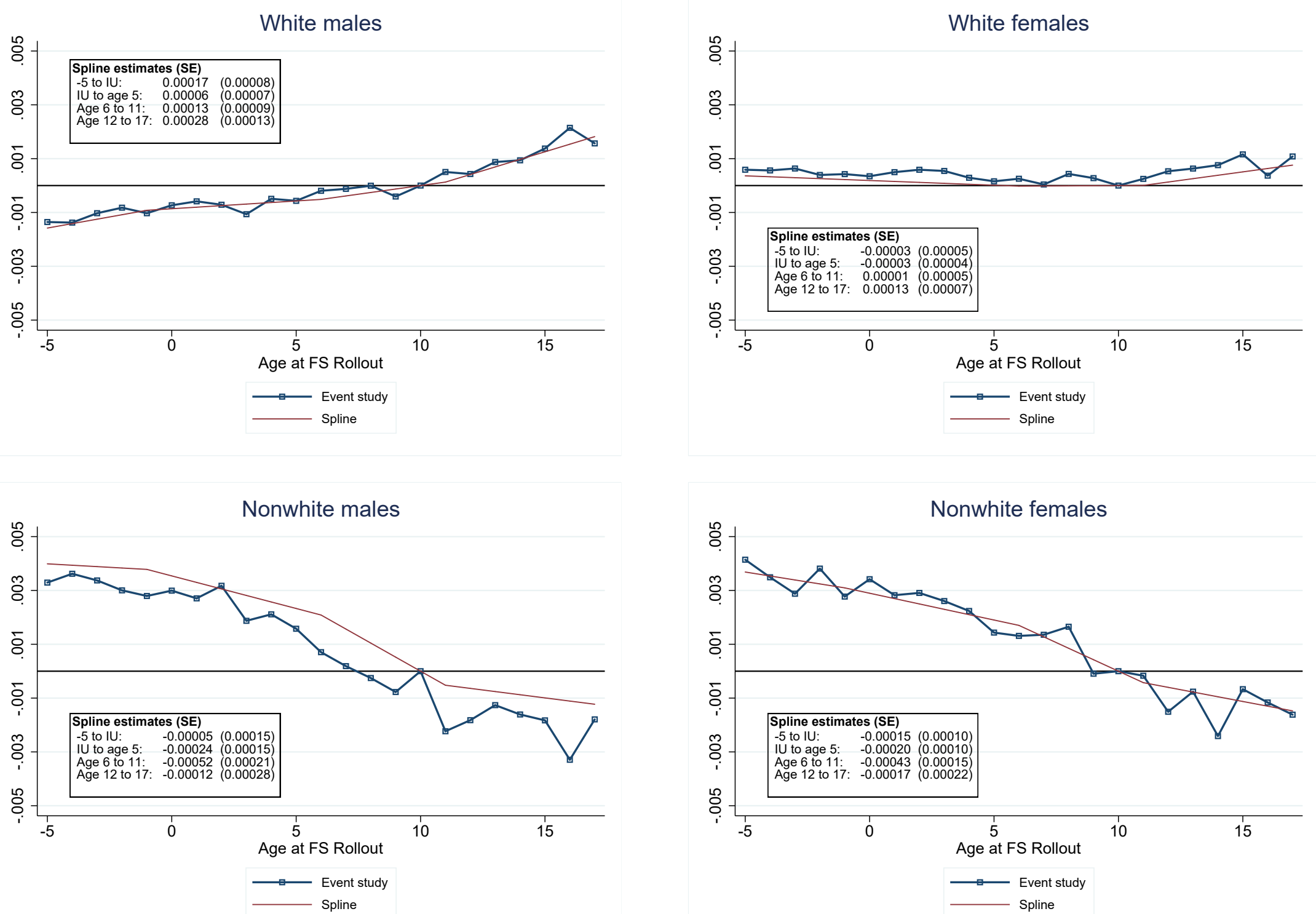

Notes: The panels plot event-study and spline estimates for survival to 2012 using the specifications in equations (1) and (2) separately by race and sex. All models include fixed effects for birth-county, birth-year, survey year, and birth-state x birth-year as well as 1960 county characteristics interacted with a linear trend in year of birth. Survival to 2012 is expressed in percentage point units. The survival estimates are based on the 114 million U.S. individuals born in the U.S. between 1950 and 1980 where we observe place of birth. See Figure 5 for more on sample, specification and data. 
Appendix Figure 5: Event-Study and Spline Estimates of the ITT Effects of Food Stamps Exposure on Incarceration by a Cohort's Age when the Program Launched, by Sex and Race
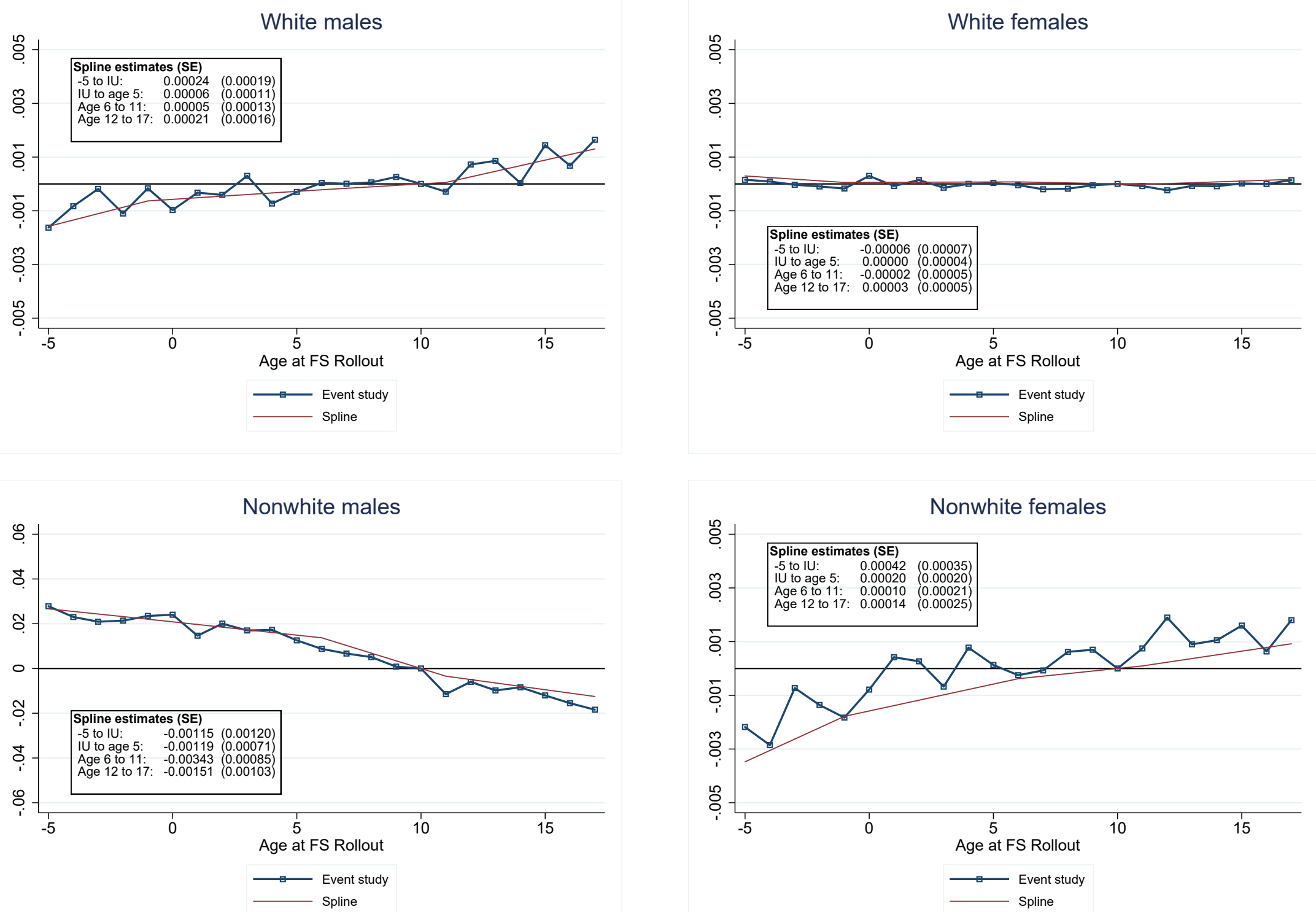

Notes: The panels plot event-study and spline estimates for survival to 2012 in the 2006-2013 ACS using the specifications in equations (1) and (2) separately by race and sex. All models include fixed effects for birth-county, birth-year, survey year, and birth-state x birth-year as well as 1960 county characteristics interacted with a linear trend in year of birth. Not incarcerated is expressed in percentage point units. See Figure 5 for more on sample, specification and data. 
Appendix Figure 6: Event-Study and Spline Estimates of the ITT Effects of Food Stamps Exposure on Neighborhood Quality by a Cohort's Age when the Program Launched, by Sex and Race
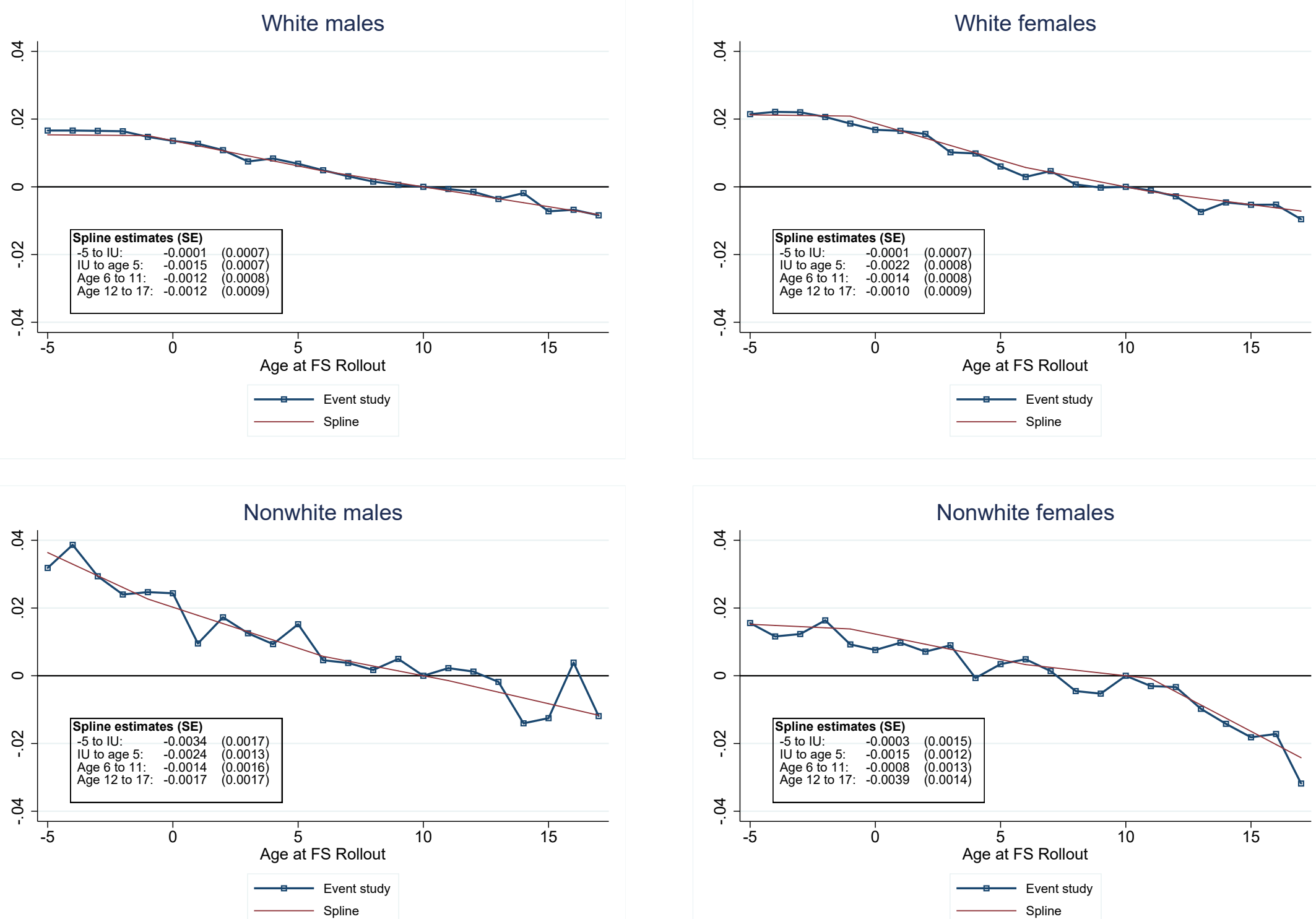

Notes: The panels plot event-study and spline estimates for standardized index of neighborhood quality using the specifications in equations (1) and (2) separately by race and sex. All models include fixed effects for birth-county, birth-year, survey year, and birth-state x birth-year as well as 1960 county characteristics interacted with a linear trend in year of birth. See Figure 5 for more on sample, specification and data. 
Appendix Figure 7: Spline Summary Estimates on the Pre-Trend of the ITT Effects of Food Stamps for Different Indices of Well-Being, Longevity, and Incarceration, by Race and Sex
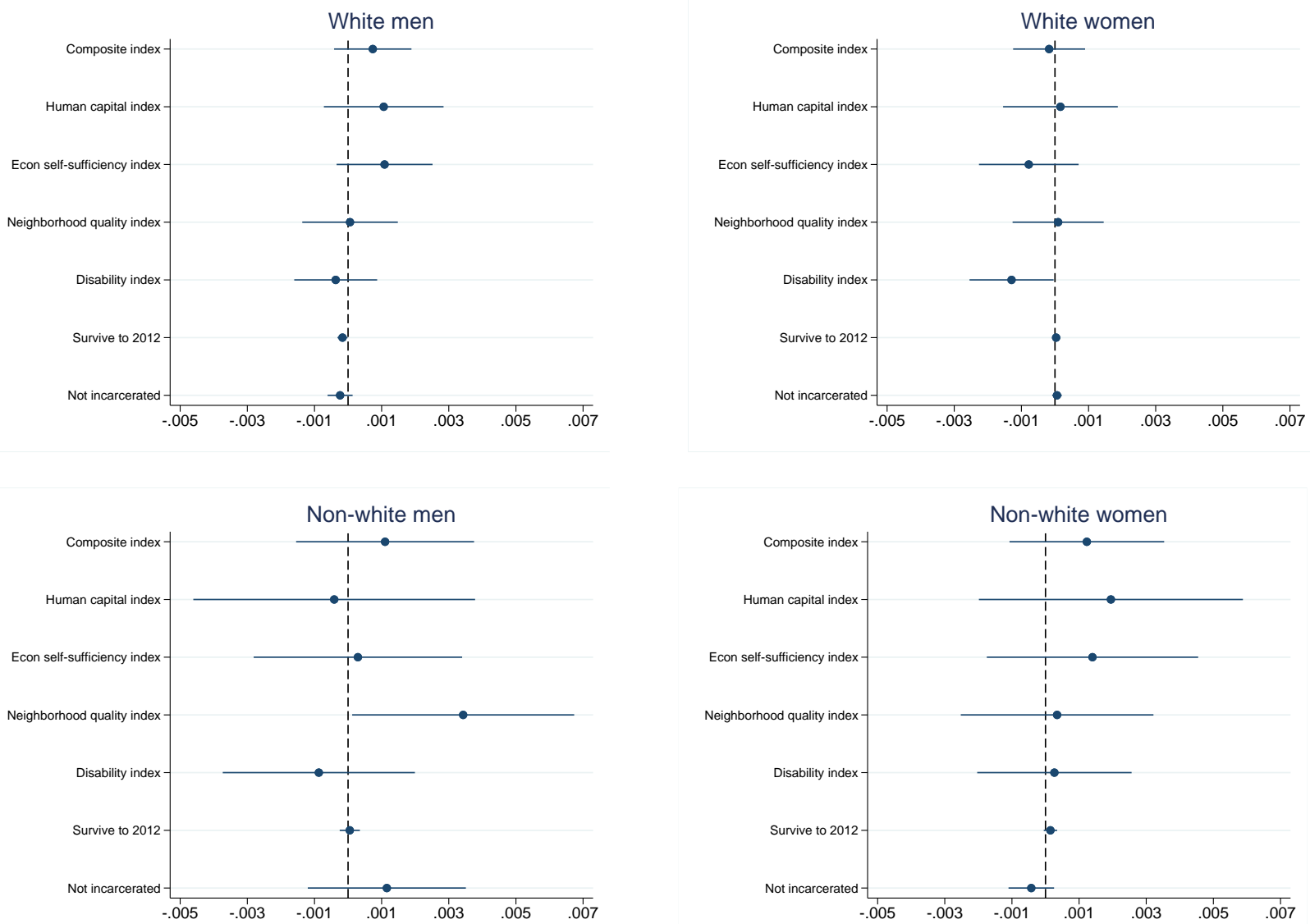

Notes: The panels plot-for different indices and subgroups - the absolute value of the estimates on the pre-trend linear splines $\left(\left|\omega_{1}\right|\right.$ covering ages -5 to -2$)$ in equations (2). See text for more information on indices and outcomes. The indices are standardized in terms of standard deviations, but "Survive to 2012" and "Not incarcerated" are in percentage point units. 95-percent confidence intervals are provided. See Figure 5 for more on sample, specification and data. 
Appendix Figure 8: Five-Year Childhood Migration Rates

(A) Five-Year Childhood Migration Rates by Age of Child, 1970 Decennial Census

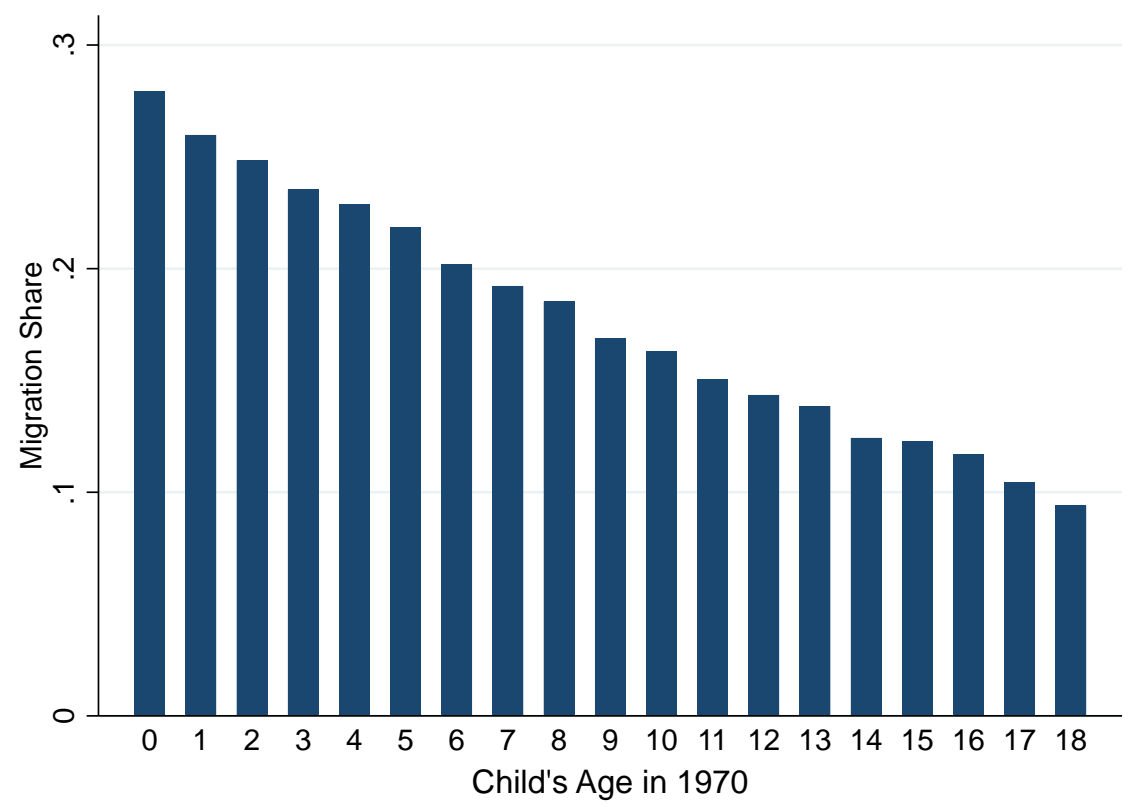

Source: 1970 Deccenial Census.

(B) Five-Year Childhood Migration Rates by Age of Child, 1980 Decennial Census

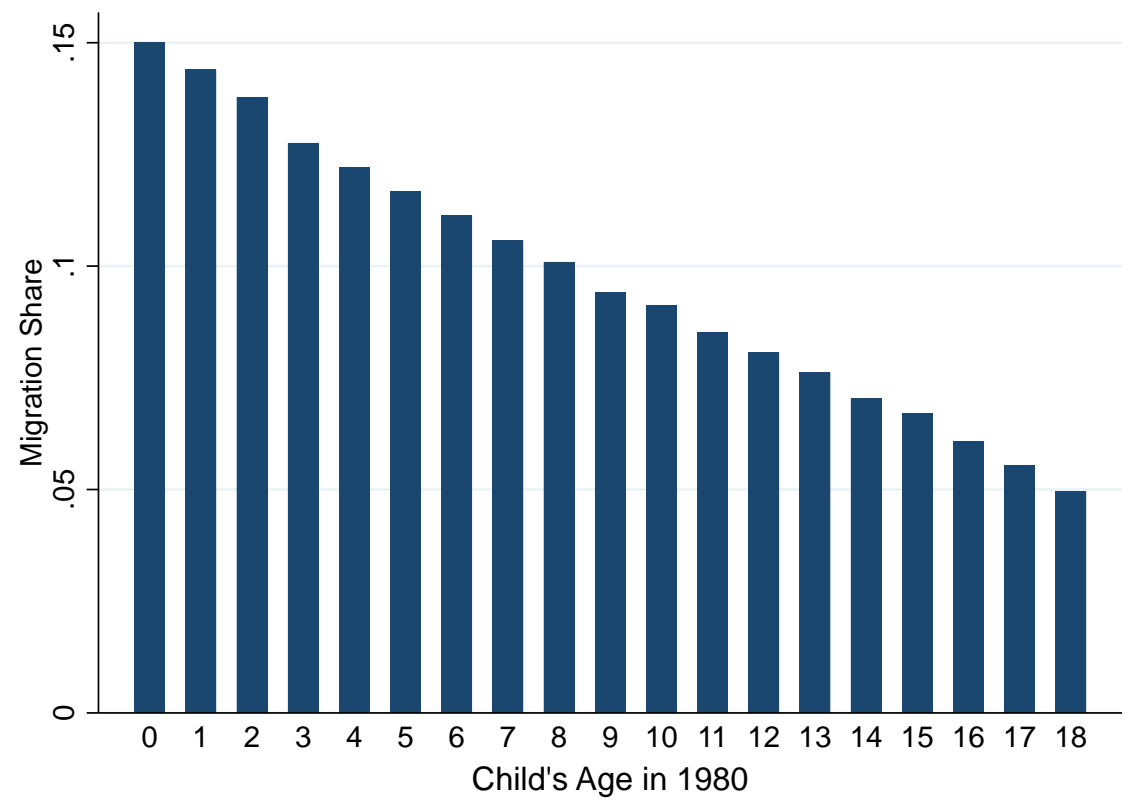

Source: 1980 Deccenial Census.

Notes: Notes: Using publicly available data from the 1970 and 1980 decennial census, the figure plots, by child age, the share of children who lived in a different county five years prior to the census year. We limit the sample to those with the child's mother (or the head of household, if no mother was present) had less than a high school degree. We use the migration of the mother (or head of household, if no mother was present) as a proxy for migration of the child. We present the results by the child's age in 1970 or 1980 . 
Appendix Table 1: Mean of the Outcomes for Adult-Wellbeing, All and by Race and Gender

\begin{tabular}{|c|c|c|c|c|c|}
\hline & All & $\begin{array}{l}\text { White } \\
\text { males }\end{array}$ & $\begin{array}{l}\text { White } \\
\text { females }\end{array}$ & $\begin{array}{c}\text { Nonwhite } \\
\text { males }\end{array}$ & $\begin{array}{c}\text { Nonwhite } \\
\text { females }\end{array}$ \\
\hline Yrs schooling & 13.760 & 13.750 & 13.910 & 13.140 & 13.370 \\
\hline HS or GED & 0.930 & 0.928 & 0.949 & 0.866 & 0.886 \\
\hline Some college & 0.665 & 0.648 & 0.700 & 0.561 & 0.635 \\
\hline College & 0.328 & 0.332 & 0.350 & 0.227 & 0.256 \\
\hline Graduate & 0.031 & 0.038 & 0.026 & 0.026 & 0.022 \\
\hline Professional occ & 0.372 & 0.363 & 0.405 & 0.260 & 0.325 \\
\hline In labor force & 0.857 & 0.932 & 0.796 & 0.862 & 0.788 \\
\hline Worked last year & 0.876 & 0.942 & 0.826 & 0.868 & 0.808 \\
\hline \# wks worked last yr & 41.810 & 46.200 & 38.460 & 41.090 & 37.220 \\
\hline Usual hrs worked /wk & 36.460 & 42.590 & 31.240 & 37.450 & 31.580 \\
\hline Log labor income & 10.570 & 10.860 & 10.300 & 10.560 & 10.260 \\
\hline Labor income $>0$ & 0.871 & 0.939 & 0.819 & 0.860 & 0.799 \\
\hline Log non-labor PI & 7.355 & 7.221 & 7.393 & 7.641 & 7.753 \\
\hline Log SF income/pov & 5.851 & 5.943 & 5.865 & 5.622 & 5.427 \\
\hline $\mathrm{SF}$ income $>0$ & 0.975 & 0.982 & 0.974 & 0.962 & 0.954 \\
\hline Not in pov & 0.903 & 0.934 & 0.904 & 0.849 & 0.782 \\
\hline Log PA income & -9.039 & -9.177 & -9.037 & -9.001 & -8.738 \\
\hline Log house value & 12.090 & 12.100 & 12.120 & 11.890 & 11.860 \\
\hline Log gross rent & 6.844 & 6.875 & 6.874 & 6.808 & 6.757 \\
\hline Home ownership & 0.785 & 0.814 & 0.819 & 0.636 & 0.599 \\
\hline Single family residence & 0.859 & 0.869 & 0.869 & 0.795 & 0.809 \\
\hline Log mean SF income/pov (tract) & 5.891 & 5.920 & 5.926 & 5.689 & 5.656 \\
\hline Log mean SF income/pov (tract) $>0$ & 0.941 & 0.944 & 0.944 & 0.919 & 0.916 \\
\hline$-1 \mathrm{x}$ teen pregnancy (tract) & -0.040 & -0.037 & -0.036 & -0.059 & -0.062 \\
\hline$-1 \mathrm{x}$ child pov rate (tract) & -0.436 & -0.422 & -0.420 & -0.519 & -0.531 \\
\hline Mean home ownership (tract) & 0.742 & 0.758 & 0.762 & 0.641 & 0.632 \\
\hline Log median home value (tract) & 11.990 & 12.010 & 12.010 & 11.840 & 11.800 \\
\hline Log median gross rent (tract) & 6.823 & 6.823 & 6.826 & 6.796 & 6.775 \\
\hline Absolute upward mobility (CH) & 42.250 & 42.620 & 42.580 & 40.420 & 40.080 \\
\hline No work disability & 0.914 & 0.918 & 0.927 & 0.859 & 0.868 \\
\hline No ambulatory disability & 0.950 & 0.956 & 0.952 & 0.933 & 0.924 \\
\hline No cognitive disability & 0.968 & 0.971 & 0.969 & 0.957 & 0.955 \\
\hline No independent learning difficulty & 0.963 & 0.970 & 0.968 & 0.934 & 0.927 \\
\hline No vision/hearing difficulty & 0.981 & 0.979 & 0.985 & 0.973 & 0.979 \\
\hline No self-care difficulty & 0.987 & 0.989 & 0.987 & 0.981 & 0.977 \\
\hline Not incarcerated & 0.984 & 0.981 & 0.997 & 0.859 & 0.989 \\
\hline Survive to 2012 & 0.956 & 0.945 & 0.972 & 0.932 & 0.963 \\
\hline Number of observations & $17,400,000$ & $7,423,000$ & $7,817,000$ & 951,000 & $1,204,000$ \\
\hline Number of cells & $4,272,000$ & $2,684,000$ & $2,781,000$ & 561,000 & 668,000 \\
\hline Number of counties & 3000 & 3000 & 3000 & 2900 & 2900 \\
\hline
\end{tabular}

Notes: The table provides means of each of the outcome variables reported in the paper, for all and by race and gender. Subindex values are unnormalized; indices are normalized. For details on sample and data, see Table 3. 
Appendix Table 2: Exposure Model Estimates of the ITT Effects of Food Stamps for Sub-Index Components, All and by Race and Gender

\begin{tabular}{|c|c|c|c|c|c|}
\hline Title & All & $\begin{array}{l}\text { White } \\
\text { males }\end{array}$ & $\begin{array}{c}\text { White } \\
\text { females }\end{array}$ & $\begin{array}{c}\text { Nonwhite } \\
\text { males }\end{array}$ & $\begin{array}{l}\text { Nonwhite } \\
\text { females }\end{array}$ \\
\hline \multicolumn{6}{|l|}{ Human capital } \\
\hline Yrs schooling & $\begin{array}{c}0.0367 \\
(0.0119)\end{array}$ & $\begin{array}{c}0.0374 \\
(0.0126)\end{array}$ & $\begin{array}{c}0.0336 \\
(0.0105)\end{array}$ & $\begin{array}{l}-0.0028 \\
(0.0251)\end{array}$ & $\begin{array}{l}-0.0045 \\
(0.0239)\end{array}$ \\
\hline HS or GED & $\begin{array}{c}0.0016 \\
(0.0009)\end{array}$ & $\begin{array}{c}0.0007 \\
(0.0009)\end{array}$ & $\begin{array}{c}0.0005 \\
(0.0009)\end{array}$ & $\begin{array}{c}0.0003 \\
(0.0032)\end{array}$ & $\begin{array}{l}-0.0013 \\
(0.0025)\end{array}$ \\
\hline Some college & $\begin{array}{c}0.0067 \\
(0.0023)\end{array}$ & $\begin{array}{c}0.0070 \\
(0.0025)\end{array}$ & $\begin{array}{c}0.0058 \\
(0.0021)\end{array}$ & $\begin{array}{c}0.0010 \\
(0.0049)\end{array}$ & $\begin{array}{c}0.0006 \\
(0.0048)\end{array}$ \\
\hline College & $\begin{array}{c}0.0088 \\
(0.0023)\end{array}$ & $\begin{array}{c}0.0091 \\
(0.0026)\end{array}$ & $\begin{array}{c}0.0081 \\
(0.0021)\end{array}$ & $\begin{array}{c}0.0030 \\
(0.0043)\end{array}$ & $\begin{array}{c}0.0020 \\
(0.0037)\end{array}$ \\
\hline Graduate & $\begin{array}{l}-0.0002 \\
(0.0004)\end{array}$ & $\begin{array}{c}0.0001 \\
(0.0006)\end{array}$ & $\begin{array}{l}-0.0006 \\
(0.0004)\end{array}$ & $\begin{array}{c}0.0013 \\
(0.0015)\end{array}$ & $\begin{array}{l}-0.0009 \\
(0.0013)\end{array}$ \\
\hline Professional occ & $\begin{array}{c}0.0046 \\
(0.0018)\end{array}$ & $\begin{array}{c}0.0047 \\
(0.0022)\end{array}$ & $\begin{array}{c}0.0027 \\
(0.0019)\end{array}$ & $\begin{array}{c}0.0040 \\
(0.0039)\end{array}$ & $\begin{array}{c}0.0007 \\
(0.0040)\end{array}$ \\
\hline \multicolumn{6}{|l|}{ Economic self sufficiency } \\
\hline In labor force & $\begin{array}{l}-0.0002 \\
(0.0009)\end{array}$ & $\begin{array}{c}0.0014 \\
(0.0008)\end{array}$ & $\begin{array}{l}-0.0049 \\
(0.0019)\end{array}$ & $\begin{array}{c}0.0026 \\
(0.0025)\end{array}$ & $\begin{array}{c}0.0044 \\
(0.0036)\end{array}$ \\
\hline Worked last year & $\begin{array}{c}0.0010 \\
(0.0009)\end{array}$ & $\begin{array}{c}0.0005 \\
(0.0008)\end{array}$ & $\begin{array}{l}-0.0034 \\
(0.0018)\end{array}$ & $\begin{array}{c}0.0053 \\
(0.0028)\end{array}$ & $\begin{array}{c}0.0038 \\
(0.0034)\end{array}$ \\
\hline \# wks worked last yr & $\begin{array}{c}0.0754 \\
(0.0493)\end{array}$ & $\begin{array}{c}0.0545 \\
(0.0503)\end{array}$ & $\begin{array}{l}-0.2111 \\
(0.0981)\end{array}$ & $\begin{array}{c}0.4391 \\
(0.1581)\end{array}$ & $\begin{array}{c}0.2036 \\
(0.1742)\end{array}$ \\
\hline Usual hrs worked /wk & $\begin{array}{c}0.0704 \\
(0.0452)\end{array}$ & $\begin{array}{c}0.1250 \\
(0.0527)\end{array}$ & $\begin{array}{l}-0.1995 \\
(0.0931)\end{array}$ & $\begin{array}{c}0.2231 \\
(0.1491)\end{array}$ & $\begin{array}{c}0.0367 \\
(0.1562)\end{array}$ \\
\hline Log labor income & $\begin{array}{c}0.0114 \\
(0.0034)\end{array}$ & $\begin{array}{c}0.0139 \\
(0.0035)\end{array}$ & $\begin{array}{c}0.0030 \\
(0.0041)\end{array}$ & $\begin{array}{l}-0.0013 \\
(0.0083)\end{array}$ & $\begin{array}{c}0.0095 \\
(0.0096)\end{array}$ \\
\hline Labor income $>0$ & $\begin{array}{c}0.0013 \\
(0.0009)\end{array}$ & $\begin{array}{c}0.0005 \\
(0.0008)\end{array}$ & $\begin{array}{l}-0.0031 \\
(0.0019)\end{array}$ & $\begin{array}{c}0.0058 \\
(0.0029)\end{array}$ & $\begin{array}{c}0.0037 \\
(0.0035)\end{array}$ \\
\hline Log non-labor PI & $\begin{array}{l}-0.0176 \\
(0.0145)\end{array}$ & $\begin{array}{l}-0.0088 \\
(0.0158)\end{array}$ & $\begin{array}{l}-0.0120 \\
(0.0194)\end{array}$ & $\begin{array}{c}0.0415 \\
(0.0588)\end{array}$ & $\begin{array}{l}-0.0353 \\
(0.0303)\end{array}$ \\
\hline Log SF income/pov & $\begin{array}{c}0.0182 \\
(0.0039)\end{array}$ & $\begin{array}{c}0.0126 \\
(0.0027)\end{array}$ & $\begin{array}{c}0.0110 \\
(0.0035)\end{array}$ & $\begin{array}{c}0.0019 \\
(0.0084)\end{array}$ & $\begin{array}{c}0.0086 \\
(0.0083)\end{array}$ \\
\hline $\mathrm{SF}$ income $>0$ & $\begin{array}{c}0.0008 \\
(0.0004)\end{array}$ & $\begin{array}{c}0.0000 \\
(0.0005)\end{array}$ & $\begin{array}{c}0.0004 \\
(0.0005)\end{array}$ & $\begin{array}{c}0.0026 \\
(0.0015)\end{array}$ & $\begin{array}{l}-0.0008 \\
(0.0016)\end{array}$ \\
\hline Not in pov & $\begin{array}{c}0.0038 \\
(0.0011)\end{array}$ & $\begin{array}{c}0.0006 \\
(0.0009)\end{array}$ & $\begin{array}{c}0.0012 \\
(0.0010)\end{array}$ & $\begin{array}{c}0.0040 \\
(0.0029)\end{array}$ & $\begin{array}{c}0.0013 \\
(0.0032)\end{array}$ \\
\hline Log PA income & $\begin{array}{l}-0.0138 \\
(0.0090)\end{array}$ & $\begin{array}{l}-0.0062 \\
(0.0146)\end{array}$ & $\begin{array}{l}-0.0076 \\
(0.0151)\end{array}$ & $\begin{array}{c}0.0026 \\
(0.0269)\end{array}$ & $\begin{array}{c}0.0021 \\
(0.0221)\end{array}$ \\
\hline
\end{tabular}


Appendix Table 2: (continued)

\begin{tabular}{|c|c|c|c|c|c|}
\hline Title & All & $\begin{array}{l}\text { White } \\
\text { males }\end{array}$ & $\begin{array}{l}\text { White } \\
\text { females }\end{array}$ & $\begin{array}{c}\text { Nonwhite } \\
\text { males }\end{array}$ & $\begin{array}{c}\text { Nonwhite } \\
\text { females }\end{array}$ \\
\hline \multicolumn{6}{|l|}{ Neighborhood quality } \\
\hline $\begin{array}{c}\log \text { house value } \\
\end{array}$ & $\begin{array}{c}0.0034 \\
(0.0047)\end{array}$ & $\begin{array}{c}0.0011 \\
(0.0048)\end{array}$ & $\begin{array}{c}0.0035 \\
(0.0040)\end{array}$ & $\begin{array}{c}0.0015 \\
(0.0099)\end{array}$ & $\begin{array}{c}-0.0098 \\
(0.0085)\end{array}$ \\
\hline House value $>0$ & $\begin{array}{c}0.0000 \\
(0.0000)\end{array}$ & $\begin{array}{c}0.0000 \\
(0.0000)\end{array}$ & $\begin{array}{c}0.0000 \\
(0.0000)\end{array}$ & $\begin{array}{c}-0.0001 \\
(0.0000)\end{array}$ & $\begin{array}{c}-0.0001 \\
(0.0001)\end{array}$ \\
\hline Log gross rent & $\begin{array}{l}-0.0030 \\
(0.0028)\end{array}$ & $\begin{array}{l}-0.0034 \\
(0.0038)\end{array}$ & $\begin{array}{c}0.0012 \\
(0.0035)\end{array}$ & $\begin{array}{c}0.0007 \\
(0.0062)\end{array}$ & $\begin{array}{l}-0.0050 \\
(0.0069)\end{array}$ \\
\hline Home ownership & $\begin{array}{c}0.0059 \\
(0.0016)\end{array}$ & $\begin{array}{c}0.0022 \\
(0.0014)\end{array}$ & $\begin{array}{c}0.0040 \\
(0.0015)\end{array}$ & $\begin{array}{l}-0.0015 \\
(0.0043)\end{array}$ & $\begin{array}{c}0.0005 \\
(0.0035)\end{array}$ \\
\hline Single family residence & $\begin{array}{c}0.0023 \\
(0.0010)\end{array}$ & $\begin{array}{c}0.0009 \\
(0.0012)\end{array}$ & $\begin{array}{c}0.0031 \\
(0.0012)\end{array}$ & $\begin{array}{c}0.0063 \\
(0.0034)\end{array}$ & $\begin{array}{l}-0.0037 \\
(0.0028)\end{array}$ \\
\hline Log mean SF income/pov (tract) & $\begin{array}{c}0.0084 \\
(0.0025)\end{array}$ & $\begin{array}{c}0.0036 \\
(0.0018)\end{array}$ & $\begin{array}{c}0.0065 \\
(0.0019)\end{array}$ & $\begin{array}{c}0.0013 \\
(0.0044)\end{array}$ & $\begin{array}{c}0.0020 \\
(0.0044)\end{array}$ \\
\hline Log mean SF income/pov (tract) $>0$ & $\begin{array}{c}0.0008 \\
(0.0002)\end{array}$ & $\begin{array}{c}0.0003 \\
(0.0002)\end{array}$ & $\begin{array}{c}0.0003 \\
(0.0001)\end{array}$ & $\begin{array}{c}0.0006 \\
(0.0004)\end{array}$ & $\begin{array}{c}0.0004 \\
(0.0004)\end{array}$ \\
\hline$-1 \mathrm{x}$ teen pregnancy (tract) & $\begin{array}{c}0.0003 \\
(0.0002)\end{array}$ & $\begin{array}{c}0.0001 \\
(0.0002)\end{array}$ & $\begin{array}{c}0.0001 \\
(0.0002)\end{array}$ & $\begin{array}{c}0.0004 \\
(0.0006)\end{array}$ & $\begin{array}{l}-0.0002 \\
(0.0005)\end{array}$ \\
\hline$-1 \times$ child pov rate (tract) & $\begin{array}{c}0.0029 \\
(0.0007)\end{array}$ & $\begin{array}{c}0.0011 \\
(0.0004)\end{array}$ & $\begin{array}{c}0.0020 \\
(0.0006)\end{array}$ & $\begin{array}{c}0.0003 \\
(0.0012)\end{array}$ & $\begin{array}{l}-0.0003 \\
(0.0010)\end{array}$ \\
\hline Mean home ownership (tract) & $\begin{array}{c}0.0037 \\
(0.0008)\end{array}$ & $\begin{array}{c}0.0015 \\
(0.0007)\end{array}$ & $\begin{array}{c}0.0028 \\
(0.0009)\end{array}$ & $\begin{array}{c}0.0000 \\
(0.0021)\end{array}$ & $\begin{array}{c}0.0008 \\
(0.0016)\end{array}$ \\
\hline Log median home value (tract) & $\begin{array}{c}0.0052 \\
(0.0031)\end{array}$ & $\begin{array}{c}0.0014 \\
(0.0026)\end{array}$ & $\begin{array}{c}0.0046 \\
(0.0022)\end{array}$ & $\begin{array}{l}-0.0014 \\
(0.0046)\end{array}$ & $\begin{array}{l}-0.0028 \\
(0.0050)\end{array}$ \\
\hline Log median gross rent (tract) & $\begin{array}{c}0.0028 \\
(0.0015)\end{array}$ & $\begin{array}{c}0.0024 \\
(0.0015)\end{array}$ & $\begin{array}{c}0.0025 \\
(0.0016)\end{array}$ & $\begin{array}{c}-0.0001 \\
(0.0030)\end{array}$ & $\begin{array}{c}-0.0008 \\
(0.0034)\end{array}$ \\
\hline Absolute upward mobility $(\mathrm{CH})$ & $\begin{array}{c}0.0354 \\
(0.0169)\end{array}$ & $\begin{array}{c}0.0279 \\
(0.0153)\end{array}$ & $\begin{array}{c}0.0160 \\
(0.0159)\end{array}$ & $\begin{array}{l}-0.0055 \\
(0.0298)\end{array}$ & $\begin{array}{c}-0.0906 \\
(0.0248)\end{array}$ \\
\hline FE county, survey year & $\mathrm{X}$ & $\mathrm{X}$ & $\mathrm{X}$ & $\mathrm{X}$ & $\mathrm{X}$ \\
\hline Cty $_{60} \mathrm{x}$ linear cohort & $\mathrm{X}$ & $\mathrm{X}$ & $\mathrm{X}$ & $\mathrm{X}$ & $\mathrm{X}$ \\
\hline State $\mathrm{x}$ birth year FE & $\mathrm{X}$ & $\mathrm{X}$ & $\mathrm{X}$ & $\mathrm{X}$ & $\mathrm{X}$ \\
\hline Number of observations & $17,400,000$ & $7,423,000$ & $7,817,000$ & 951,000 & $1,204,000$ \\
\hline Number of cells & $4,272,000$ & $2,684,000$ & $2,781,000$ & 561,000 & 668,000 \\
\hline Number of counties & 3,000 & 3,000 & 3,000 & 2,900 & 2,900 \\
\hline
\end{tabular}

Notes: Each column and row provides estimates for the exposure model in equation (3). The unit of analysis is at the birth-county $\mathrm{x}$ birth-year $\mathrm{x}$ birth-month $\mathrm{x}$ survey-year level and the coefficient is on the exposure variable: the share of months between conception and age 5 that a cohort would have been exposed to Food Stamps based on when the program began in the cohort's county of birth. Standard errors are clustered by county of birth and are in parentheses. Each outcome is an unnormalized sub-index. Estimated models and samples are identical to Table 3. 
Appendix Table 3: Spline Estimates of the Estimated ITT Effects of Food Stamps Exposure on Different Indices of Well-being, by Race and Gender

\begin{tabular}{|c|c|c|c|c|c|}
\hline & All & $\begin{array}{l}\text { White } \\
\text { males }\end{array}$ & $\begin{array}{l}\text { White } \\
\text { females }\end{array}$ & $\begin{array}{c}\text { Nonwhite } \\
\text { males }\end{array}$ & $\begin{array}{c}\text { Nonwhite } \\
\text { females }\end{array}$ \\
\hline \multicolumn{6}{|c|}{ Panel A: Composite } \\
\hline Pre-trend: -5 to IU & $\begin{array}{l}-0.0007 \\
(0.0005)\end{array}$ & $\begin{array}{l}-0.0007 \\
(0.0006)\end{array}$ & $\begin{array}{c}0.0002 \\
(0.0005)\end{array}$ & $\begin{array}{l}-0.0011 \\
(0.0014)\end{array}$ & $\begin{array}{l}-0.0012 \\
(0.0012)\end{array}$ \\
\hline IU to age 5 & $\begin{array}{l}-0.0017 \\
(0.0007)\end{array}$ & $\begin{array}{l}-0.0016 \\
(0.0006)\end{array}$ & $\begin{array}{l}-0.0008 \\
(0.0006)\end{array}$ & $\begin{array}{l}-0.0012 \\
(0.0010)\end{array}$ & $\begin{array}{l}-0.0017 \\
(0.0010)\end{array}$ \\
\hline Age 6 to 11 & $\begin{array}{l}-0.0003 \\
(0.0008)\end{array}$ & $\begin{array}{c}-0.0008 \\
(0.0006)\end{array}$ & $\begin{array}{c}0.0002 \\
(0.0007)\end{array}$ & $\begin{array}{l}-0.0006 \\
(0.0012)\end{array}$ & $\begin{array}{l}-0.0006 \\
(0.0012)\end{array}$ \\
\hline Age 12 to 17 & $\begin{array}{l}-0.0005 \\
(0.0009)\end{array}$ & $\begin{array}{l}-0.0011 \\
(0.0007)\end{array}$ & $\begin{array}{l}-0.0001 \\
(0.0008)\end{array}$ & $\begin{array}{c}0.0007 \\
(0.0013)\end{array}$ & $\begin{array}{l}-0.0024 \\
(0.0011)\end{array}$ \\
\hline \multicolumn{6}{|c|}{ Panel B: Human captial } \\
\hline Pre-trend: -5 to IU & $\begin{array}{l}-0.0004 \\
(0.0007)\end{array}$ & $\begin{array}{c}-0.0011 \\
(0.0009)\end{array}$ & $\begin{array}{l}-0.0002 \\
(0.0009)\end{array}$ & $\begin{array}{c}0.0004 \\
(0.0021)\end{array}$ & $\begin{array}{l}-0.0019 \\
(0.0020)\end{array}$ \\
\hline IU to age 5 & $\begin{array}{l}-0.0021 \\
(0.0008)\end{array}$ & $\begin{array}{c}-0.0023 \\
(0.0008)\end{array}$ & $\begin{array}{l}-0.0016 \\
(0.0007)\end{array}$ & $\begin{array}{l}-0.0005 \\
(0.0017)\end{array}$ & $\begin{array}{l}-0.0019 \\
(0.0015)\end{array}$ \\
\hline Age 6 to 11 & $\begin{array}{c}-0.0004 \\
(0.0010)\end{array}$ & $\begin{array}{c}-0.0012 \\
(0.0009)\end{array}$ & $\begin{array}{c}0.0002 \\
(0.0010)\end{array}$ & $\begin{array}{c}0.0008 \\
(0.0021)\end{array}$ & $\begin{array}{c}0.0004 \\
(0.0018)\end{array}$ \\
\hline Age 12 to 17 & $\begin{array}{c}-0.0005 \\
(0.0011) \\
\end{array}$ & $\begin{array}{c}-0.0013 \\
(0.0011) \\
\end{array}$ & $\begin{array}{c}-0.0001 \\
(0.0011) \\
\end{array}$ & $\begin{array}{c}0.0021 \\
(0.0021) \\
\end{array}$ & $\begin{array}{c}-0.0019 \\
(0.0018) \\
\end{array}$ \\
\hline \multicolumn{6}{|c|}{ Panel C: Neighborhood quality } \\
\hline Pre-trend: -5 to IU & $\begin{array}{c}-0.0002 \\
(0.0007)\end{array}$ & $\begin{array}{l}-0.0001 \\
(0.0007)\end{array}$ & $\begin{array}{l}-0.0001 \\
(0.0007)\end{array}$ & $\begin{array}{l}-0.0034 \\
(0.0017)\end{array}$ & $\begin{array}{l}-0.0003 \\
(0.0015)\end{array}$ \\
\hline IU to age 5 & $\begin{array}{c}-0.0022 \\
(0.0010)\end{array}$ & $\begin{array}{c}-0.0015 \\
(0.0007)\end{array}$ & $\begin{array}{c}-0.0022 \\
(0.0008)\end{array}$ & $\begin{array}{c}-0.0024 \\
(0.0013)\end{array}$ & $\begin{array}{c}-0.0015 \\
(0.0012)\end{array}$ \\
\hline Age 6 to 11 & $\begin{array}{c}-0.0008 \\
(0.0011)\end{array}$ & $\begin{array}{c}-0.0012 \\
(0.0008)\end{array}$ & $\begin{array}{c}-0.0014 \\
(0.0008)\end{array}$ & $\begin{array}{c}-0.0014 \\
(0.0016)\end{array}$ & $\begin{array}{l}-0.0008 \\
(0.0013)\end{array}$ \\
\hline Age 12 to 17 & $\begin{array}{l}-0.0005 \\
(0.0012) \\
\end{array}$ & $\begin{array}{l}-0.0012 \\
(0.0009) \\
\end{array}$ & $\begin{array}{c}-0.0010 \\
(0.0009)\end{array}$ & $\begin{array}{c}-0.0017 \\
(0.0017)\end{array}$ & $\begin{array}{l}-0.0039 \\
(0.0014)\end{array}$ \\
\hline \multicolumn{6}{|c|}{ Panel D: Survive to 2012} \\
\hline Pre-trend: -5 to IU & $\begin{array}{c}0.0000 \\
(0.0000)\end{array}$ & $\begin{array}{c}0.0002 \\
(0.0001)\end{array}$ & $\begin{array}{c}0.0000 \\
(0.0001)\end{array}$ & $\begin{array}{l}-0.0001 \\
(0.0002)\end{array}$ & $\begin{array}{l}-0.0001 \\
(0.0001)\end{array}$ \\
\hline IU to age 5 & $\begin{array}{c}-0.0001 \\
(0.0001)\end{array}$ & $\begin{array}{c}0.0001 \\
(0.0001)\end{array}$ & $\begin{array}{c}0.0000 \\
(0.0000)\end{array}$ & $\begin{array}{c}-0.0002 \\
(0.0001)\end{array}$ & $\begin{array}{l}-0.0002 \\
(0.0001)\end{array}$ \\
\hline Age 6 to 11 & $\begin{array}{c}-0.0001 \\
(0.0001)\end{array}$ & $\begin{array}{c}0.0001 \\
(0.0001)\end{array}$ & $\begin{array}{c}0.0000 \\
(0.0001)\end{array}$ & $\begin{array}{c}-0.0005 \\
(0.0002)\end{array}$ & $\begin{array}{l}-0.0004 \\
(0.0001)\end{array}$ \\
\hline Age 12 to 17 & $\begin{array}{c}0.0001 \\
(0.0001) \\
\end{array}$ & $\begin{array}{c}0.0003 \\
(0.0001) \\
\end{array}$ & $\begin{array}{c}0.0001 \\
(0.0001) \\
\end{array}$ & $\begin{array}{c}-0.0001 \\
(0.0003) \\
\end{array}$ & $\begin{array}{c}-0.0002 \\
(0.0002) \\
\end{array}$ \\
\hline \multicolumn{6}{|c|}{ Panel E: Not incarcerated } \\
\hline Pre-trend: -5 to IU & $\begin{array}{c}0.0000 \\
(0.0001)\end{array}$ & $\begin{array}{c}0.0002 \\
(0.0002)\end{array}$ & $\begin{array}{l}-0.0001 \\
(0.0001)\end{array}$ & $\begin{array}{l}-0.0012 \\
(0.0012)\end{array}$ & $\begin{array}{c}0.0004 \\
(0.0003)\end{array}$ \\
\hline IU to age 5 & $\begin{array}{c}0.0000 \\
(0.0001)\end{array}$ & $\begin{array}{c}0.0001 \\
(0.0001)\end{array}$ & $\begin{array}{c}0.0000 \\
(0.0000)\end{array}$ & $\begin{array}{c}-0.0012 \\
(0.0007)\end{array}$ & $\begin{array}{c}0.0002 \\
(0.0002)\end{array}$ \\
\hline Age 6 to 11 & $\begin{array}{c}-0.0001 \\
(0.0001)\end{array}$ & $\begin{array}{c}0.0001 \\
(0.0001)\end{array}$ & $\begin{array}{c}0.0000 \\
(0.0000)\end{array}$ & $\begin{array}{c}-0.0034 \\
(0.0009)\end{array}$ & $\begin{array}{c}0.0001 \\
(0.0002)\end{array}$ \\
\hline Age 12 to 17 & $\begin{array}{c}0.0002 \\
(0.0001)\end{array}$ & $\begin{array}{c}0.0002 \\
(0.0002)\end{array}$ & $\begin{array}{c}0.0000 \\
(0.0000)\end{array}$ & $\begin{array}{c}-0.0015 \\
(0.0010)\end{array}$ & $\begin{array}{c}0.0001 \\
(0.0002)\end{array}$ \\
\hline
\end{tabular}

Notes: See notes for Table 3 . 
Appendix Table 4: The effect of childhood FSP exposure on migration

\begin{tabular}{lcccc}
\hline \hline & \multicolumn{2}{c}{$(1)$} & $(3)$ & $(4)$ \\
\cline { 2 - 4 } & \multicolumn{2}{c}{$1968-1970$ Birth Sample } & \multicolumn{2}{c}{ 1965-1970 Birth Sample } \\
\cline { 2 - 4 } & $\begin{array}{c}\text { Moved to another county } \\
\text { by age } 5\end{array}$ & $\begin{array}{c}\text { Moved to another county } \\
\text { with FSP by age } 5\end{array}$ & $\begin{array}{c}\text { Moved to another county } \\
\text { by age } 5\end{array}$ & $\begin{array}{c}\text { Moved to another county } \\
\text { with FSP by age 5 }\end{array}$ \\
\hline & & & & \\
Share of Age 0-5 with FSP & 0.046 & 0.190 & 0.125 & 0.133 \\
(Using County of Birth) & $(0.837)$ & $(0.379)$ & $(0.060)$ & $(0.022)$ \\
FE birth-county, survey year & $\mathrm{X}$ & $\mathrm{X}$ & $\mathrm{X}$ \\
Birth year FE & $\mathrm{X}$ & $\mathrm{X}$ & $\mathrm{X}$ \\
Number of observations & 785 & $\mathrm{X}$ & 1648 & 1648 \\
Mean DV & 0.224 & 785 & 0.185 & 0.142 \\
$R^{2}$ & 0.567 & 0.195 & 0.415 & 0.443 \\
\hline \hline
\end{tabular}

Source: Public and Restricted Panel Study of Income Dynamics.

Notes: Using the Panel Study of Income Dynamics, we explore the impact of geographic mobility on measurement error and directed migration. The restricted PSID allows us to observe the county and state of residence for most individuals in the PSID sample, starting in 1968. This means we can see the county of birth for those born in or after 1968. Our two samples include children born between 1965-1970 and 1968-1970. In selecting these two year of birth samples, we balance the need for sufficient sample size with the limitation of county of residence being observed starting in 1968. Additionally, because Food Stamps is available in all counties in 1975, there is no potential for endogenous or directed migration after that. Therefore we provide estimates for two samples, one that includes 785 children born in 1968-1970, with full information on residence from birth to age 5 . The second expands to 1648 children born 1965-1970. In both cases we limit to births up to 1970 since our exposure by age 5 (1975) is the key variable. 
Appendix Table 5: Estimated ITT Effects of Food Stamps Exposure between Conception and Age 5 on Life Expectancy

\begin{tabular}{lccc}
\hline \hline & $(1)$ & $(2)$ & $(3)$ \\
\hline \%IU - Age 5 & 0.249 & 0.165 & 0.176 \\
& $(0.052)$ & $(0.042)$ & $(0.030)$ \\
& & & \\
FE county, birth year, survey year & $\mathrm{X}$ & $\mathrm{X}$ & $\mathrm{X}$ \\
Cty60 x linear cohort & & $\mathrm{X}$ & $\mathrm{X}$ \\
State X birth year FE & & & $\mathrm{X}$ \\
Number of observations & $17,400,000$ & $17,400,000$ & $17,400,000$ \\
Number of cells & $4,272,000$ & $4,272,000$ & $4,272,000$ \\
Number of counties & 3000 & 3000 & 3000 \\
$R^{2}$ & 0.779 & 0.792 & 0.800 \\
\hline \hline
\end{tabular}

Notes: Each column provides estimates for the exposure model in equation (3). The unit of analysis is at the birthcounty $\mathrm{x}$ birth-year $\mathrm{x}$ birth-month $\mathrm{x}$ survey-year level, and the coefficient is on the exposure variable: the share of months between conception and age 5 that a cohort would have been exposed to Food Stamps based on when the program began in the cohort's county of birth. All columns include fixed effects for birth-county, birth-year, birthmonth, and survey year. Column 2 adds 1960 county characteristics interacted with a linear trend in year of birth. Column 3 adds birth-state x birth-year fixed effects Standard errors are clustered by county of birth and indicated in parentheses. The number of observations, number of cells and number of counties are rounded to the nearest 1,000 for disclosure purposes. 